FERNANDO HENRIQUE E PAULA DA LUZ

\title{
METODOLOGIA PARA EXECUÇÃO DE APLICAÇÕES PARALELAS BASEADAS NO MODELO BSP COM TAREFAS HETEROGÊNEAS
}

Tese apresentada à Escola Politécnica da Universidade de São Paulo para obtenção do Título de Doutor em Ciências. 
FERNANDO HENRIQUE E PAULA DA LUZ

\section{METODOLOGIA PARA EXECUÇÃO DE APLICAÇÕES PARALELAS BASEADAS NO MODELO BSP COM TAREFAS HETEROGÊNEAS}

Tese apresentada à Escola Politécnica da Universidade de São Paulo para obtenção do Título de Doutor em Ciências.

Área de Concentração:

Engenharia de Computação

Orientadora:

Liria Matsumoto Sato 
Este exemplar foi revisado e corrigido em relação à versão original, sob responsabilidade única do autor e com a anuência de seu orientador.

São Paulo, de de

Assinatura do autor:

Assinatura do orientador:

Catalogação-na-publicação

Luz, Fernando Henrique e Paula da

Metodologia para execução de aplicações paralelas baseadas no modelo BSP com tarefa heterogêneas / F. H. P. Luz -- versão corr. -- São Paulo, 2015. $128 \mathrm{p}$.

Tese (Doutorado) - Escola Politécnica da Universidade de São Paulo. Departamento de Engenharia de Computação e Sistemas Digitais.

1.Computação de Alto Desempenho 2.Escalonamento de tarefas 3.BSP I.Universidade de São Paulo. Escola Politécnica. Departamento de Engenharia de Computação e Sistemas Digitais II.t. 
À Júlia pelo apoio incondicional, ao Théo por iluminar a nossa vida e à Sam pela falta que ela faz aqui... 


\section{AGRADECIMENTOS}

A construção deste trabalho teve o auxílio de diversas pessoas, de forma direta e indireta, que colaboraram com o processo de desenvolvimento desta tese.

Agradeço primeiramente à minha orientadora, Profa. Dra. Liria Matsumoto Sato, que desde a definição do tema até a entrega da última versão para a gráfica, participou ativamente da produção desta tese com comentários, indagações, questionamentos, sugestões, esclarecimentos, orientações e revisões, muitas vezes abrindo mão do seu tempo livre para contribuir com este trabalho.

Ao pessoal do laboratório Tanque de Provas Numérico (TPN), entre eles: O grupo CODE/MPS, que ao longo destes anos auxiliaram o meu processo de formação acadêmica e profissional; O pessoal da Informática, dando todo o suporte para a utilização do ambiente do cluster; O grupo HIDRO, arrumando problemas para serem resolvidos; $O$ finado grupo MIDIA, também chamado de jardim da infância; E por fim, o Prof. Dr. Kazuo Nishimoto e todo o corpo docente do laboratório que contribuem para a evolução do laboratório.

Aos meus amigos, tanto os de São Carlos quanto os da Bela Vista, que serviram de suporte nos momentos de dificuldades e sempre ajudando a me manter motivado e feliz.

A minha família, por todo o suporte que me deram desde a minha infância até os dias de hoje, muito obrigado vovó Alice, tias Lúcia e Hélia. Em especial eu gostaria de agradecer aos meus pais Adunias e Cleusa, a minha segunda mãe lara, os meus irmãos Roberto e Paulo e as minhas irmãs Ligia e Flávia, por participarem (e ainda participam) de diversos momentos da minha vida e contribuindo para o que eu me tornei.

A toda a família da minha esposa, que agora eu já faço parte, por toda ajuda e apoio em todos os momentos, principalmente o seu Marcelo a dona Mys pela ajuda em casa, e o Thiago e a Nathália pelo suporte em todos os momentos.

Um agradecimento especial para a minha amiga, companheira, parceira, confidente e esposa Júlia, que sempre acreditou no meu potencial, por suportar a minha ausência no desenvolvimento desta tese e por dar o presente mais valioso para a nossa vida, o nosso filho Théo. 


\section{RESUMO}

A computação paralela permite uma série de vantagens para a execução de aplicações de grande porte, sendo que o uso efetivo dos recursos computacionais paralelos é um aspecto relevante da computação de alto desempenho. Este trabalho apresenta uma metodologia que provê a execução, de forma automatizada, de aplicações paralelas baseadas no modelo BSP com tarefas heterogêneas. É considerado no modelo adotado, que o tempo de computação de cada tarefa secundária não possui uma alta variância entre uma iteração e outra. A metodologia é denominada de ASE e é composta por três etapas: Aquisição (Acquisition), Escalonamento (Scheduling) e Execução (Execution). $\mathrm{Na}$ etapa de Aquisição, os tempos de processamento das tarefas são obtidos; na etapa de Escalonamento a metodologia busca encontrar a distribuição de tarefas que maximize a velocidade de execução da aplicação paralela, mas minimizando o uso de recursos, por meio de um algoritmo desenvolvido neste trabalho; e por fim a etapa de Execução executa a aplicação paralela com a distribuição definida na etapa anterior. Ferramentas que são aplicadas na metodologia foram implementadas. Um conjunto de testes aplicando a metodologia foi realizado e os resultados apresentados mostram que os objetivos da proposta foram alcançados.

Palavras-chave: Computação de Alto Desempenho. Escalonamento de tarefas. BSP. 


\section{ABSTRACT}

Parallel computing allows for a series of advantages on the execution of large applications and the effective use of parallel resources is an important aspect in the High Performance Computing. This work presents a methodology to provide the execution, in an automated way, of parallel applications based on BSP model with heterogeneous tasks. In this model it is assumed that the computation time between iterations does not have a high variance. The methodology is entitled ASE and it is composed by three stages: Acquisition, Scheduling and Execution. In the Acquisition step, the tasks' processing time are obtained; In the Scheduling step, the methodology finds the ideal arrangement to distribute the tasks to maximize the execution speed and, simultaneously, minimize the use of resources. This is made using an algorithm developed in this work; and lastly the Execution step, where the parallel application is executed in the distribution defined in the previous step. The tools used in the methodology were implemented. A set of tests to apply the methodology were made and the results shown that the objectives were reached.

Keywords: High Performance Computing. Tasks scheduling. BSP. 


\section{LISTA DE ILUSTRAÇÕES}

1 Taxonomia de Flynn $\ldots \ldots \ldots \ldots$

2 Fila de Tarefas . . . . . . . . . . . . . . . . 34

3 Modelo de difusão . . . . . . . . . . . . . . . . 37

4 Superstep do modelo BSP . . . . . . . . . . . . . . 45

5 Modelo BSP adaptado . . . . . . . . . . . . . . . . . 49

6 Esquematização das etapas que definem a metodologia de execução. . . . . . . . . . . . . . . . . . . . . . 52

7 Representação dos termos definidos na nomenclatura . . . . . . 55

8 Exemplo de um arquivo clog2 . . . . . . . . . . . . . . 69

9 Tempo médio e desvio padrão do processamento para cada tarefa nos Cenários 1 e 2. . . . . . . . . . . . . . . . . 76

10 Tempo médio e desvio padrão do processamento para cada tarefa nos Cenários 3 e 4 . . . . . . . . . . . . . . . . . . . 77

11 Tempo médio e desvio padrão do processamento para cada tarefa nos Cenários 5 e $6 . \ldots$. . . . . . . . . . . . . . . . . 78

12 Escalonamento das tarefas do Cenário 1 para um conjunto de 16 recursos paralelos. . . . . . . . . . . . . . . . 80

13 Escalonamento das tarefas do Cenário 1 para um conjunto de 20 recursos paralelos. 
14 Escalonamento das tarefas do Cenário 2 para um conjunto de 16 recursos paralelos.

15 Escalonamento das tarefas do Cenário 3 para um conjunto de 16 recursos paralelos.

16 Escalonamento das tarefas do Cenário 4 para um conjunto de 16 recursos paralelos.

17 Escalonamento das tarefas do Cenário 5 para um conjunto de 16 recursos paralelos.

18 Escalonamento das tarefas do Cenário 6 para um conjunto de 16 recursos paralelos.

19 Speedup dos recursos considerando o cenário 1 utilizando o escalonamento Round Robin e ASE. . . . . . . . . . . . . . . . . 86

20 Speedup dos recursos considerando o cenário 2 utilizando o escalonamento Round Robin e ASE. . . . . . . . . . . . . . . . 86

21 Speedup dos recursos considerando o cenário 3 utilizando o escalonamento Round Robin e ASE. . . . . . . . . . . . . . . . 88

22 Speedup dos recursos considerando o cenário 4 utilizando o escalonamento Round Robin e ASE. . . . . . . . . . . . . . . . . 88

23 Speedup dos recursos considerando o cenário 5 utilizando o escalonamento Round Robin e ASE. . . . . . . . . . . . . . . 89

24 Speedup dos recursos considerando o cenário 6 utilizando o escalonamento Round Robin e ASE. . . . . . . . . . . . . . . . . 89

25 Eficiência dos recursos considerando o cenário 1 utilizando o escalonamento Round Robin e ASE. . . . . . . . . . . . . . . 90 
26 Eficiência dos recursos considerando o cenário 3 utilizando o escalonamento Round Robin e ASE. . . . . . . . . . . . . . . 91

27 Eficiência dos recursos considerando o cenário 5 utilizando o escalonamento Round Robin e ASE. . . . . . . . . . . . . . . . . 91

28 Eficiência dos recursos considerando o cenário 2 utilizando o escalonamento Round Robin e ASE. . . . . . . . . . . . . . . . 92

29 Eficiência dos recursos considerando o cenário 4 utilizando o escalonamento Round Robin e ASE. . . . . . . . . . . . . . . . . 93

30 Eficiência dos recursos considerando o cenário 6 utilizando o escalonamento Round Robin e ASE. . . . . . . . . . . . . . . . . 93

31 Fluxo de execução do processo de execução do TPN, mostrando a relação entre forças e posicionamento. . . . . . . . . 97

32 Fluxo de execução do processo de execução do TPN, utilizando a representação do BSP adaptado. . . . . . . . . . . . . . . . 97

33 Variação do número de recursos fornecido para o Caso C, ocorrendo na aplicação TPN. . . . . . . . . . . . . . . . . . . 103 


\section{LISTA DE TABELAS}

1 Lista dos conjuntos de tarefas criadas para cada cenário. . . . . 74

2 Casos elaborados para a simulação do TPN onde será utilizada a distribuição original e a proposta pela ASE. . . . . . . . . . . . 101

3 Comparação do resultado da forma atual de escalonamento do TPN e da metodologia ASE nos casos especificados da Tabela 2 . Foi obtido o número ideal de recursos paralelos e executado utilizando as duas formas de distribuição. . . . . . . . . . . 102 


\section{LISTA DE ABREVIATURAS}

API Application Programming Interface (Interface de Programação de Aplicativos)

ASE Acquisition/Scheduling/Execution (Aquisição - Escalonamento Execução)

BRAMS Brazilian developments on the Regional Atmospheric Modelling System

BSP Bulk-Synchronous Parallel

CGM Coarse Grained Multicomputer

CUDA Compute Unified Device Architecture

DNA Ácido Desoxirribonucleico

GPU Graphical Processing Unit (Unidade de Processamento Gráfico)

JSON JavaScript Object Notation

IBM International Business Machines

MIMD Multiple Instruction Multiple Data

MISD Multiple Instruction Single Data

MPE Multi-Processing Environment

MPI Message Passing Interface

MPICH MPI over CHameleon 
MPICL MPI Portable Instrumented Communication Library

OpenMPI Open Message Passage Interface

PVM Parallel Virtual Machine

QCD Cromodinâmica Quântica (Quantum ChromoDynamics)

RNA Ácido Ribonucleico

SIMD Single Instruction Multiple Data

SISD Single Instruction Single Data

SLURM Simple Linux Utility for Resource Management

TPN Tanque de Provas Numérico

UMA Acesso de Memória Uniforme (Uniform Memory Acess)

XML Extensible Markup Language

NFS Network File System 


\section{SUMÁRIO}

$\begin{array}{llr}1 & \text { Introdução } & 15\end{array}$

1.1 Objetivo . . . . . . . . . . . . . . . . . . . . 19

1.2 Motivações e Justificativa . . . . . . . . . . . . . . 20

1.3 Metodologia do desenvolvimento do trabalho . . . . . . . . . . 21

1.4 Organização do texto . . . . . . . . . . . . . . 22

2 Computação Paralela $\quad 23$

2.1 Métricas . . . . . . . . . . . . . . . . . . . . . 24

2.1 .1 Speedup ..................... 24

2.1 .2 Eficiência . . . . . . . . . . . . . . . . . . 24

2.1 .3 Super-Linear . . . . . . . . . . . . . . 25

2.1 .4 Lei de Amdahl . . . . . . . . . . . . . . . . . . 26

2.2 Taxonomia de Flynn . . . . . . . . . . . . . . . . . . 28

2.3 Passagem de Mensagem . . . . . . . . . . . . . . . . . . . 29

2.4 Profiling de Aplicações Paralelas . . . . . . . . . . . . . . 30

3 Técnicas de paralelização de aplicações e escalonamento de cargas $\quad 32$

3.1 Modelos de escalonamento de cargas . . . . . . . . . . . . 32

3.1.1 Escalonamento de cargas estático . . . . . . . . . . . 32 
3.1.2 Escalonamento de cargas dinâmico . . . . . . . . . . 33

3.1.2.1 Fila de tarefas $\ldots \ldots \ldots \ldots \ldots$

3.1.2.2 Modelo de difusão . . . . . . . . . . . . . . . . 35

3.2 Aplicações paralelas . . . . . . . . . . . . . . . . 38

3.2.1 Simulador Tanque de Provas Numérico . . . . . . . . . 38

3.2 .2 BRAMS . . . . . . . . . . . . . . . . . . 39

3.2.3 Alinhamento múltiplo de sequências . . . . . . . . . . 40

3.3 Considerações sobre as técnicas . . . . . . . . . . . . 41

4 Metodologia para execução de aplicações paralelas baseadas no modelo BSP com tarefas heterogêneas 43

4.1 Modelo da aplicação paralela . . . . . . . . . . . . . . . . . 44

4.1.1 Bulk-Synchronous Parallel (BSP) . . . . . . . . . . . 44

4.1.2 Tempo de execução em um superstep . . . . . . . . . . 47

4.1.3 O uso do BSP neste trabalho . . . . . . . . . . . 48

4.2 Automação do processo de execução . . . . . . . . . . . . 50

4.3 Formato de Arquivo de Saída . . . . . . . . . . . . . . . . 51

4.4 A metodologia ASE $\ldots \ldots \ldots \ldots \ldots$

4.4 .1 Aquisição . . . . . . . . . . . . . . 53

4.4 .2 Escalonamento . . . . . . . . . . . . . . . . . . 54

4.4.2.1 Nomenclatura . . . . . . . . . . . . . . . . . 54

4.4.2.2 Algoritmo Geral . . . . . . . . . . . . . . 57 
4.4.2.3 Escalonamento de tarefas . . . . . . . . 59

4.4.2.4 Alocação da tarefa "centralizadora" . . . . . . . 61

4.4 .3 Execução . . . . . . . . . . . . . . . . . . 62

4.5 Vantagens . . . . . . . . . . . . . . . . . 62

5 Execução utilizando os mecanismos da metodologia 65

5.1 Aplicação paralela com comunicação por passagem de mensa-

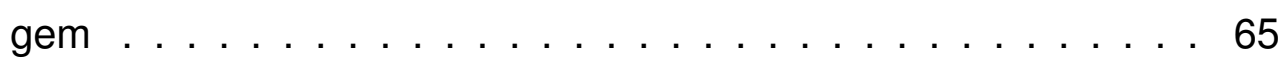

5.2 Obtenção dos tempos . . . . . . . . . . . . . 666

5.2.1 Profiling de aplicações paralelas utilizando o MPE . . . . 66

5.2.1.1 Funcionamento . . . . . . . . . . 66

5.2 .1 .2 Utilização . . . . . . . . . . . . . . 68

5.2.1.3 Uso do MPE na etapa de obtenção de tempos . 69

5.3 Formato de Arquivo de Saída . . . . . . . . . . . . . . . . 70

5.4 Script de Execução . . . . . . . . . . . . . . . . . . . . . 71

6 Testes, resultados e análises $\quad 72$

6.1 Ambiente paralelo . . . . . . . . . . . . . . . 72

6.2 Caso de teste . . . . . . . . . . . . . 73

6.3 Cenários ......................... 73

6.4 Teste: Medição . . . . . . . . . . . . . . . . . . . . . . 74

6.5 Teste: Escalonamento . . . . . . . . . . . . . . . . 78

6.5 .1 Distribuição . . . . . . . . . . . . . . . . . . . . 79 
6.5 .2 Saturação . . . . . . . . . . . . . . . . . . . . . . 85

6.5.2.1 Análise pelo Speedup . . . . . . . . . . . . . 85

6.5.2.2 Análise pela Eficiência . . . . . . . . . . 9 90

6.6 Teste: Limitação dos recursos . . . . . . . . . . . . . . . . . . . . 94

6.7 Teste: Aplicação Real - TPN . . . . . . . . . . . . . . 95

6.7 .1 Estrutura . . . . . . . . . . . . . . 96

6.7 .2 Balanceamento Atual . . . . . . . . . . . . . . 96

6.7.3 Implementação da ASE . . . . . . . . . . . . . . . . 101

6.7 .4 Testes . . . . . . . . . . . . . . . . . . . 101

7 Conclusões 105

7.1 Contribuições . . . . . . . . . . . . . . . 106

7.2 Propostas Futuras . . . . . . . . . . . . . . . . 107

$\begin{array}{ll}\text { Referências } & 108\end{array}$

Apêndice A - Implementação em Python da metodologia ASE 112 


\section{INTRODUÇÃO}

Nos dias atuais, os computadores estão cada vez mais presentes na vida das pessoas, desde sistemas embarcados em automóveis até o uso de datacenters para a hospedagem de páginas na World Wide Web (W3C, 2011).

Em alguns casos, o uso massivo da computação se faz necessário, o que acaba impulsionando a busca por mais poder computacional. Uma das soluções para a obtenção do ganho de processamento é através da Lei de Moore, elaborada por Gordon E. Moore, a qual definia que a quantidade de transistores em um processador dobra a cada 18 meses (MOORE, 1998; CHIEN; KARAMCHETI, 2013; VENU, 2011; BORKAR, 2007).

Inicialmente, esses transistores extras eram utilizados para possibilitar um aumento na capacidade de cálculo do processador, mas à medida que os processadores foram evoluindo, alguns problemas limitavam essa evolução, tais como o resfriamento do processador, o consumo de energia e a complexidade do circuito lógico. Uma das soluções para a obtenção do ganho de processamento é utilizar esses transistores extras na criação de múltiplos núcleos de processamento. Esta ideia foi iniciada pela International Business Machines (IBM) em 2001 no processador POWER4 (VAJDA, 2011), iniciando a era multi-core dos computadores.

lan Foster define em (FOSTER, 1995) que um computador paralelo é um conjunto de processadores que trabalham de forma cooperativa para solucio- 
nar um problema computacional, englobando supercomputadores paralelos com centenas ou milhares de processadores, rede de Workstations, Workstations com múltiplos núcleos e sistemas embarcados.

A computação paralela é amplamente utilizada na pesquisa científica e em (KAUFMANN; SMARR, 1992) são relatadas algumas revoluções que ocorreram com o uso de supercomputadores em áreas da ciência.

A necessidade crescente das aplicações científicas por poder computacional pode estar relacionada à demanda de maiores velocidades de execução e maiores precisões nos resultados.

Algumas das áreas que se beneficiam da computação de alto desempenho são as análises de padrões do DNA, que é um polímero de nucleotídeos responsável em realizar a transferência genética. Ele possui o formato de dupla hélice constituído por pares de bases, sendo que a quantidade de pares existentes varia de espécie para espécie. Por exemplo, o maior cromossomo humano possui aproximadamente 220 milhões de pares. No trabalho de (TIBSHIRANI et al., 1999) mostra a utilização da computação de alto desempenho para a categorização dos pares envolvidos e identificação de grupos com comportamentos similares.

Outra área que faz uso da computação paralela é a análise astronômica, onde o artigo (BRESCIA; LONGO; PASIAN, 2010) apresenta que um dos grandes problemas atualmente no campo da astronomia/astrofísica é que a taxa dos dados coletados ao longo dos últimos anos cresce devido à melhoria dos equipamentos de detecção, telescópios e instrumentos espaciais. Entretanto, a quantidade de informação que se consegue utilizar decresce, devido à complexidade e à necessidade de processamento para tratar essa quantidade massiva de dados. O emprego da computação paralela permite melhorar este panorama. 
Outro campo da ciência que utiliza a computação paralela de forma massiva é a Cromodinâmica Quântica (Quantum ChromoDynamics) (QCD), que não pode ser estudada pelos métodos analíticos usuais de teorias de campo, baseados em teoria de perturbação (LANDAU; BINDER, 2005). O estudo da QCD descreve as interações fundamentais entre as Partículas Elementares descrevendo as suas propriedades por meio de uma formulação de rede que demanda uma grande necessidade de recurso computacional (LUZ, 2010).

Outra utilização para a computação paralela é na execução de simulações numéricas em estágios preliminares da pesquisa, permitindo uma análise preliminar na elaboração do projeto e de pontos críticos do modelo. Torna possível realizar correções e proporcionar economia de recursos, esforços e tempo.

Um exemplo é o simulador hidrodinâmico do TPN, proposto inicialmente em uma versão sequencial no trabalho de Fucatu em (FUCATU, 1998) e posteriormente portado para um ambiente paralelo, sendo que detalhes deste ambiente podem ser encontrados em (LUZ; GASPAR; NISHIMOTO, 2009). Esta versão paralela permite simular o arranjo de distribuição das linhas de embarcação, em um tempo de execução que viabilizará a verificação das condições de equilíbrio dinâmico para diferentes condições ambientais, antes de realizar o experimento em escala reduzida, reduzindo o custo do desenvolvimento de um projeto.

Estes são apenas alguns exemplos de software que possuem uma demanda por recurso computacional, onde a utilização de máquinas sequenciais não permite executar essas simulações em sua plenitude. A computação paralela possibilita o uso de múltiplos recursos de processamento para executar essas aplicações.

Mas a escrita de um programa em uma máquina paralela possui diferenças significativas em relação à programação sequencial (DONGARRA et al., 
2003). Antes de migrar uma aplicação sequencial para uma aplicação paralela, deve-se verificar:

- como será a distribuição das etapas de processamento;

- quais serão os pontos de sincronização;

- se a aplicação será portável para um ambiente paralelo;

- a viabilidade de conversão dos algoritmos sequenciais para algoritmos paralelos;

- a possibilidade de fragmentar a execução;

- a forma que será realizada a distribuição das cargas.

A implementação de uma aplicação paralela inadequada ou uma má distribuição das suas cargas na máquina paralela pode causar perda de desempenho e desperdício de recursos, que poderiam estar alocados para outras execuções.

Como cada aplicação possui uma forma específica para o fenômeno que se deseja modelar, não é possível inferir uma regra geral para todas as aplicações.

Se na etapa de execução de uma aplicação paralela as informações das cargas de cada uma das tarefas paralelas estivessem disponíveis, o correto escalonamento das cargas poderia minimizar o desperdício de recursos, pois manteria os processadores ocupados na maior parte do tempo.

As informações sobre o custo computacional de cada tarefa paralela não são conhecidas antes da execução da aplicação, pois dependem das características do modelo a ser executado e da arquitetura utilizada. 
Se as principais características das tarefas paralelas, tais como o custo computacional, a comunicação e a memória fossem obtidas para a realização da distribuição de cargas de forma eficiente e automatizada, sem a necessidade de modificações no código fonte original, forneceria uma grande contribuição para o aprimoramento das execuções de aplicações paralelas.

Outro aspecto importante é a definição da quantidade de recursos que serão utilizados na execução da aplicação. O ideal seria utilizar a quantidade máxima de recursos que minimize o tempo de execução e o desperdício dos recursos alocados.

\subsection{Objetivo}

O objetivo desta tese é apresentar uma metodologia que melhore a execução de uma aplicação paralela por meio de um mecanismo de escalonamento e efetue o cálculo do número de recursos fornecidos para a execução paralela maximizando a velocidade de execução e minimizando a ociosidade dos recursos.

Para esta metodologia, somente são consideradas aplicações paralelas baseadas no modelo Bulk-Synchronous Parallel (BSP), que consiste em uma aplicação composta por $N$ tarefas (sendo uma tarefa principal e $N-1$ secundárias) e todas elas possuindo $T$ iterações (chamadas de supersteps). Em cada iteração, as tarefas secundárias recebem dados da tarefa principal, realizam cálculos com esses dados, e depois retornam os resultados para a tarefa principal.

Cada tarefa neste modelo possui um tempo de computação $t_{n}$, que não varia de iteração para iteração, mas este tempo pode diferir dos tempos das demais tarefas (não necessariamente $t_{n}$ é igual a $t_{n+1}$ ). 
A metodologia é composta por três etapas. A primeira delas consiste em realizar uma breve execução da aplicação, com o processamento de apenas algumas iterações, com a finalidade apenas de mensurar os tempos gastos por cada tarefa paralela, tais como o tempo de comunicação, o tempo de processamento e o tempo de espera. Estes tempos são utilizados como dados de entrada para a próxima etapa, que determina a distribuição de tarefas paralelas para os nós disponibilizados. E por fim a ultima etapa consiste em realizar a execução da aplicação paralela em si, no arranjo determinado. Todas estas etapas são executadas de forma automatizada e de maneira não intrusiva, isto é, sem a necessidade de se modificar o código fonte original da aplicação.

\subsection{Motivações e Justificativa}

A forma de realizar o escalonamento para alcançar o balanceamento de carga tem um grande impacto no desempenho de uma execução paralela. A quantidade de processadores utilizados na execução paralela, sem que ocorra desperdício de recursos é um ponto importante para o uso dos recursos (KALE, 1988).

A comunidade científica tem focado esforços não só em obter um ganho no tempo de execução, mas também em maximizar a eficiência dos ambientes paralelos, tais como a proposta do Green 500 (The Green500, 2012).

Além disso, ao criar uma proposta que não realiza modificações no código fonte originais, permite-se que diversas aplicações utilizem os resultados deste trabalho, bastando apenas adaptar o workflow que gerencia a execução da aplicação, através de um script especificado pela metodologia.

A interdependência desta adequação é outro ponto importante, pois esta metodologia é independente da linguagem de programação utilizada na apli- 
cação paralela e também pode ser utilizada em diferentes ambientes paralelos, pois ela se adapta para ser executada de forma automatizada em diferentes ambientes paralelos.

O modelo utilizado para descrever as aplicações paralelas descreve as características de diversas aplicações, como por exemplo, o simulador numérico do TPN/Dynasim.

O TPN/Dynasim é um simulador numérico capaz de representar matematicamente condições idênticas às geradas em um tanque físico, sem as restrições dimensionais, representando o comportamento de sistemas oceânicos flutuantes que trabalham na exploração e produção de petróleo e gás.

\subsection{Metodologia do desenvolvimento do trabalho}

Primeiramente foram estudadas algumas métricas de análise de desempenho de aplicações paralelas, para permitir a realização de comparações entre as execuções paralelas. Concorrentemente foram estudados alguns modelos de programação paralela para decidir em qual este trabalho se enquadra e finalmente, algumas ferramentas computacionais foram analisadas para auxiliar o processo de implementação da metodologia.

Com o embasamento teórico bem fundamentado, a metodologia foi descrita de forma abstrata para ser implementada em um ambiente paralelo descrito pelo modelo BSP, para certificar o funcionamento da metodologia em diferentes condições. Após isso, desenvolveu-se um algoritmo para escalonar as tarefas paralelas.

Além disso, avaliou o uso da metodologia tanto em uma aplicação paralela teste quanto em uma aplicação real, como o intuito de verificar a sua eficiência. 


\subsection{Organização do texto}

A tese foi elaborada da seguinte forma: O Capítulo 2 apresenta uma descrição das métricas presentes na computação, e conceitos relacionados à programação paralela. No Capítulo 3 são apresentados alguns modelos de escalonamento utilizados para a programação paralela e são apresentadas algumas aplicações paralelas e a relação deste trabalho com a comunidade cientifica. A descrição abstrata da proposta desta metodologia e as adaptações realizadas no modelo BSP, além dos detalhes do algoritmo elaborado para o escalonamento das cargas foram apresentados no Capítulo 4. No Capítulo 5 está uma implementação da metodologia e os resultados da aplicação em uma simulação paralela teste no Capítulo 6. Por fim, no Capítulo 7 estão as conclusões do trabalho e propostas de trabalhos futuros. 


\section{COMPUTAÇÃO PARALELA}

A programação paralela permite obter aumento na velocidade de execução e melhoria na precisão, sem ter a necessidade de aguardar por máquinas sequenciais mais potentes. Isso é obtido por meio do fracionamento das computações necessárias em uma execução e distribuir esses pedaços menores em diversas máquinas, de forma que as cargas fiquem sempre balanceadas.

Este trabalho propõe uma metodologia para realizar uma distribuição destas tarefas de forma a maximizar o desempenho e minimizar o desperdício de recursos durante a execução paralela.

Alguns conceitos utilizados no desenvolvimento deste trabalho serão apresentados neste capítulo. As aplicações paralelas podem ser classificadas em diferentes tipos de modelos, que são definidos com base nas características da sua comunicação, a forma de execução e o tempo de processamento. Além disso, diversas métricas podem ser utilizadas para avaliar o desempenho de uma aplicação.

Desta forma, neste capítulo são apresentadas algumas métricas que podem ser utilizadas para realizar comparações entre execuções paralelas (Seção 2.1), além de aspectos da computação paralela, tais como a Taxonomia de Flynn (Seção 2.2), o modelo de passagem de mensagem (Seção 2.3) e do procedimento de realização de profiling de aplicações paralelas (Seção 2.4). 


\subsection{Métricas}

Para a descrição das métricas desta seção, além das referências citadas nas subseções, foram utilizadas as fontes (GRAMA et al., 2003; FOSTER, 1995; WILLMORE, 2012; ROCHA, 2007; BERZINS, 2010).

\subsubsection{Speedup}

O Speedup define uma medida de desempenho, e é mensurado pela divisão entre o tempo de execução da aplicação sequencial pelo tempo de execução da aplicação em paralelo.

$$
S(n)=\frac{T_{s}}{T_{p}(n)}
$$

Onde:

- $T_{s}$ é o tempo de execução da aplicação sequencial.

- $T_{p}(n)$ é o tempo da execução da aplicação paralela.

- $n$ define o número de unidades processantes utilizadas na computação.

- $S(n)$ é o Speedup.

Vale ressaltar que $T_{s} \neq T_{p}(1)$, isto é, o tempo de execução da aplicação sequencial é diferente do tempo de execução da aplicação paralela usando apenas uma única unidade de processamento.

\subsubsection{Eficiência}

A eficiência mede o grau de aproveitamento dos recursos computacionais. Para obter a medida de eficiência de uma aplicação paralela deve-se fazer a 
divisão do Speedup pela quantidade de recursos computacionais disponibilizados para a execução.

$$
E(n)=\frac{S(n)}{n}=\frac{T_{s}}{n T_{p}(n)}
$$

Em um sistema ideal, o Speedup é igual a $n$, o que acaba tornando a eficiência igual a 1. Mas na prática, o Speedup é sempre um número menor que $n$ e o valor de eficiência que temos nas aplicações paralelas são sempre um valor entre 0 e 1 .

\subsubsection{Super-Linear}

É esperado que o Speedup alcançado em uma aplicação paralela terá um valor menor ou igual ao número de processadores.

Isso ocorre devido a não possibilidade de conversão total do código sequencial para uma aplicação paralela, isto é, sempre uma aplicação paralela conservará uma parte sequencial do seu código sequencial, que não pode ser paralelizado, afetando desta forma o Speedup.

Outro fator que pode contribuir para a obtenção de um Speedup menor é o custo da comunicação devido ao paralelismo em sistemas distribuídos, tais como os clusters de computadores.

O Speedup super-linear é quando uma aplicação obtém um Speedup $S(n)>n$. Isto pode ocorrer, pois no cálculo do Speedup considera-se apenas o número de processadores, sendo que os demais recursos do sistema poderiam estar sendo utilizados mais adequadamente, tornando a aplicação paralela mais eficiente.

Um exemplo de ocorrência deste fenômeno é a redução do tempo de 
acesso à memória RAM. Isto ocorre quando um working set de um problema é maior que o tamanho da memória cache disponível quando executado de forma sequencial, mas pode ser distribuído entre as caches de memória dos múltiplos processadores utilizados na execução paralela.

\subsubsection{Lei de Amdahl}

Uma das métricas mais utilizadas dentro da análise de desempenho de aplicações paralelas é fornecida pela lei de Amdahl (AMDAHL, 1967; FOSTER, 1995), sendo que toda aplicação paralela possui no seu algoritmo um componente sequencial que irá limitar o Speedup.

Reescrevendo a fórmula do Speedup apresentada na Equação (2.1) em funções do tempo gasto com o trecho sequencial do código e do tempo gasto com a seção paralela do código e o tempo gasto com a comunicação entre tarefas, obtém-se:

$$
S(n)=\frac{T_{s}}{T_{p}(n)}=\frac{C_{s e q}+C_{p a r}}{C_{s e q}+\frac{C_{p a r}}{n}+C_{c o m}}
$$

Onde:

- $C_{s e q}$ define as computações que só podem ser realizadas sequencialmente.

- $C_{p a r}$ define as computações que podem ser realizadas em paralelo.

- $C_{\text {com }}$ define as computações gastas com a inicialização / comunicação / sincronização entre as tarefas paralelas.

Como em uma aplicação paralela, $C_{c o m} \geq 0$, então:

$$
S(n) \leq \frac{C_{s e q}+C_{p a r}}{C_{s e q}+\frac{C_{p a r}}{n}}
$$


e se:

$$
f=\frac{C_{s e q}}{C_{s e q}+C_{p a r}}
$$

que define a fração $f$ de computação que só pode ser realizada sequencialmente tem-se que:

$$
S(n) \leq \frac{\frac{C_{\text {seq }}}{f}}{C_{\text {seq }}+\frac{C_{\text {seq }}\left(\frac{1}{f}-1\right)}{n}}
$$

levando a

$$
S(n) \leq \frac{\frac{1}{f}}{1+\frac{\left(\frac{1}{f}-1\right)}{n}}=\frac{1}{f+\frac{1-f}{n}}
$$

finalmente

$$
S(n) \leq \frac{n}{(n-1) f+1}
$$

Sendo que $0 \leq f \leq 1$ é a fração de computação que só pode ser realizada sequencialmente. Assim a lei de Amdahl diz que o Speedup máximo que uma aplicação paralela com $n$ unidades processantes pode obter é dado pela Inequação (2.8).

Além disso, a lei de Amdahl permite determinar o limite máximo de Speedup que uma determinada aplicação poderá alcançar independentemente do número de processadores utilizados.

Um das limitações que a Lei de Amdahl possui é que ela ignora o custo das operações de comunicações e sincronizações que são associadas à introdução de paralelismo dentro de uma aplicação. 


\subsection{Taxonomia de Flynn}

Flynn em (FLYNN, 1972) apresenta uma classificação dos ambientes paralelos, que é utilizada até os dias atuais, tendo como base o fluxo de instruções e o fluxo de dados. Essa taxonomia foi inicialmente dividida em quatro classes.

Figura 1 - Relação da taxonomia proposta por Flynn.
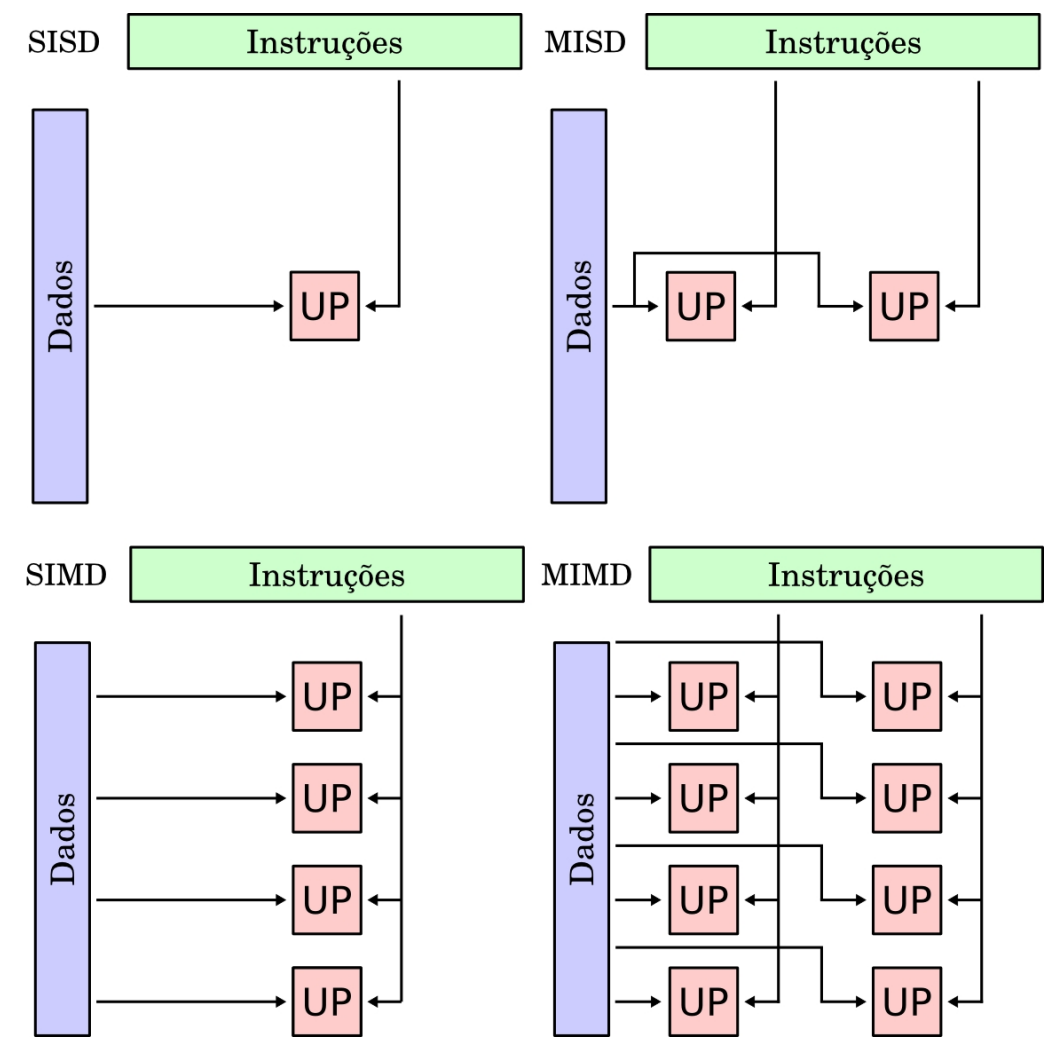

Fonte: Adaptado de Colin M.L. Burnett em http://commons.wikimedia.org/wiki.

Single Instruction Single Data (SISD): os computadores sequenciais sem explorar nenhum aspecto de paralelismo se enquadram nesta classificação. Máquinas que se enquadram dentro desta classificação executam uma única instrução em um único dado, por unidade de tempo.

Single Instruction Multiple Data (SIMD): nesta categoria, uma única instrução é aplicada em um conjunto de dados de entrada por unidade de 
tempo. As máquinas vetoriais em um passado da computação paralela e atualmente os processadores Graphical Processing Unit (Unidade de Processamento Gráfico) (GPU) são exemplos de máquinas que se enquadram nesta classificação. O ganho da execução paralela aqui é obtido por um alto throughput, mesmo que a latência para disponibilizar o conjunto de dados no processador seja alta.

Multiple Instruction Single Data (MISD): não é muito comum máquinas dentro desta classificação, pois um conjunto de múltiplas instruções é aplicado a um mesmo dado de entrada. Algumas aplicações que podem se enquadrar aqui são programas com tolerância a falhas ou ambientes heterogêneos que devem produzir o mesmo resultado para uma dada entrada.

Multiple Instruction Multiple Data (MIMD): a maioria das máquinas paralelas se enquadra nesta categoria, onde sistemas distribuídos e processadores com múltiplos cores podem processar diferentes instruções em diferentes fluxos de dados.

Pode-se observar na Figura 1 visualmente como é utilizada a taxonomia proposta por Flynn.

Algumas variações desta taxonomia podem ser encontradas, mas essencialmente essa proposta já é bastante completa para os estudos deste trabaIho.

\subsection{Passagem de Mensagem}

A computação paralela permite que diversos processadores consigam trabalhar cooperativamente para a resolução de uma computação. Para permitir 
que as tarefas paralelas possam trocar informação durante a execução existem diferentes formas, sendo uma delas a programação por passagem de mensagem.

O modelo de passagem de mensagem pode ser implementado por uma biblioteca, que irá prover um conjunto de funções e métodos para permitir a manipulação das mensagens enviadas e recebidas entre as tarefas.

Esse modelo permite a realização de trocas de dados entre processos na mesma máquina e entre processos em máquinas distintas, desde que estejam conectados por uma rede.

Exemplos de especificações de bibliotecas de passagem de mensagem são PVM - Parallel Virtual Machine (GEIST et al., 1995) e MPI - Message Passing Interface (Message Passage Interface Forum, 2009), sendo que este último é atualmente o padrão mais utilizado.

\subsection{Profiling de Aplicações Paralelas}

O profiling permite determinar o comportamento e a caracterização da execução de uma aplicação paralela durante a sua execução.

O profiling permite determinar o comportamento e a caracterização da execução de uma aplicação paralela durante a sua execução. Por meio do

profiling é possível montar um perfil da aplicação. É possível determinar o tempo de execução de uma computação, de quanto tempo levou a comunicação entre tarefas, do uso de memória utilizado pelas tarefas, a quantidade de comunicações que foram realizadas entre tarefas, etc.

Na metodologia proposta, o profiling é utilizado para obter o tempo de computação de cada tarefa, o tempo gasto de comunicação e de que forma 
as tarefas se comportam durante as transmissões de mensagens.

Alguns exemplos de implementações de profiling são a ferramenta Multi-Processing Environment (MPE)/Jumpshot (ZAKI et al., 1999; CHAN et al., 2007), a MPI Portable Instrumented Communication Library (MPICL)/Paragraph (HEATH; ETHERIDGE, 1991) e PVaniM (TOPOL; STASKO; SUNDERAM, 1998).

Pode ser citado o trabalho (VETTER, 2000) como exemplo de uso do profiling, onde é apresentada uma proposta de reclassificação das mensagens trocadas no sistema, apresentando onde tem a ocorrência de atrasos em algumas mensagens trocadas. De posse destes dados, um desenvolvedor da aplicação pode reorganizar as comunicações, melhorando desta forma o desempenho da mesma.

Outro exemplo a ser citado é a proposta apresentada em (OLIVEIRA; LAINE; MIDORIKAWA, 2003) que propõe uma metodologia de análise e predição de desempenho de primitivas do Message Passing Interface (MPI). Além disso, existe a possibilidade de encontrar gargalos no código elaborado. 


\section{TÉCNICAS DE PARALELIZAÇÃO DE APLICAÇÕES E ESCALONAMENTO DE CARGAS}

Neste capítulo são relatadas algumas técnicas e características de aplicações paralelas. Primeiramente são apresentados alguns modelos de escalonamentos que podem ser utilizados no desenvolvimento de aplicações paralelas. Na sequência são apresentadas algumas aplicações paralelas, comentando-se a forma da implementação do paralelismo dentro das mesmas.

Por fim são feitas considerações sobre as técnicas apresentadas.

\subsection{Modelos de escalonamento de cargas}

O escalonamento de carga eficiente é um dos pontos principais para uma execução paralela com uma alta relação de custo-benefício. Algumas das possibilidades de classificação de escalonamento de cargas são descritas nesta seção.

\subsubsection{Escalonamento de cargas estático}

A principal vantagem desta forma de distribuição de cargas é a sua eficiência, pois não causa nenhuma sobrecarga para a redistribuição de cargas na execução da aplicação paralela. 
Para arquiteturas paralelas do tipo Acesso de Memória Uniforme (Uniform Memory Acess) (UMA), geralmente uma iteração é utilizada para o cálculo da sua carga, onde carga é considerada o tempo gasto em uma computação de um bloco ou um ciclo de processamento.

Para aplicar este tipo de balanceamento com uma taxa de sucesso aceitável, deve-se saber, de acordo com os parâmetros iniciais, o tempo de execução das tarefas em tempo de compilação.

Mas isso nem sempre é possível, pois tais parâmetros podem variar de acordo com a arquitetura e a quantidade de recursos utilizados na computação, como por exemplo, o uso de memória.

\subsubsection{Escalonamento de cargas dinâmico}

Em algumas aplicações, não é possível prever o tempo gasto com a computação em um passo de iteração. A alternativa nestes casos é prover um escalonamento das cargas durante a sua execução, implicando em um custo para gerenciar o andamento da execução.

O escalonamento dinâmico enquadra-se nos diferentes modelos apresentados nas subseções a seguir.

\subsubsection{Fila de tarefas}

Esta forma de escalonamento baseia-se em uma fila de tarefas onde os processadores disponíveis para realizar o cálculo paralelo vão coletando as tarefas para processar.

No momento em que um dado processador termina de realizar o seu cálculo, ele vai novamente para a fila e obtém da fila uma nova tarefa para ser processada. 
Vale ressaltar que o número de tarefas a serem processadas precisa ser maior que a quantidade de processadores disponibilizados para a sua execução.

Figura 2 - Esquematização do funcionamento do balanceamento dinâmico utilizando fila de tarefas, sendo que as tarefas são independentes.

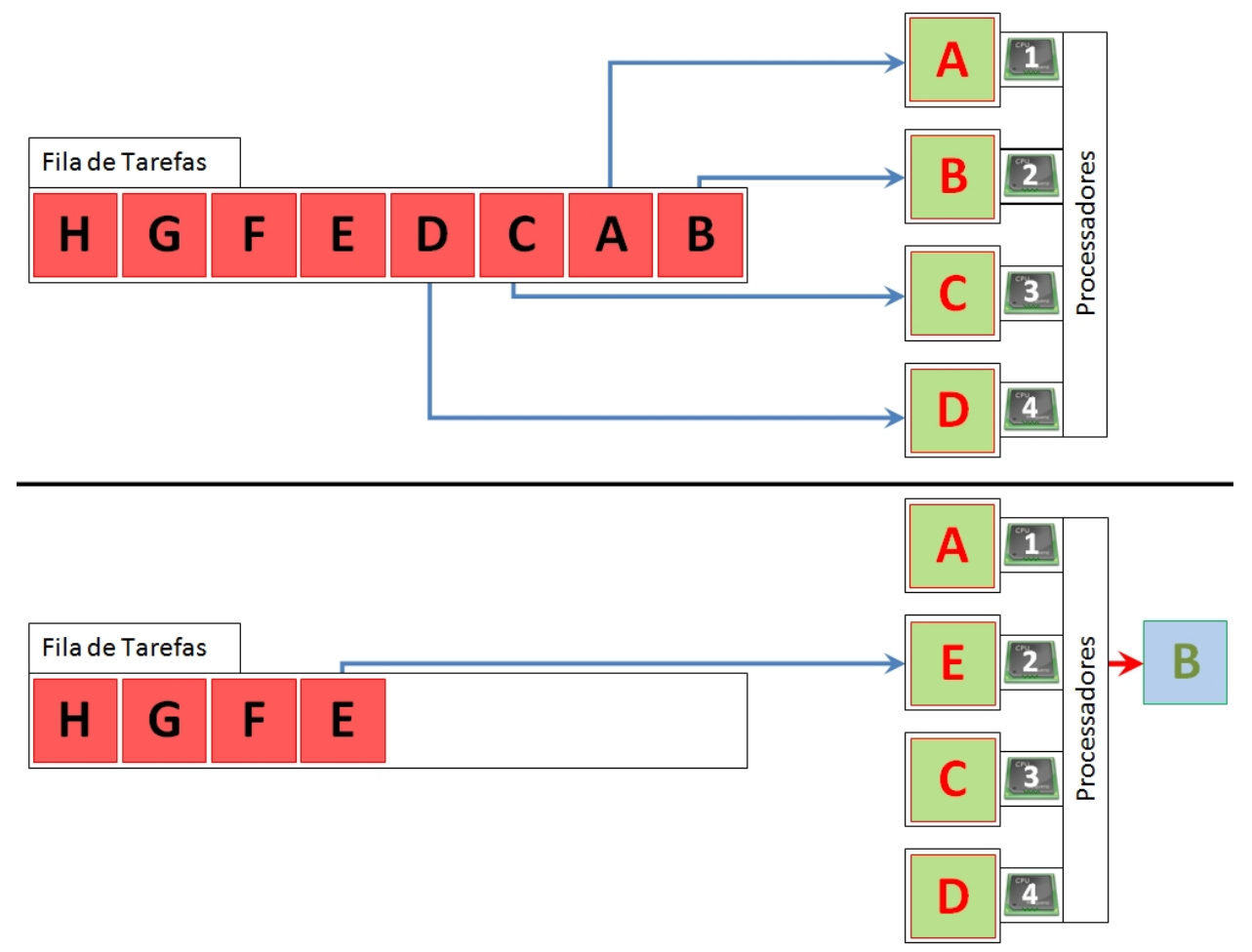

Fonte: Próprio Autor (2013).

Na Figura 2 é apresentado o funcionamento do escalonamento dinâmico utilizando o conceito de fila de tarefas.

Na parte superior da figura, tem-se a fila de tarefas que devem ser processadas e os processadores disponibilizados para realizar os cálculos sobre as mesmas. Cada processador obtém uma tarefa da fila, onde neste caso:

- O processador $\mathbf{1}$ calcula a tarefa $\mathbf{A}$;

- O processador 2 computa a tarefa B;

- O processador $\mathbf{3}$ computa a tarefa $\mathbf{C}$; 
- O processador 4 computa a tarefa $\mathbf{D}$.

Após um processador ter encerrado o cálculo, ele obtém uma nova tarefa para ser processada. Na parte inferior da Figura 2 o Processador 2 finalizou o cálculo da Tarefa B e obtém uma nova tarefa para ser processada, no caso a Tarefa E.

Este algoritmo possui uma implementação bastante simples, na qual as unidades processantes vão obtendo as tarefas para calcular e quando finalizam a sua computação, solicitam uma nova tarefa para calcular.

Alguns dos problemas desta implementação são:

- A quantidade de tarefas deverá ser sempre maior que a quantidade de processadores disponibilizados para o cálculo.

- As cargas das tarefas não são mensuradas neste algoritmo, o que pode ser um problema. Por exemplo, no caso em que o último elemento da lista de tarefa tem um maior volume de computação, enquanto um dos processadores processa esta última tarefa, os demais podem ficar ociosos.

Algumas propostas que utilizam o conceito de fila de tarefas são apresentadas em (KRUSKAL; WEISS, 1985), (POLYCHRONOPOULOS; KUCK, 1987), (TANG; YEW, 1986) e (MARKATOS; LEBLANC, 1994).

\subsubsection{Modelo de difusão}

No modelo de difusão as cargas são distribuídas geralmente de maneira uniforme e o balanceamento de cargas é analisado durante a execução da aplicação paralela. 
Se em algum instante a distribuição for considerada desbalanceada, uma redistribuição das cargas é realizada pelas tarefas, transferindo carga de processamento para os processos vizinhos, como em um processo de difusão.

A Figura 3 ilustra o funcionamento deste modelo. Na parte superior da figura, as Tarefas A, B, C e D foram igualmente distribuídas com base em algum parâmetro de entrada. Após uma evolução da simulação, a aplicação paralela realiza uma análise e verifica se alguns processadores estão sobrecarregados em relação a outros processadores.

Para tentar resolver este problema, ocorre a comunicação entre as tarefas e elas fazem um redimensionamento das suas fronteiras com as tarefas vizinhas. Este procedimento é realizado até o instante em que as cargas das tarefas a serem processadas estejam balanceadas, ou se alcance o limite máximo de granularidade, que se permita a transferência de cargas entre processos.

Esta proposta de escalonamento é bastante interessante, pois teoricamente o sistema tenta buscar o balanceamento ideal para a carga que ele deseja processar.

Os problemas apresentados no modelo de difusão são apresentados a seguir:

- Não é toda aplicação paralela que permite a implementação desta proposta, pois seria necessário realizar um fracionamento dos elementos que irão ser computados, sendo necessário possuir um nível de granularidade alto a fim de permitir a migração dos elementos que serão utilizados para computação de valores.

- O redimensionamento entre as tarefas pode nunca alcançar o equilíbrio, o que pode causar uma oscilação no processo de balanceamento. 
Figura 3 - Esquematização do funcionamento do balanceamento dinâmico utilizando modelo de difusão.

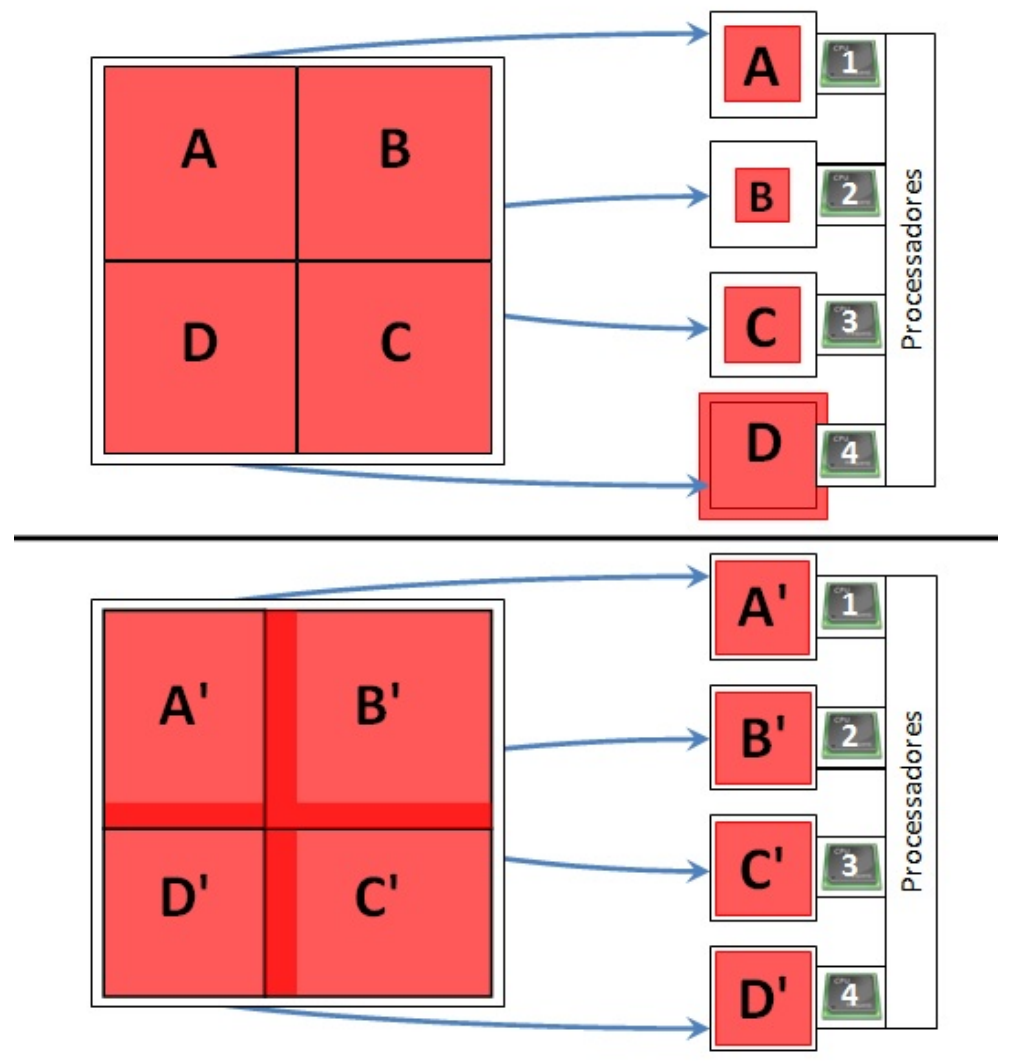

Fonte: Próprio Autor (2013).

- O custo de ficar realizando uma análise de desempenho durante a execução impacta no tempo total da execução da aplicação, quanto mais frequentes forem essas análises, mais influenciarão na execução final.

- A comunicação neste modelo acaba impactando no desempenho da execução da aplicação. Essa influência deve ser levada em conta no momento de se mensurar as cargas da tarefa.

Um exemplo de algoritmo que utiliza esse modelo é apresentado em (LIN; KELLER, 1987). 


\subsection{Aplicações paralelas}

Nesta seção é apresentado um conjunto de aplicações paralelas, sendo que em cada uma delas, é comentado sobre a técnica de paralelização utilizada para prover o paralelismo na aplicação.

\subsubsection{Simulador Tanque de Provas Numérico}

O aplicativo TPNSolver foi desenvolvido para realizar simulações da dinâmica do acoplamento de corpos flutuantes com linhas de amarração e risers sobre a ação de diferentes condições ambientais (NISHIMOTO et al., 2003). Este simulador foi desenvolvido em uma colaboração entre a comunidade acadêmica e a Petrobras.

O problema do cálculo do potencial no domínio do tempo é calculado pelas forças de onda que atuam nos corpos, e modelos empíricos são utilizados para descrever a força de corrente e de vento. Para a representação das linhas de amarração e risers são utilizadas técnicas complexas baseadas no modelo de elementos finitos com ação de forças de hidrodinâmica não linear.

Devido à quantidade de elementos a serem computados, o tempo de uma execução é longo. A programação paralela auxilia no processo de cálculo (LUZ; GASPAR; NISHIMOTO, 2009).

A técnica de comunicação utilizada no TPNSolver foi desenvolvida pelo próprio grupo e é baseada em socket. Socket (STEVENS; FENNER; RUDOFF, 2003) define uma Application Programming Interface (Interface de Programação de Aplicativos) (API) de baixo nível que permite que programas comuniquem entre si.

Usar socket permite ter uma flexibilidade na realização e no gerencia- 
mento das comunicações, mas acaba resultando em um esforço extra para o gerenciamento e controle dos dados entre as tarefas paralelas, além do aumento da complexidade para a manutenção do código. A portabilidade também fica comprometida, pois a aplicação só funciona em ambiente UNIX.

Uma linha pode ter uma computação mais elevada dependendo do modelo utilizado para descrever o seu comportamento, a quantidade de discretização que ela possui, se ela possui computações intermediárias dentro de um passo de simulação.

No TPNSolver, estes valores são utilizados para determinar um peso para cada tarefa e desta forma, poder realizar o escalonamento das tarefas. Alguns problemas que surgem nesta proposta são a obtenção da correta correlação entre o peso dado a cada uma das tarefas com os parâmetros citados e definir qual processador irá executar um dado conjunto de tarefas, pois da forma atual, elas são apenas separadas por nós.

\subsubsection{Brazilian developments on the Regional Atmospheric Modelling System (BRAMS)}

O BRAMS (INPE/CPTEC, 2006) é um projeto de colaboração de diversas universidades com o objetivo de desenvolver um modelo de previsão para os centros meteorológicos para a região do Brasil. Atualmente o código é mantido apenas pelo grupo de desenvolvedores do CPTEC/INPE.

Para prover o paralelismo para esta aplicação é utilizado o framework de balanceamento de cargas dinâmico chamado Charm++, desenvolvido na Universidade de Illinois, é baseado na virtualização do processador de tal forma que permite a migração de threads entre processadores.

O Charm++ é baseado nos seguintes aspectos: 
- Eficiência e portabilidade: sendo que ele pode ser executado sem nenhuma modificação no seu código fonte original, em máquinas MIMD com ou sem memória compartilhada;

- Tolerância à latência: o Charm++ utiliza a "execução orientada a mensagem", isto é, o processador é alocado ao processo somente quando a mensagem é recebida, ou seja, enquanto o processo atual estiver bloqueado, o processador executa outro processo;

- Balanceamento Dinâmico de Carga: a migração e criação dinâmica são permitidas devido a diversas estratégias de balanceamento disponíveis no Charm++;

- Reuso e modularidade: permite o reuso de elementos de outras aplicações paralelas desenvolvidas com o Charm++, com estruturas chamadas de "module", isto é, "modules" de aplicações paralelas distintas podem ser combinados e trocar dados entre si.

Um trabalho recente do aplicativo BRAMS (FAZENDA et al., 2014), apresenta a possibilidade de utilizar balanceamento dinâmico de cargas por meio da combinação do Charm++ com o uso de GPU.

\subsubsection{Alinhamento múltiplo de sequências}

O alinhamento múltiplo de sequências é utilizado para a determinação da estrutura de proteínas, Ácido Desoxirribonucleico (DNA) e RNA. É considerada uma ferramenta fundamental na área de bioinformática e a sua resolução é de alta complexidade.

Diversos estudos foram conduzidos para propor métodos eficientes para resolvê-lo. Em um deles (VASCONCELLOS et al., 2014), é apresentada uma 
proposta de algoritmo paralelo utilizando o modelo de programação BSP, com implementações em MPI e Compute Unified Device Architecture (CUDA), possibilitando a manipulação de um número maior de sequências, além disso, sequências com tamanhos maiores.

No Capítulo 4 o BSP é aprofundado, pois será utilizado no desenvolvimento deste trabalho.

\subsection{Considerações sobre as técnicas}

Nesta seção são feitas algumas considerações sobre as técnicas apresentadas nas seções anteriores.

A aplicação do TPNSolver foi implementada com uma implementação própria de padrão de comunicação, baseada em sockets. Este tipo de solução deve ser evitado devido à alta complexidade para gerenciar e manter essa solução de comunicação, além de não possuir uma robustez de implementações baseadas em padrões.

O processo de escalonamento das cargas baseado em heurística é uma forma imprecisa de distribuir as tarefas, pois os valores obtidos podem variar de acordo com a arquitetura e com o ambiente paralelo utilizado para gerar os valores de base para a heurística.

Já o Charm++ permite que a distribuição das cargas seja determinada em um nível abaixo do utilizado para realizar a programação, além de utilizar uma linguagem de alto nível. A dificuldade é que todo o código já existente deverá ser portado para esta linguagem, para permitir fazer uso destes ganhos.

Nos trabalhos observados que utilizam o BSP, a principal utilização é no desenvolvimento de novos de algoritmos. Sendo que o modelo pode ser usado 
de forma mais ampla, definindo características gerais de como a aplicação paralela deverá se comportar durante a sua execução.

Uma das grandes dificuldades é a necessidade de alterar o código fonte da aplicação original, e além disso, compreender as características do problema paralelo e determinar de que forma pode-se melhorar o algoritmo paralelo.

Seria interessante que uma ferramenta que propusesse formas de realizar o escalonamento das tarefas e conseguisse diminuir a ociosidade dos recursos paralelos, sem prejudicar o desempenho da aplicação. Outro aspecto interessante realizar o procedimento de maneira automatizada e sem alterações no código fonte. 


\section{METODOLOGIA PARA EXECUÇÃO DE APLICAÇÕES PARALELAS BASEADAS NO MODELO BSP COM TAREFAS HETEROGÊNEAS}

A metodologia aqui denominada de ASE - Acquisition/Scheduling/Execution (Aquisição - Escalonamento - Execução), que tem como objetivo realizar a execução de aplicações paralelas baseadas no modelo BSP, contendo tarefas heterogêneas, é aqui apresentada.

Esta metodologia reduz a ociosidade dos recursos de processamento alocados para execução da aplicação, sem prejudicar o desempenho da mesma. Para tanto, tem como base um algoritmo de escalonamento adequado ao modelo de aplicações, que promove uma distribuição balanceada da computação heterogênea das tarefas. É também calculado o número de recursos de processamento a partir do qual o seu acréscimo não implica em uma melhora do desempenho da execução.

Além disso, a técnica desenvolvida neste trabalho foi planejada de forma a não ter a necessidade de se alterar o código fonte original e ser totalmente automatizada. Esta característica não foi encontrada em nenhum outro método na literatura.

A metodologia Acquisition/Scheduling/Execution (Aquisição - Escalonamento - Execução) (ASE) é composta por três etapas: Aquisição, Escalonamento e Execução. 
A etapa de Aquisição consiste em obter os tempos de processamento das tarefas paralelas de forma automatizada, para possibilitar a distribuição das cargas paralelas.

Já a etapa de Escalonamento é responsável em realizar o escalonamento das cargas com base nas informações obtidas no passo anterior, procurando melhorar o uso dos recursos sem prejudicar a execução paralela.

Na etapa de Execução, a aplicação paralela é executada utilizando o número de recursos obtido na etapa anterior.

Neste capítulo inicialmente é apresentado o modelo de aplicação paralela para o qual a metodologia foi concebida. Na sequência são apresentadas de forma abstrata as ferramentas utilizadas para a implementação da metodologia.

E por fim, são apresentadas cada uma das três etapas da metodologia.

\subsection{Modelo da aplicação paralela}

A descrição do modelo da aplicação permite estabelecer de maneira mais ampla quais aplicações paralelas estão aptas para utilizar a metodologia deste trabalho. Isto é necessário devido a grande variedade de aplicações paralelas.

A metodologia é aplicável a aplicações paralelas baseadas em uma variante do modelo BSP.

\subsubsection{Bulk-Synchronous Parallel - BSP}

O modelo BSP define um nível de abstração entre programas e máquinas paralelas, evitando uma correlação entre os hardwares utilizados e os aplicativos desenvolvidos, tentando fazer uma analogia ao modelo da máquina de 
Von Neumann aplicado em máquinas sequenciais (VALIANT, 1990).

As suas principais características estão descritas em (VALIANT, 1990; HILL; SKILLICORN, 1998; SUJITHAN; HILL, 1997) e pode-se definir a sua estrutura pelas seguintes etapas:

1. Um número $N$ de componentes executando processamento e/ou funções de memória, sendo que, cada um deles geralmente consiste de um processador sequencial com um acesso a memória local;

2. Um roteador que provê a distribuição das mensagens ponto a ponto entre os componentes;

3. Uma etapa de sincronização dos componentes, em intervalos regulares com duração de $L$ unidades de tempo (onde $L$ é chamado de parâmetro de periodicidade).

Figura 4 - Estrutura de um superstep no modelo BSP, que é dividido Computações Locais, Comunicações Globais e Barreira de Sincronização.

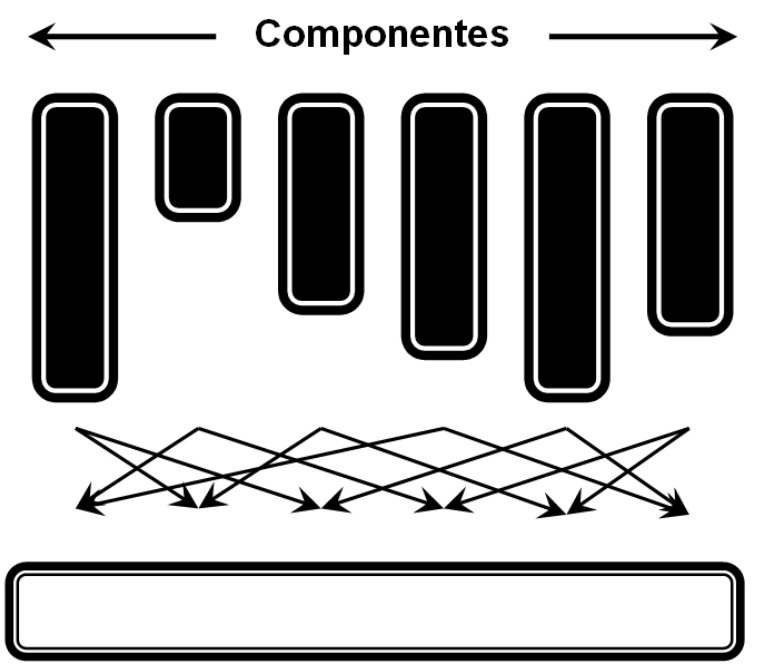

\section{Computações \\ Locais \\ Comunicações \\ Globais}

Barreira de

Sincronização

Fonte: Adaptado de (HILL; SKILLICORN, 1998) (2014).

Os intervalos regulares, também chamados de supersteps, podem ser divididos em três fases, conforme apresentado na Figura 4. 
1. As computações são realizadas localmente em cada processador pelos componentes, utilizando valores armazenados na sua memória local;

2. As comunicações entre processadores, envolvendo transferência de dados entre os componentes;

3. Uma barreira de sincronização, que indica a finalização da execução de um superstep, onde todos os dados necessários para o inicio do próximo superstep devem estar disponíveis na memória local dos componentes.

$\mathrm{Na}$ implementação do modelo do BSP, evita-se a dependência da localidade realizando um mapeamento entre as tarefas e processadores de forma aleatória. Outra característica deste modelo é a possibilidade de prever o tempo das comunicações globais. Devido a estes elementos, é possível com o BSP verificar a influência média da comunicação na execução.

As suas principais propriedades de acordo com (SKILLICORN; HILL; MCCOLL, 1996) são:

- Facilidade de escrita: Os programas desenvolvidos utilizando o modelo BSP são parecidos com a escrita de programas sequenciais. Apenas o mínimo de informação deve ser apresentado para descrever o paralelismo;

- É independente da arquitetura alvo: Pois a sua concepção independe da arquitetura paralela utilizada, isto é, muitos programas não são modificados ao alterar a arquitetura, definindo assim a sua correlação com a portabilidade;

- O desempenho da aplicação em uma dada arquitetura é previsível: O tempo gasto em uma execução utilizando o modelo BSP pode ser obtido com um conjunto de parâmetros da simulação. 


\subsubsection{Tempo de execução em um superstep}

As considerações a seguir foram baseadas no artigo de (HILL; SKILLICORN, 1998).

Considere que durante a fase de comunicação, cada processador envia e recebe um conjunto de mensagens. O número máximo destes conjuntos é chamado de $h$ e o conjunto total de todas as mensagens enviadas é denominado de $h$-relation.

O tempo de entrega de um $h$-relation pode ser capturado por um parâmetro, denominado $g$, que mede a permeabilidade da rede para um tráfego contínuo de destinos uniformemente distribuídos. É definido então que o valor de uma $h$ - relation de uma single word é entregue em um tempo $h g$, expressos em unidades de instruções do processador.

Se um ambiente paralelo possui um valor baixo de $g$ significa que o mesmo é bom para permutações de entrega. O parâmetro $g$ depende da rede de conexão da máquina paralela, dos protocolos de comunicação, dos algoritmos de roteamento desta rede, do sistema de gerenciamento do buffer e da forma que o sistema de execução do BSP foi implementado.

Vale ressaltar que $g$ é definido com base em um tráfego contínuo, que pode causar imprecisão quando apenas um conjunto pequeno de dados for transferido, devido ao custo de inicializar a comunicação acaba predominando o tempo da comunicação em mensagens pequenas.

Outro parâmetro utilizado neste modelo é o custo do uso da barreira de sincronização, definido por $l$, que também pode ser indicado em termos de unidades de tempo de execução de instruções.

Explicados estes parâmetros, pode-se definir o tempo de execução de um 
superstep é definido pela soma do máximo tempo gasto nas computações locais em um dado superstep, o tempo para entregar a $h$-relation e o tempo requerido para realizar a sincronização no final, que pode ser expresso pela Equação 4.1,

$$
\text { superstep execution time }=\underset{\text { process }}{\operatorname{MAX}} w_{i}+\underset{\text { process }}{\operatorname{MAX}} h_{i} g+l
$$

sendo que $i$ itera sobre todos os processos e $w_{i}$ é o tempo de computação de um processo $i$.

\subsubsection{O uso do BSP neste trabalho}

As características do BSP, descritas na Seção 4.1.1, são utilizadas como base para descrever o modelo de aplicação em que se aplica a metodologia.

A aplicação paralela possui um conjunto finito de supersteps. O tempo que cada tarefa gasta para realizar as suas computações dentro de um superstep não varia muito entre os supersteps. Além disso, o tempo associado a cada tarefa pode ser heterogêneo.

A Figura 5 apresenta as características do modelo adaptado do BSP.

O modelo possui dois tipos de tarefas, o primeiro deles é chamado de tarefa "centralizadora". Esta tarefa é responsável em realizar a sincronização entre as tarefas, atualizar as informações a serem computadas pelas outras tarefas e realizar a interação com o usuário.

Já o outro tipo de tarefa é responsável em realizar as computações paralelas da aplicação, sendo que em cada superstep recebem uma atualização do valor a ser computado, realiza a sua processamento e envia o resultado para a tarefa "centralizadora". Este tipo de tarefa foi denominada unicamente por tarefas 
Figura 5 - Modelo BSP adaptado para ser utilizado na metodologia. Cada seção tracejada representa um superstep.

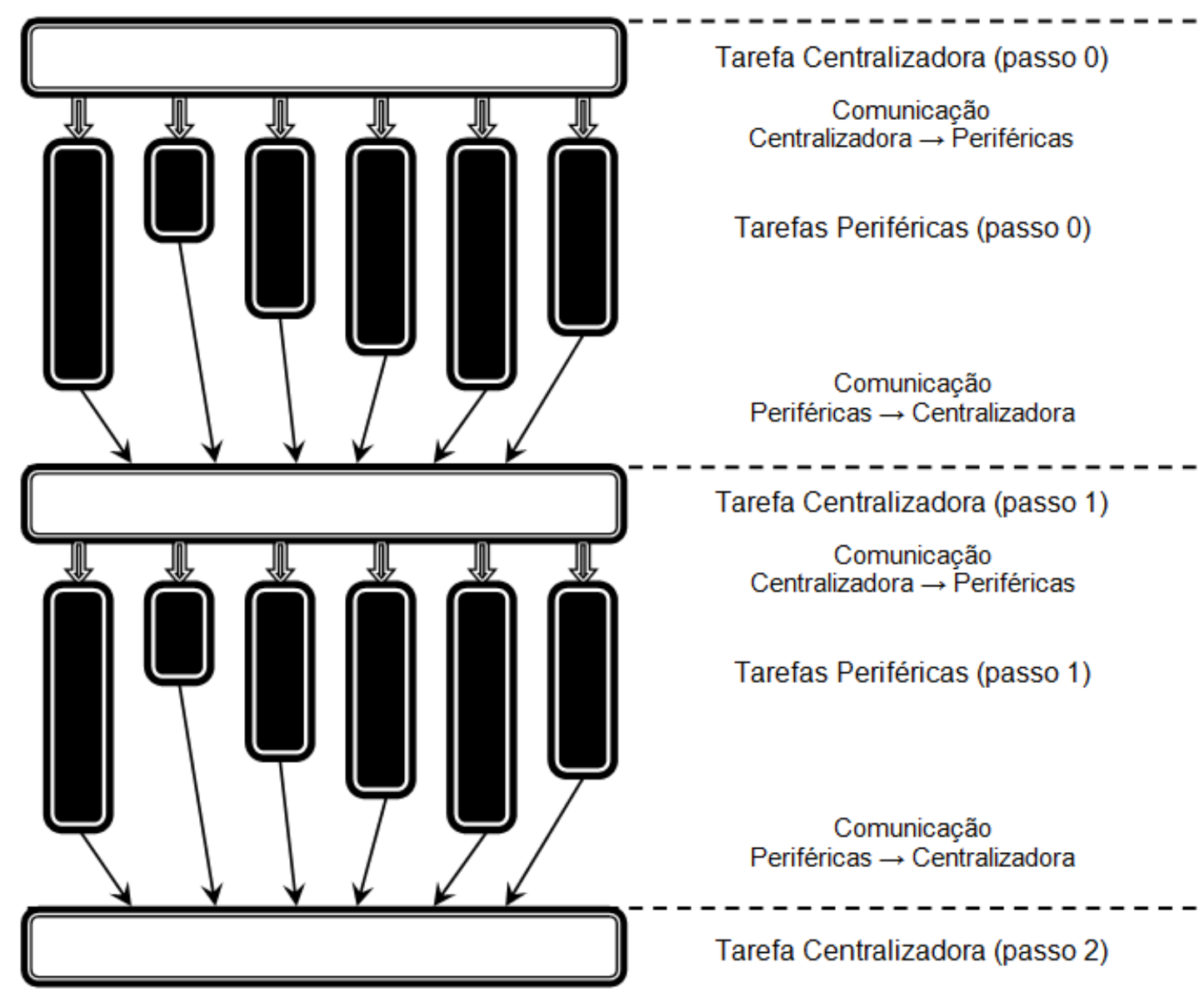

Fonte: Próprio Autor (2014).

Dentro do modelo há apenas uma tarefa "centralizadora" e $N$ tarefas "computadoras".

A iteração entre as tarefas dentro de um superstep pode ser descrito da seguinte forma:

1. A tarefa "centralizadora" envia os respectivos dados para cada uma das tarefas "computadoras" poderem executar a sua computação e entra no estado de espera, aguardando receber os dados das tarefas "computadoras". 
2. As tarefas "computadoras" recebem os valores da tarefa "centralizadora" e iniciam a computação dos dados recebidos. Vale ressaltar que neste processo de comunicação podem ocorrer comunicações entre as tarefas "computadoras", mas só a comunicação dos resultados finais com a tarefa "centralizadora" é que define o encerramento da iteração da tarefa "computadora".

3. A tarefa "centralizadora" recebe os dados computados de todas as tarefas "computadoras" e realiza um conjunto de cálculos antes de entrar na próxima iteração. Este processo de aguardar os resultados das tarefas "computadoras" consiste de um ponto de sincronização entre as tarefas, definido no modelo com o nome de superstep.

4. O tempo para execução de cálculos de cada uma das tarefas "computadoras" com a computação dentro de uma iteração é heterogêneo. Isto leva a um tempo de espera pela tarefa "centralizadora" para receber os resultados de todas as tarefas. Além disso, isto causa a espera de algumas tarefas "computadoras" no recebimento dos dados a serem processados no próximo superstep.

5. O tempo gasto com a computação de uma dada tarefa durante uma iteração deve variar pouco em relação às demais iterações durante a execução da aplicação.

\subsection{Automação do processo de execução}

O processo de execução de uma aplicação deve acionar automaticamente cada etapa que compõe a metodologia, através de um workflow. Para isto é necessário utilizar uma linguagem que permita compor a execução da aplicação implementando o fluxo das etapas. Tal linguagem deve permitir o acesso 
ao sistema operacional, ao sistema de arquivos, à manipulação de dados estatísticos e portabilidade em uma grande quantidade de sistemas operacionais.

A escolha por uma linguagem interpretada permite atender os requisitos descritos acima sem ter que realizar uma compilação para cada ambiente diferente, além de facilitar a manipulação do sistema de arquivos por meio do interpretador da linguagem.

Alguns exemplos de linguagens interpretadas são o Python (Python Software Foundation., 2015), o interpretador de comandos em bash (Free Software Foundation, Inc., 2015) e o PHP (The PHP Group, Inc., 2015)

\subsection{Formato de Arquivo de Saída}

Devido ao fato que os dados obtidos em cada uma das etapas podem ser reutilizados, tanto pela própria metodologia quanto por programas externos, é interessante definir um formato padrão para estruturar os resultados das etapas.

Algumas possibilidades são utilizar os padrões Extensible Markup Language (XML) (BRAY et al., 2008) e JavaScript Object Notation (JSON) (Ecma International, 2015).

\subsection{A metodologia ASE}

A metodologia desenvolvida nesta tese é constituída de três etapas: Aquisição, Escalonamento e Execução.

A obtenção dos tempos de cada tarefa que integra a aplicação paralela ocorre na etapa de Aquisição, sendo que os resultados podem ser armazenados em um arquivo ou podem ser inseridos diretamente na próxima etapa. 
A etapa de Escalonamento é responsável em descobrir qual a melhor distribuição das tarefas, considerando a heterogeneidade das suas computações, visando promover o balanceamento de carga. Para isto, esta etapa utiliza os valores de tempos de processamentos das tarefas obtidos na etapa anterior ou de um arquivo contendo os tempos coletados em uma execução anterior da aplicação. Os resultados desta etapa também podem ser armazenados em um arquivo de saída ou podem ser transmitidos diretamente para a etapa seguinte.

E por fim, na etapa de Execução, é gerada uma execução paralela baseada na distribuição de cargas definida pela etapa anterior. As informações sobre a distribuição das tarefas e a quantidade de recursos que serão utilizados podem ser obtidas via arquivo ou por transmissão direta dos cálculos da etapa anterior.

A geração de arquivos em algumas das etapas permite reaproveitar dados calculados em execuções anteriores, que não sofreram alterações.

A relação entre estas etapas é apresentada na Figura 6.

Figura 6 - Esquematização das etapas que definem a metodologia de execução.

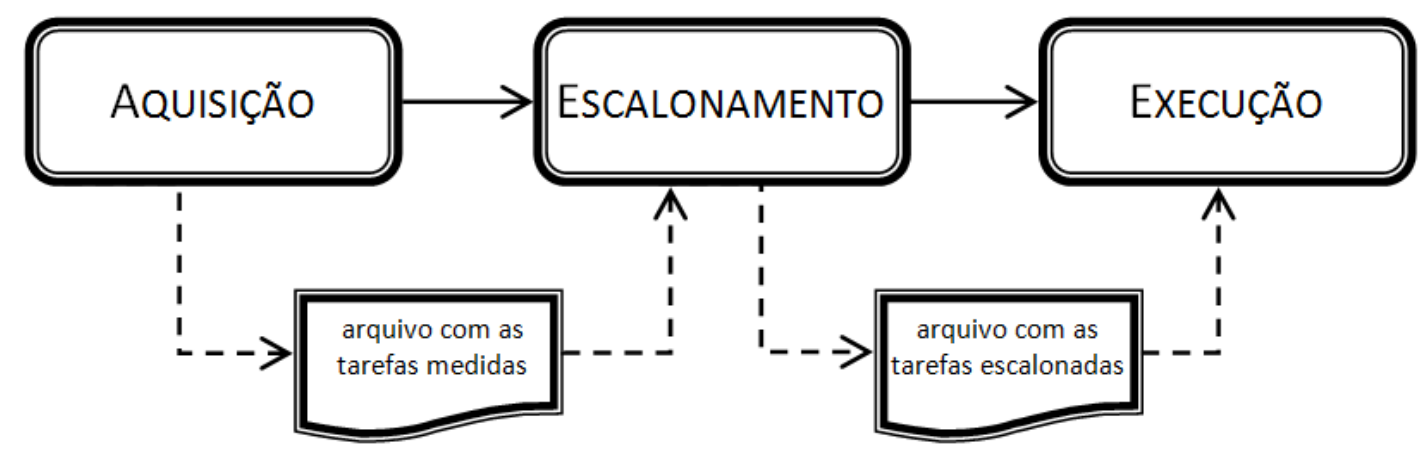

Fonte: Próprio Autor (2015).

Nas seções seguintes, são apresentadas com detalhes cada uma das três etapas que descrevem a metodologia ASE, começando pela etapa de Aquisi- 
ção, depois será apresentada a etapa de Escalonamento e por fim a etapa de Execução.

\subsubsection{Aquisição}

A etapa de Aquisição dentro da metodologia ASE realiza a obtenção dos tempos das tarefas paralelas, a serem utilizados na etapa seguinte, que realiza o escalonamento. Esta etapa precisa executar um pequeno número de supersteps, em comparação com a quantidade total, para obter as informações sobre o tempo de execução da aplicação.

Para isso, é utilizada uma rotina de captura dos dados que, baseada na execução de passos temporais determina quantas comunicações foram realizadas entre as tarefas "computadoras" e a tarefa "centralizadora". Desta forma, é possível determinar quando ocorre a ultima comunicação entre uma tarefa "computadora" e a tarefa "centralizadora" dentro de um superstep, definindo o tamanho de um superstep.

Para cada tarefa, uma estatística simples de valor médio e desvio padrão é calculada, de acordo com a quantidade de passos temporais presentes.

Os passos para esta etapa podem ser resumidos da seguinte forma:

1. Verificar a quantidade de passos temporais que serão utilizados para executar a etapa de medição;

2. Utilizar uma ferramenta de profiling para capturar as principais instruções da execução paralela;

3. De acordo com as instruções capturadas, determinar o tempo que cada tarefa gasta realizando uma computação dentro de um passo temporal, e a comunicação com as outras tarefas; 
4. Armazenar todas estas informações dentro de um arquivo de saída estruturado, ou inserir os dados calculados para a próxima etapa de escalonamento.

Na seção seguinte é apresentado o algoritmo utilizado para realizar o escalonamento das cargas.

\subsubsection{Escalonamento}

O processo de escalonamento das cargas paralelas é a parte central da metodologia.

Utilizando os tempos de processamento obtidos (Seção 4.4.1), para cada quantidade de recursos de processamento, o algoritmo realiza uma distribuição das tarefas, considerando a heterogeneidade dos tempos e promovendo o balanceamento de cargas e a redução da ociosidade.

Para cada quantidade de recursos de processamento, iniciando de dois recursos até um valor máximo em que qualquer acréscimo não impacta na melhora do desempenho, é realizado o escalonamento das tarefas.

A seguir são apresentadas as denominações para os tempos dentro da execução paralela, que foram capturados e são utilizados no algoritmo de escalonamento das tarefas.

\subsubsection{Nomenclatura}

A nomenclatura utilizada para cada uma das marcas temporais dentro da execução paralela é apresentadas a seguir para facilitar a compreensão dos algoritmos apresentados na Seção 4.4.2.2.

Tempos do $i$-ésimo processo 
Aqui são apresentadas as marcas temporais que são associadas às tarefas "computadoras", isto é, que realizam a computação distribuída nos recursos paralelos. A Figura 7 apresenta algumas destas marcações.

Figura 7 - Representação dos termos definidos na nomenclatura considerando a tarefa 3 . O número 1 representa $t r d_{3} ; \mathrm{O}$ número 2 indica $t p_{3}$; O número 3 representa $0 \mathrm{ttd}_{3}$; O número 4 define o $\mathrm{tte}_{3}$; O número 5 indica $\mathrm{o} \mathrm{ttet}_{3}$ e por fim $\mathrm{O} t t_{3}$ pode ser definido como a soma de 1 com 2 e 3 .

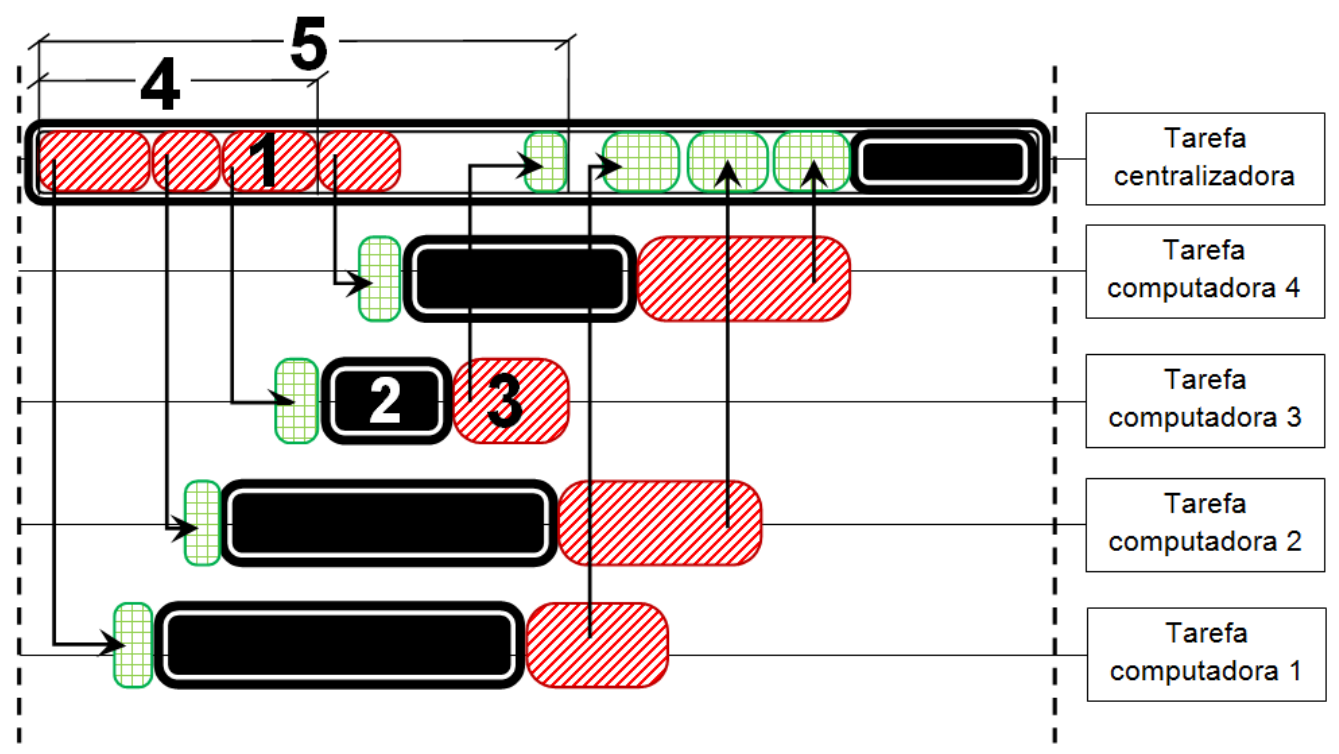

Fonte: Próprio Autor (2015).

$\boldsymbol{t r d}_{\boldsymbol{i}}$ Tempo de Recepção dos Dados pela tarefa "computadora" $i$ : É definido pelo instante em que a tarefa "centralizadora" começa a enviar dados para as tarefas "computadoras" e esse dado chega para uma dada tarefa "computadora" $i$;

$\boldsymbol{t} \boldsymbol{p}_{\boldsymbol{i}}$ Tempo de Processamento da tarefa "computadora" $i$ : É o tempo gasto pela tarefa "computadora" $i$ realizando a sua computação, não considerando o compartilhamento de processador com as outras tarefas;

$\boldsymbol{t t d}_{\boldsymbol{i}}$ Tempo de Transmissão de Dados da tarefa "computadora" $i$ com a tarefa "centralizadora": É o tempo gasto para a comunicação entre a tarefa "computadora" $i$ com a tarefa "centralizadora"; 
$\boldsymbol{t t e}_{\boldsymbol{i}}$ Tempo Total de Espera: contabilizado a partir do inicio dos envios de dados pela tarefa "centralizadora" com as tarefas "computadoras";

$$
t t e_{i}=\sum_{j=1}^{i} t r d_{j}
$$

ttet $_{i}$ Tempo Total gasto entre o início dos Envios de dados pela tarefa "centralizadora" (sem considerar o time-sharing) para as tarefas "computadoras" até o momento que os dados começam a ser Transmitidos pela tarefa "computadora" $i$ para a tarefa "centralizadora". Considerando o time-sharing entre as tarefas alocadas no mesmo nó;

$\boldsymbol{t t}_{\boldsymbol{i}}$ Tempo Total gasto pela tarefa "computadora" $i$.

\section{Tempos do $k$-ésimo recurso}

Aqui são apresentados os tempos relacionados à comunicação e ao processamento em cada recurso. Recurso é qualquer elemento processante paralelo que será utilizado na execução paralela.

$\boldsymbol{t e i}_{\boldsymbol{k}}$ Tempo entre o início dos Envios dos dados pela tarefa "centralizadora" para as tarefas "computadoras" e o Início do processamento no recurso $k$;

te $f_{k}$ Tempo entre o início dos Envios dos dados pela tarefa "centralizadora" para as tarefas "computadoras" e o Final do processamento no recurso $k$;

$\boldsymbol{t t p r}_{\boldsymbol{k}}$ Tempo Total de Processamento no Recurso (considerando o time sharing);

$\boldsymbol{t t c r}_{\boldsymbol{k}}$ Tempo Total de Comunicação no Recurso, de todas as tarefas que estão no recurso. 


\section{Outras variáveis}

Aqui são apresentadas outras variáveis que são utilizadas dentro do algoritmo de escalonamento das cargas.

n_recurso $O$ número de recursos paralelos que foram disponibilizados para a execução das tarefas. Recurso pode ser uma máquina monoprocessada ou uma máquina com múltiplos processadores;

n_tarefa O número de tarefas que deverão ser executadas na aplicação paralela.

A seguir será descrito o funcionamento do algoritmo que proverá uma forma melhor de distribuir essas cargas.

\subsubsection{Algoritmo Geral}

O algoritmo de escalonamento das cargas pode ser iniciado após a etapa de Aquisição ou utilizando os tempos coletados armazenados em um arquivo.

Logo no início (Algoritmo 1: 3) uma função de ordenação coloca a lista de tarefas em ordem decrescente baseado no tempo de processamento de cada tarefa.

Na sequência o algoritmo realiza a inicialização da variável tte para cada processo paralelo que será executado (Algoritmo 1:4), e calcula quanto tempo cada tarefa irá demorar em receber os dados para iniciar a sua computação.

Após isso, é variada a quantidade de recurso a ser utilizada na execução paralela, verificando até o momento em que o Speedup começa a parar de crescer (Algoritmo 1: 10). Inicia-se a execução com o número máximo de recursos e vai decrementando o número de recursos um a um. A busca é 


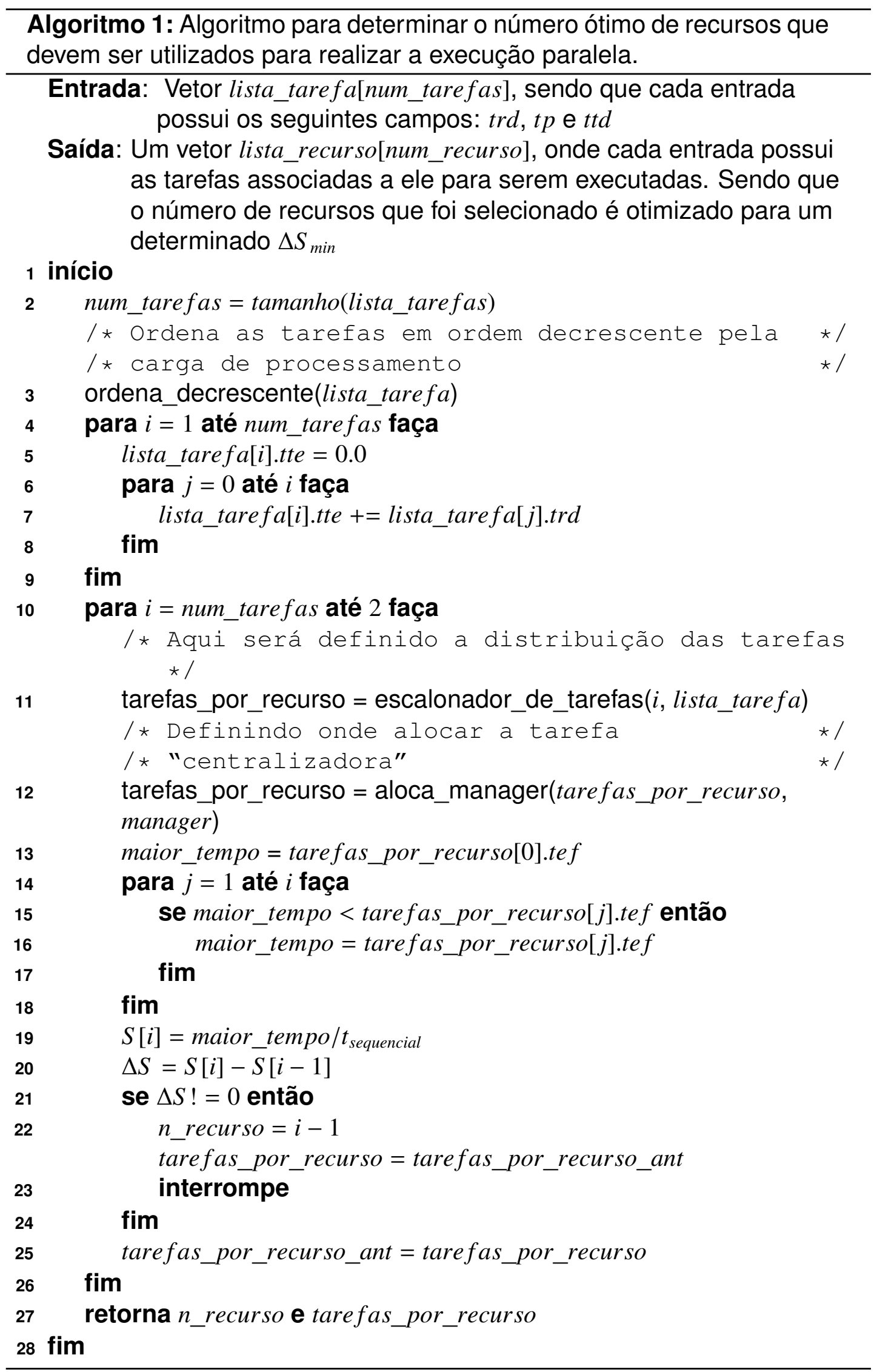


interrompida no momento em que ao remover um recurso, o Speedup sofre uma variação no seu valor.

Dentro do procedimento acima a função escalonador_de_tarefas é chamada, sendo responsável em fazer a distribuição das tarefas para cada um dos recursos fornecidos (Algoritmo 1: 11). Essa função é explicada no Algoritmo 2.

Na sequência, é chamada a função aloca_manager, que insere a tarefa "centralizadora" no nó que possui a maior quantidade de tempo gasto com comunicação, essa função é detalhada no Algoritmo 3.

O algoritmo retorna as variáveis n_recurso e tarefas_por_recurso, que representam o número otimizado de recursos e a lista de tarefas por recursos, respectivamente.

\subsubsection{Escalonamento de tarefas}

A função escalonador_de_tarefas é responsável em fazer a distribuição da lista de tarefas "computadoras" em um conjunto de recursos. Busca obter a melhor distribuição das cargas a serem processadas e retorna a distribuição obtida para o Algoritmo 1.

O funcionamento do algoritmo consiste na recepção do vetor de tarefas que devem ser distribuídas e o número de recursos que foram disponibilizados.

Em Algoritmo 2: 3 uma tarefa é inserida em cada recurso disponibilizado. Sendo que as informações como o tempo que o recurso irá demorar em iniciar a sua computação (tei) que é o tempo total de espera da tarefa i (tte), o tempo que o recurso irá demorar a retornar os dados computados (tef) que é o tempo total de espera mais o tempo gasto com o processamento da tarefa i $(t t e+t p)$ 
e o tempo total que o recurso gasta para realizar a computação $(t t p r)$ que é o tempo total de processamento da tarefa $(t p)$ são inicializadas nesta etapa.

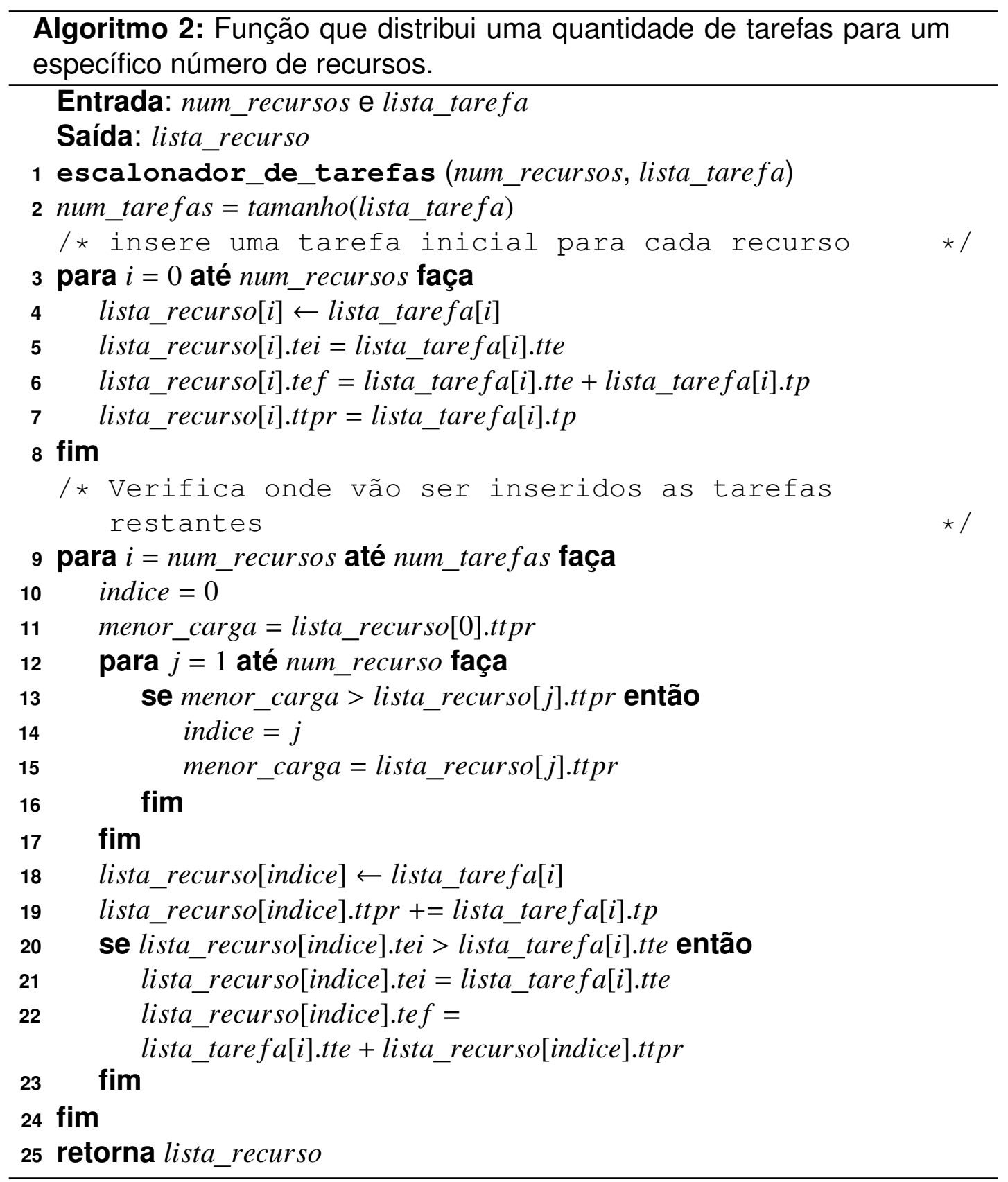

A partir de Algoritmo 2: 9 são realizadas as distribuições das tarefas que ainda não foram atribuídas para algum recurso. $O$ recurso que possuir a menor carga de processamento é escolhido para se atribuir a próxima tarefa, conforme apresentado no laço em Algoritmo 2: 12, e neste instante são atualizadas as variáveis que definem o seu estado (Algoritmo 2: 18 até Algo- 
ritmo 2: 22).

Por final é retornada a lista de recurso onde cada célula desta lista possui uma quantidade de tarefas associadas para serem processadas.

\subsubsection{Alocação da tarefa "centralizadora"}

O algoritmo que define a alocação da tarefa "centralizadora" seleciona o recurso que possui o maior gasto com comunicação, para minimizar o efeito da comunicação na execução como um todo.

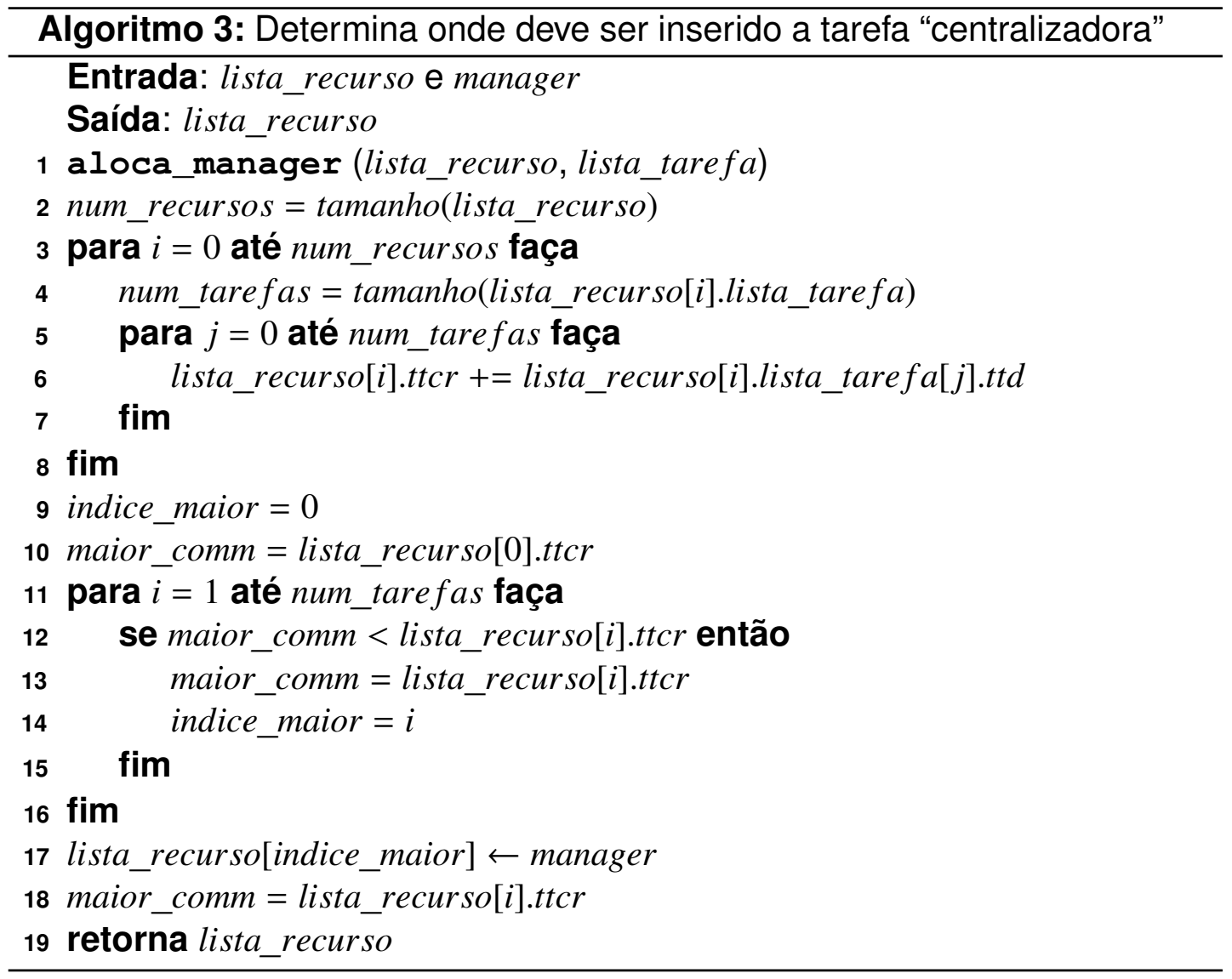

O algoritmo basicamente faz uma varredura da lista de recursos (Algoritmo 3: 3) e calcula o custo de comunicação de cada recurso e na sequência seleciona o recurso que possui maior custo com a comunicação (Algoritmo 3: 11) para atribuir a tarefa "centralizadora". 


\subsubsection{Execução}

A etapa da Execução é a etapa responsável em iniciar a execução propriamente dita, com a quantidade de recursos estabelecida e com as tarefas paralelas escalonadas de maneira balanceada.

A execução utiliza a informação de em qual recurso irá executar cada tarefa paralela, gerada na etapa de escalonamento e armazenada em arquivo.

Algumas vantagens da metodologia são apresentadas na seção a seguir.

\subsection{Vantagens}

\section{Aquisição de informações}

Alguns dos escalonamentos dinâmicos, conforme apresentado na Seção 3.1.2, possuem um problema de desempenho que é a necessidade de coleta de informação durante a execução da aplicação paralela, para permitir avaliar se a aplicação esta sendo executada de forma balanceada.

Caso o escalonamento não esteja com uma distribuição considerada balanceada, um reescalonamento das tarefas paralelas acaba sendo necessário. Estas medições influenciam a desempenho da aplicação paralela, porque a coleta de dados acaba consumindo tempo e recursos de processamento.

Na proposta apresentada, o efeito destas medições dentro da execução é minimizado, pois a medição para aferir as cargas das tarefas paralelas será apenas executada no início da execução da aplicação, na fase denominada de Aquisição (mais detalhes na Seção 4.4.1), sendo que o tempo gasto nesta fase é apenas uma pequena fração do tempo total da execução da aplicação.

Além disso, com a proposta desta tese, os resultados obtidos com esta 
Aqui sição podem ser reutilizados diversas vezes, desde que não ocorra modificação nos parâmetros de entrada que definem o que a aplicação paralela irá executar.

\section{Não Intrusivo}

A metodologia permite que toda informação necessária para escalonar as tarefas paralelas para obter o escalonamento das cargas seja obtida de maneira autônoma do código fonte da aplicação paralela.

Isso permite que o seu uso em qualquer aplicação paralela não esteja condicionada ao conhecimento dos detalhes da programação efetuada no programa paralelo original, desde que seja respeitado o modelo definido na Seção 4.1 .

Além disso, o código fonte da aplicação paralela é tratado como "caixapreta", onde a compreensão de possíveis complexidades existentes dentro da aplicação paralela não é necessária. Qualquer modificação em um código fonte, se não realizada com o devido cuidado, pode causar inconsistências no seu funcionamento. No momento que algum resultado apresentar um comportamento estranho, pode-se inferir que este comportamento pode ter sido originado das alterações realizadas no código fonte original. Nossa metodologia evita este tipo de problema.

\section{Correlação entre a aplicação e o ambiente paralelo}

A fase de Aquisição verifica o comportamento das tarefas paralelas no ambiente paralelo que a aplicação será executada. Desta forma, as informações obtidas para realizar o escalonamento das tarefas estão baseadas no mesmo ambiente que será usado para a execução.

Se a aplicação paralela for executada em outro local, o processo de Aquisição pode ser realizado novamente, permitindo desta forma um es- 
calonamento das tarefas mais adaptado ao ambiente paralelo de execução, adequando à execução paralela para diferentes tipos de hardware paralelos. 


\section{EXECUÇÃO UTILIZANDO OS MECANISMOS DA METODOLOGIA}

Neste capítulo é apresentada a aplicação da metodologia, com o uso de scripts e ferramentas, visando uma execução da aplicação automatizada, chamando e processando cada uma das suas etapas.

\subsection{Aplicação paralela com comunicação por passagem de mensagem}

O modelo de comunicação paralela e distribuída com passagem de mensagens escolhido para ser utilizado neste trabalho foi o MPI. O Message Passing Interface (Message Passage Interface Forum, 2009) é uma especificação de interface para a realização de programas de passagem de mensagem, utilizados principalmente na programação paralela.

Esta interface permite realizar um conjunto de funções que possibilita a troca de informações entre aplicações paralelas, permitindo a abstração da comunicação no processo de codificações de programas.

Como foi dito, o MPI é apenas uma especificação, e existem diferentes implementações, tais como o MPI over CHameleon (MPICH) que é desenvolvido pelo Argonne National Laboratory, o Open Message Passage Interface (OpenMPI) que é um projeto com múltiplos membros, o Intel MPI desenvolvido pela Intel e o MS-MPI que é uma implementação provida pela Micro- 
soft.

\subsection{Obtenção dos tempos}

A obtenção dos tempos é uma parte crucial para o sucesso da implementação da metodologia. O tempo de cada tarefa é responsável na definição do escalonamento da aplicação paralela.

Ao utilizar uma implementação MPI, pode-se utilizar o MPE para realizar a captura dos tempos de cada uma das operações primitivas do MPI.

O MPE fornece um conjunto de ferramentas que podem ser utilizadas desde a realização de um profiling das aplicações paralelas, quanto um registro das atividades de uma aplicação de forma automática.

\subsubsection{Profiling de aplicações paralelas utilizando o MPE}

O MPE é desenvolvido pelo Argonne National Laboratory e distribuído em conjunto com a implementação MPICH (BALAJl et al., 2011), mas pode ser utilizado em todas as implementações MPI que seguem as especificações definidas em (Message Passage Interface Forum, 2009), sendo necessário apenas realizar uma ligação com as bibliotecas de profiling do MPE (CHAN; GROPP; LUSK, 2008).

\subsubsection{Funcionamento}

O MPE utiliza como arquivo de registro das atividades realizadas dentro da aplicação paralela um arquivo no formato CLOG-2, que possui todas as informações de execução das instruções básicas do MPI (como por exemplo, o mpi_recv, mpi_send, etc). 
No artigo (ZAKI et al., 1999), é detalhado o funcionamento da produção de arquivos de log pelo MPE, sendo que algumas suposições são feitas, tais como:

- O processo de logging deve ser eficiente e não deve afetar o comportamento do programa. Desta forma, o processo de leitura e escrita deve ser postergado para após a execução do programa.

- Apenas um arquivo de log é gerado ao final da execução, ao invés de um para cada processo paralelo.

- Uma aplicação paralela executa em diferentes máquinas, e cada uma destas máquinas possui um relógio interno que não está sincronizado com as outras máquinas. Desta forma é necessária uma sincronização das marcas temporais entre os logs de cada uma das tarefas.

- Os dados armazenados devem ser autodescritivos.

O MPE utiliza o formato CLOG, que executa os seguintes procedimentos para gerar o arquivo de geração de log:

- Para obter uma marca temporal, o CLOG chama a rotina MPI_Wtime, que retorna um número em ponto flutuante de segundos passados desde um tempo no passado. Assume-se que MPI_Wtime é razoavelmente eficiente em qualquer implementação MPI, ao invés de uma forma particular qualquer que pode não ser a forma mais eficiente de se obter a marca temporal em uma dada máquina. Além de facilitar a portabilidade;

- Quando um registro de log é realizado, ele é armazenado dentro de um buffer dentro da memória. Ao acabar o espaço do buffer, um novo buffer é criado dentro da memória. Isso evita que o processo de escrita influencie a execução paralela, alterando as medidas; 
- Ao final da computação, os buffers são processados para inserir informações que são idênticas em todos os registros, tais como o id do processo. Neste instante, os tempos das marcas temporais são ajustados;

- Ao final da execução, todas as tarefas participam do processo de mesclagem dos logs para a criação de um único arquivo de log. Após o último registro de log é escrito e pós-processado, enviando todos os registros para o processo 0 , chamado de root. Para a comunicação dos registros é utilizado o $\mathrm{MPI}$.

O arquivo gerado pelo MPE é composto por uma sequência de marcas temporais, sendo possível saber quando uma tarefa paralela está executando, ou quando ela está esperando em um ponto de sincronização, ou realizando uma comunicação, entre outras informações.

\subsubsection{Utilização}

O MPE permite definir marcações dentro do código MPI, mas é possível utilizar o profiling das principais funções definidas pelo MPI. Isto é, as principais chamadas do MPI são armazenadas dentro do arquivo do log. Isso inclui MPI_send, MPI_recv, MPI_Barrier, entre outras chamadas disponíveis na interface MPI.

Para fazer uso dos registros de log, basta realizar a ligação do programa paralelo com a biblioteca do MPE.

mpicpp -mpilog -o meu_programa meu_programa.cpp

Isso irá causar a geração do profile de maneira automática na execução da aplicação. Ao executar o programa: 
Um arquivo de log com o mesmo nome do aplicativo (no exemplo seria meu_programa.clog2) é gerado ao final da execução, com todas as marcações utilizadas pelo MPI.

\subsubsection{Uso do MPE na etapa de obtenção de tempos}

$\mathrm{O}$ arquivo clog2 consiste em uma lista com todas as informações temporais de todas as chamadas básicas do MPI, conforme o exemplo apresentado na Figura 8.

Figura 8 - Saída do arquivo clog2 utilizando o comando clog2_print.

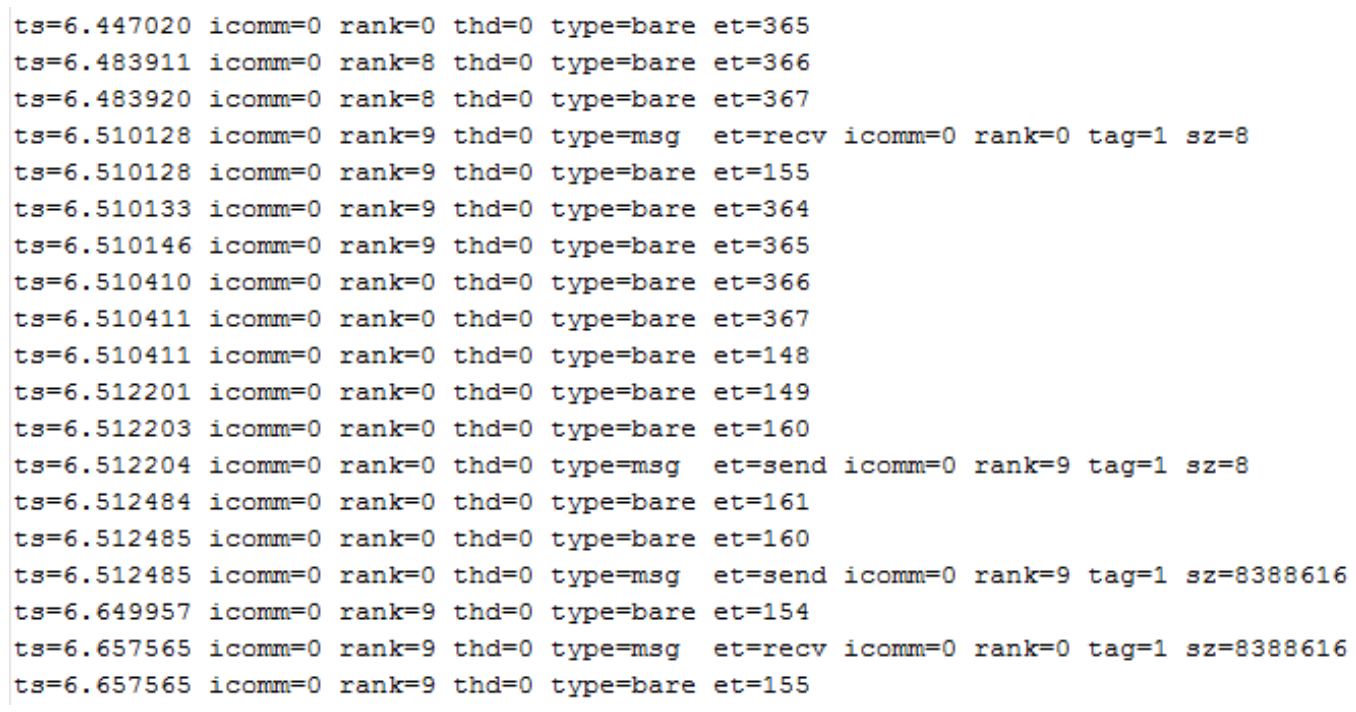

Fonte: Próprio Autor (2014)

Este arquivo possui um conjunto de identificadores, tais como, ts que representa o instante de tempo que um evento ocorreu, icomm é o canal de comunicação que a mensagem trafegou, rank representa a identificação da tarefa, thd representa a identificação da thread que a captura do tempo da aplicação foi obtida e os próximos campos dependem da tag type, que indica o tipo de informação que está sendo armazenada.

Utilizando a Figura 8, considere que a antepenúltima linha (t s=6. 649957 i comm=0 rank=9 thd=0 type=bare et=154) indica que o rank 9 está se 
preparando para enviar uma mensagem, na penúltima linha a mensagem é enviada para 0 rank 0 (t $s=6.657565$ icomm $=0$ rank $=9$ thd $=0$ type $=m s g$ et=recv icomm=0 rank=0 tag=1 sz=8388616) e por fim, na última linha apresenta quando o canal de comunicação é encerrado ( $\mathrm{s}=6.657565$ i comm=0 rank=9 thd=0 type=bare et=155). O tempo de duração deste evento é a subtração do valor de ts da última linha menos o valor de ts da antepenúltima linha, que neste caso leva ao tempo de $0.007608 \mathrm{~s}$.

\subsection{Formato de Arquivo de Saída}

Para cada uma das etapas de geração de dados, é realizado a gravação do arquivo de saída. O formato escolhido de estrutura de arquivo foi o JSON (Ecma International, 2015), que possibilita uma série de vantagens, enumeradas a seguir:

- Formato texto, permitindo a leitura do seu conteúdo sem a necessidade de tradução;

- Permite o armazenamento dos dados por meio de um par chave-valor, permitindo uma descrição autoexplicativa dos dados armazenados;

- É um formato bastante utilizado na internet, e possibilita um acesso fácil aos dados em qualquer aplicação desenvolvida nesta plataforma;

- O parseamento do arquivo é mais simplificado;

- O arquivo possui tamanho reduzido em comparação com o xml. 


\subsection{Script de Execução}

O script de execução permite executar as etapas da metodologia em uma sequencia, além de possibilitar a manipulação de elementos do sistema operacional, e outras aplicações de forma mais acessível.

Apesar de linguagens compiladas também permitirem os mesmos recursos, elas tem um problema da necessidade de obter bibliotecas externas para conseguir ter estes recursos.

O Python (Python Software Foundation., 2015) foi a linguagem utilizada para realizar a implementação da metodologia. Inicialmente a linguagem utilizada foi o Shell Script (Bash) (Free Software Foundation, Inc., 2015), mas ao considerar o aspecto de portabilidade e funções disponíveis para execução de instruções de sistema, o uso de ferramentas estatísticas, realizar manipulação de arquivos e facilidade de desenvolvimento, o Python acabou sendo preferido.

Código 5.1 - Trecho do script utilizando a metodologia ASE.

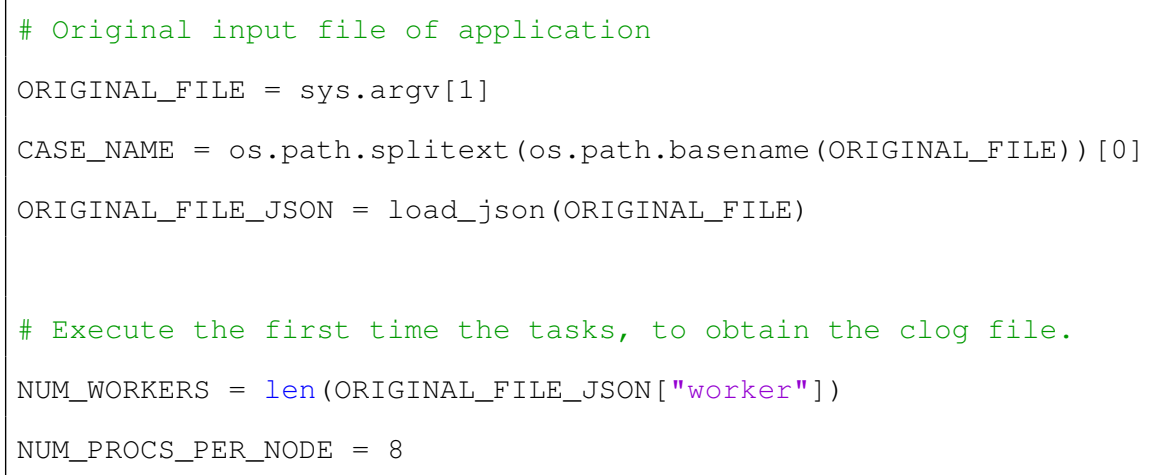

Maiores detalhes da implementação podem ser observados no Apêndice $A$, que contém os códigos fontes da implementação apresentada neste capítulo. 


\section{TESTES, RESULTADOS E ANÁLISES}

Neste capítulo são apresentados os testes realizados na metodologia.

Primeiramente é descrito o ambiente computacional em que foram executados os testes e em seguida são apresentados os testes, os seus resultados a as análises.

\subsection{Ambiente paralelo}

O ambiente paralelo utilizado para a realização dos testes foi cedido pelo Laboratório Tanque de Provas Numérico (depto. Engenharia Naval - Escola Politécnica - Universidade de São Paulo), obtido em um projeto de rede temática com a Petrobras.

O cluster do TPN é baseado no sistema operacional GNU/Linux e incorpora as técnicas mais modernas de manutenção e viabilidade para um ambiente eficiente e confiável para soluções complexas, sendo que a distribuição do Linux instalada é a CentOS. Para o gerenciamento dos seus recursos é utilizado o Simple Linux Utility for Resource Management (SLURM) (Lawrence Livermore National Laboratory, 2011).

A capacidade total do cluster é em torno de 15 TFlops, providos por 192 nós de processamento. Cada um dos nós possui oito cores Intel Nehalem de 2.8 GHz, 14 Gb de memória RAM e não possuem disco local. 
O sistema de armazenamento possui cerca de 150 TB de espaço, que utiliza Network File System (NFS). Os nós permitem que se utilizem conexões InfiniBand ou Gigabit ethernet.

\subsection{Caso de teste}

Para validação da metodologia, foi desenvolvida uma programa que conseguisse reproduzir o comportamento de aplicações paralelas, possibilitando verificar se o escalonamento das tarefas estava sendo realizado conforme o esperado.

Essa aplicação foi escrita utilizando MPI e cria uma tarefa "centralizadora" e $N$ tarefas "computadoras". Para cada uma destas tarefas é possível ajustar os seguintes parâmetros:

- Número de tarefas paralelas;

- Tamanho dos dados comunicados entre as tarefas;

- Tempo de processamento de cada uma das tarefas;

- Número de passos temporais executados;

- A ordem em que as tarefas serão executadas.

Sendo assim, foram elaborados diversos cenários para verificar o comportamento da metodologia, mostrados na próxima seção.

\subsection{Cenários}

A definição de cenário é um conjunto de tarefas com tempos prédeterminados utilizados para validação da metodologia ASE. 
Ao executar um cenário utilizando a metodologia, espera-se que com os valores dos tempos coletados pela metodologia sejam coerentes com os valores da execução da aplicação paralela, que as tarefas sejam corretamente escalonadas e por fim a aplicação seja executada de forma distribuída da forma estabelecida.

Para cada cenário elaborado foram criados os seguintes conjuntos de tarefas, apresentados na Tabela 1, onde foram variadas a quantidade de tarefas e a variabilidade dos tempos de execução das tarefas que compõem o cenário, para caracterizar a heterogeneidade dos tempos de processamento das tarefas.

\begin{tabular}{|c|c|c|c|c|c|c|c|c|}
\hline \multirow{2}{*}{ Cenário } & \multicolumn{2}{|c|}{ Tarefas tipo 1} & \multicolumn{2}{|c|}{ Tarefas tipo 2} & \multicolumn{2}{|c|}{ Tarefas tipo 3} & \multicolumn{2}{|c|}{ Tarefas tipo 4} \\
\hline & Qtde. & tempo [ms] & Qtde. & tempo [ms] & Qtde. & tempo [ms] & Qtde. & tempo [ms] \\
\hline 1 & 100 & {$[30,34]$} & - & - & - & - & - & - \\
\hline 2 & 30 & {$[30,34]$} & 15 & {$[24,26]$} & 50 & {$[10,15]$} & 5 & {$[2,5]$} \\
\hline 3 & 200 & {$[30,34]$} & - & - & - & - & - & - \\
\hline 4 & 60 & {$[30,34]$} & 30 & {$[24,26]$} & 100 & {$[10,15]$} & 10 & {$[2,5]$} \\
\hline 5 & 20 & {$[30,34]$} & - & - & - & - & - & - \\
\hline 6 & 5 & {$[30,34]$} & 4 & {$[24,26]$} & 8 & {$[10,15]$} & 4 & {$[2,5]$} \\
\hline
\end{tabular}

Tabela 1 - Lista dos conjuntos de tarefas criadas para cada cenário. Para cada tipo de tarefa é determinado uma faixa de tempo de computação da tarefa e a quantidade de tarefas criadas dentro daquele tipo.

Com estas informações, foi especificado um conjunto de testes que está apresentado nas próximas seções.

\subsection{Teste: Medição}

Na metodologia ASE, a etapa de Aquisição é responsável em obter os tempos das tarefas que compõe a aplicação paralela, e assim conseguir realizar a distribuição das mesmas.

Esta etapa é importante pois as etapas seguintes utilizam os valores obti- 
dos nesta etapa para tomar as suas decisões.

Este teste visa verificar se os tempos obtidos de cada tarefa, utilizando o MPE, estão corretos. Para isso, os tempos que foram designados para cada uma das tarefas estão especificados na Tabela 1 e desta forma, foi possível verificar se ocorre uma correlação com os valores obtidos dos tempos com os valores esperados para cada uma das tarefas.

Ao testar cada cenário, foram executadas 10 medições de tempo, para que fosse calculado um valor médio e o desvio padrão destas medidas. O valor médio permite verificar se o valor está próximo do esperado e o desvio padrão verifica se o resultado possui muita oscilação em relação ao valor médio.

No cenário 1 há 100 tarefas "computadoras" com tempos de execução dentro de um superstep entre $30 \mathrm{~ms}$ a $34 \mathrm{~ms}$, isto é, com baixa heterogeneidade.

No cenário 2 também há 100 tarefas "computadoras", com os tempos de execução dentro de um superstep na faixa de 4 ms a 34 ms. Ou seja, as tarefas possuem uma alta heterogeneidade com relação ao tempo de execução.

A Figura 9 apresenta os tempos médios das tarefas e o desvio padrão de cada tempo obtido dos Cenários 1 e 2 .

Os valores médios obtidos estão coerentes com os valores esperados apresentados na Tabela 1.

Devido ao baixo valor de variância destas medidas, pode-se concluir que os valores dos tempos obtidos das tarefas na implementação da ASE, possuem uma alta correlação com os valores esperados, comprovando a sua eficácia.

Os pares de Cenários 3-4 e 5-6 possuem características semelhantes a par de Cenários 1-2, onde a única modificação é o número de tarefas diferen- 
Figura 9 - Tempo médio e desvio padrão do processamento para cada tarefa nos Cenários 1 e 2.

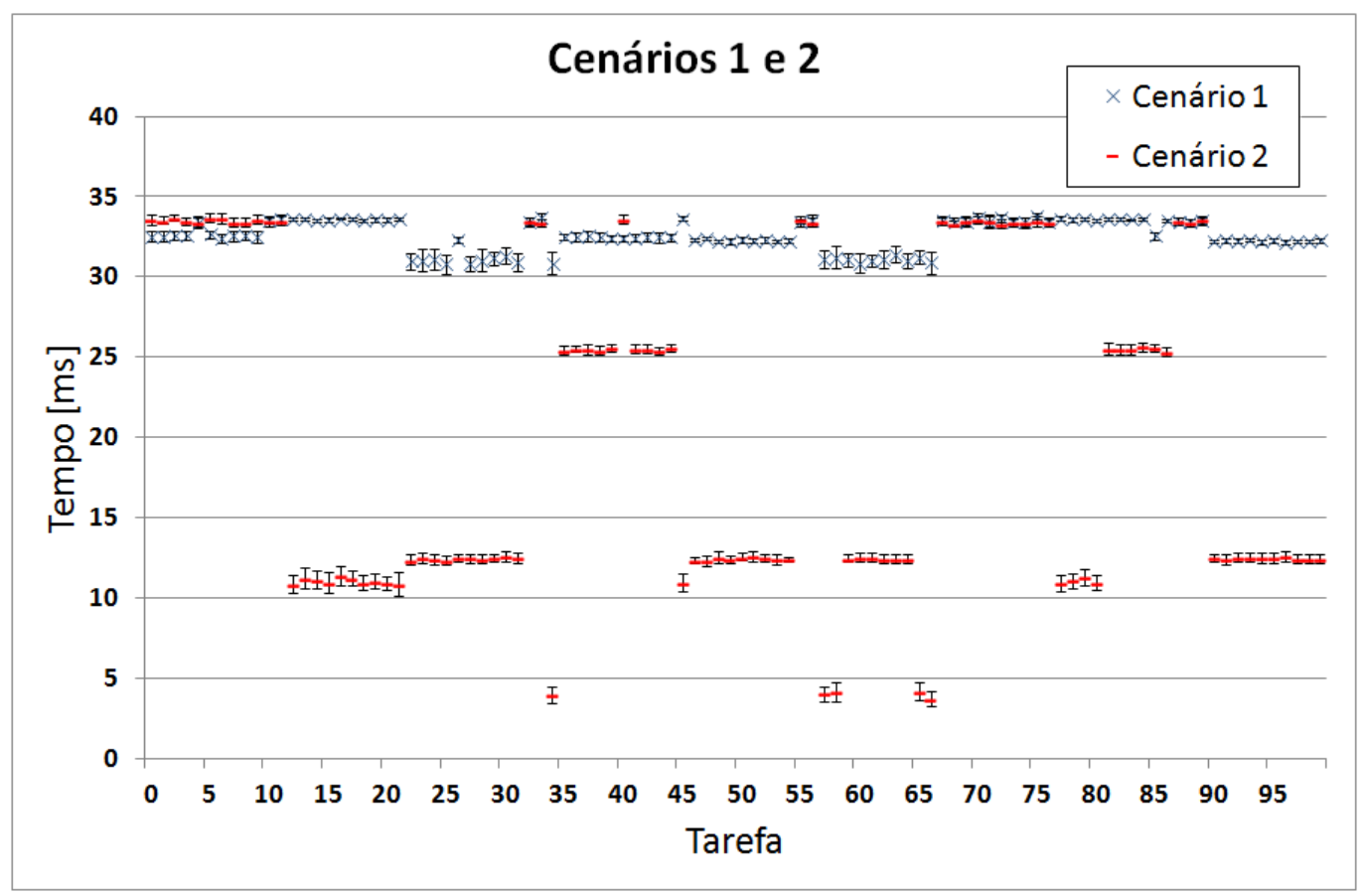

Fonte: Próprio Autor (2015).

tes.

O par de Cenários 3-4 consiste em realizar execuções com um número maior de tarefas.

O Cenário 3 foi composto por um conjunto de tarefas com baixa heterogeneidade com relação ao tempo de execução dentro de um superstep, com as tarefas com tempos entre 30 ms e 34 . ms Já no Cenário 4, as tarefas possuíam tempos de execução entre 4 ms a 34 ms dentro de um superstep.

A Figura 10 apresenta os valores médios e os desvios padrões para cada um dos cenários.

Novamente foi observado que a variância dos valores obtidos foi baixa para cada tempo de tarefas, o que permite ter uma alta confiabilidade dos valores obtidos e os valores médios também estão condizentes com os valores esperados na Tabela 1. 
Figura 10 - Tempo médio e desvio padrão do processamento para cada tarefa nos Cenários 3 e 4.

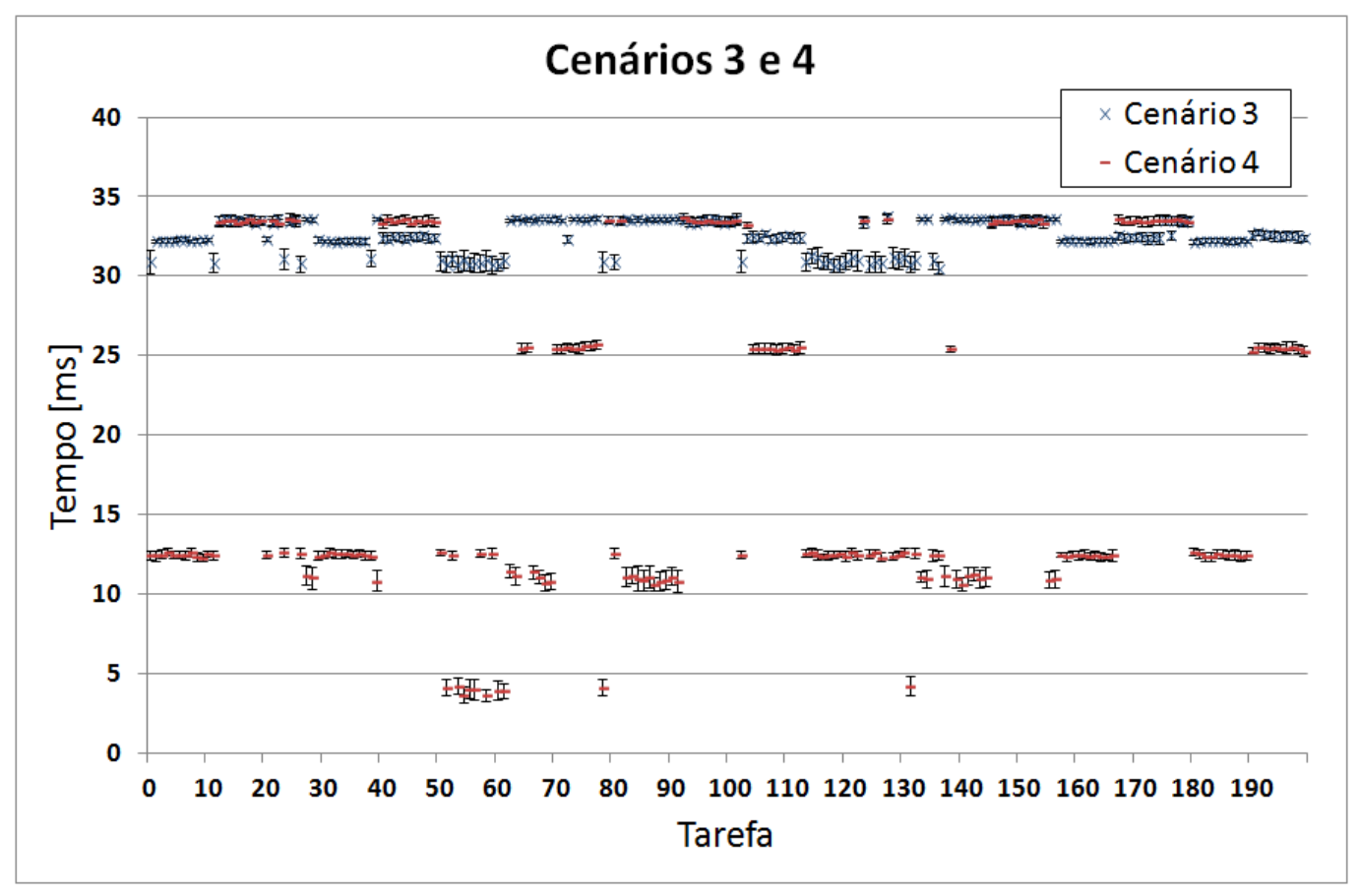

Fonte: Próprio Autor (2015).

Por fim, no par de Cenários 5-6 são compostos por um pequeno grupo de tarefas, para verificar o comportamento da metodologia com um número baixo de tarefas.

Novamente um arranjo com pouca heterogeneidade dos tempos das tarefas foi elaborado para o Cenário 5. Já o Cenário 6 foi composto por tarefas distribuídas em uma faixa maior de tempo de tarefas.

A Figura 11 apresenta os tempos médios e a variância de cada uma das tarefas dos Cenários 5 e 6.

Novamente os valores médios obtidos nos Cenários 5 e 6 foram coerentes com os valores esperados e com uma baixa variância.

A execução dos seis cenários permitiu verificar que a etapa de Aquisição não possui nenhuma restrição com o número de tarefas para a obtenção dos seus tempos de execução. 
Figura 11 - Tempo médio e desvio padrão do processamento para cada tarefa nos Cenários 5 e 6.

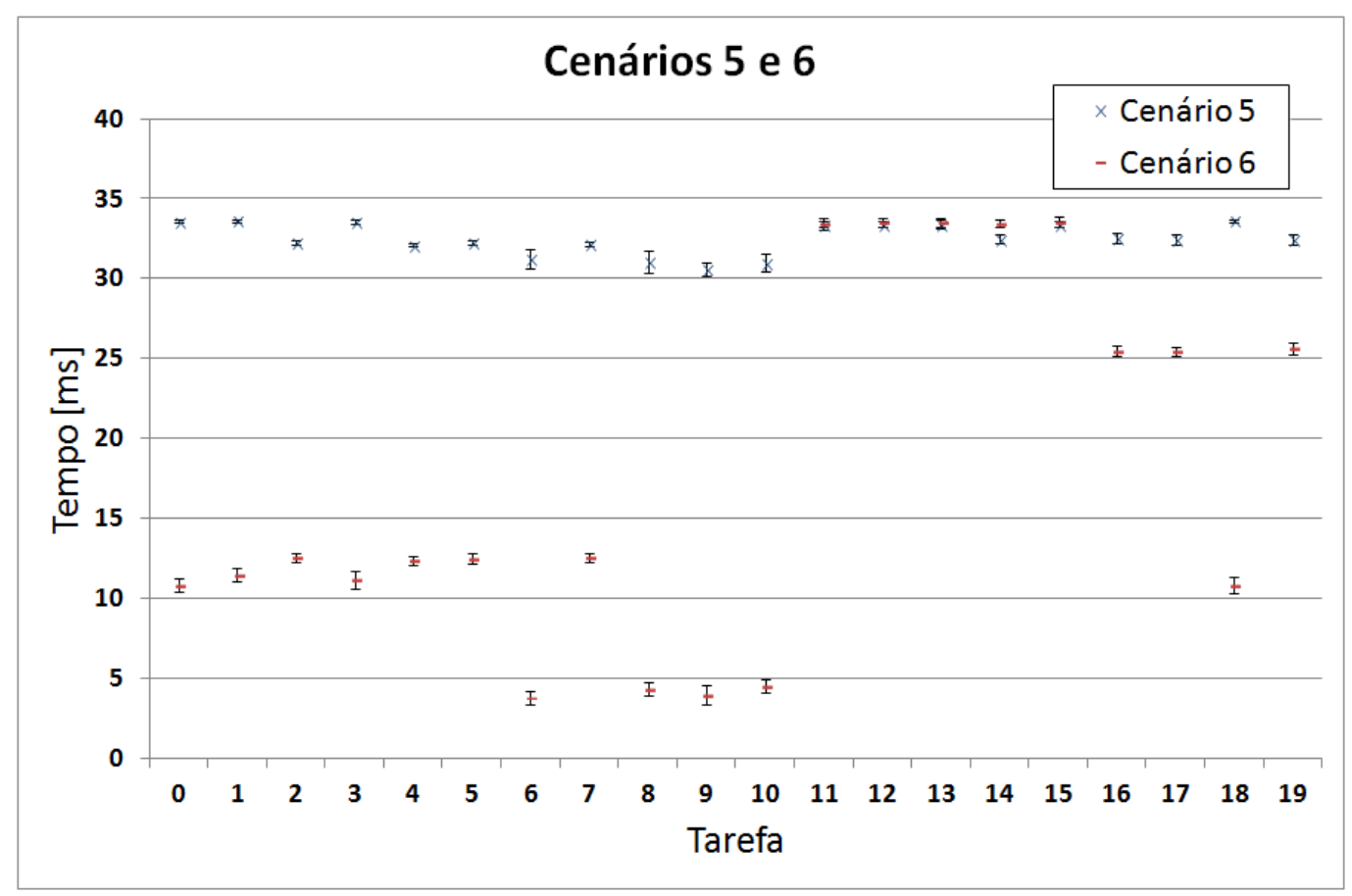

Fonte: Próprio Autor (2015).

Além disso, em todos os cenários os tempos médios possuem uma baixa variância, isto é, eles oscilam muito pouco em relação ao valor obtido.

Com base nestes resultados, foram usados como parâmetros de entrada para as outras etapas da metodologia. A seguir é apresentado o teste que mostra o processo de escalonamento das tarefas para um conjunto de recursos paralelos fixo.

\subsection{Teste: Escalonamento}

A realização dos testes de escalonamento servem para verificar se a forma de distribuir as tarefas entre os recursos computacionais disponíveis conseguiram diminuir o tempo total de execução da aplicação paralela.

O algoritmo definido na metodologia ASE para o escalonamento foi com- 
parado com escalonamento Round Robin, que é o algoritmo padrão que o MPI utiliza para realizar o escalonamento das tarefas.

Foram realizados dois tipos de testes para a etapa Escalonamento da metodologia ASE.

O primeiro deles consistiu em comparar o escalonamento da metodologia ASE com o escalonamento Round Robin para um número fixo de recursos computacionais. Isto é, verificar qual escalonamento permite a execução de um superstep no menor tempo.

O segundo teste verifica se em qual é o menor valor de recursos paralelas que se obtém o melhor valor Speedup.

Nas próximas subseções são apresentados os detalhes da montagem dos testes e as suas análises.

\subsubsection{Distribuição}

Este teste constitui em realizar o escalonamento das tarefas considerando 16 recursos paralelos, e desta forma, comparar a distribuição final das tarefas considerando o escalonamento Round Robin e o provido pela metodologia ASE.

Foram utilizados os resultados da seção anterior, obtidos na etapa de Aquisição e considerado todos os cenários.

A tarefa que leva mais tempo para ser processada dentro de um superstep é a que determina o tempo de execução da aplicação. Até a sua finalização, as outras tarefas ficam no estado de aguardando e não realizam computação efetiva. Desta forma, pode-se dizer que está ocorrendo desperdício de recursos. 
No primeiro cenário, o escalonamento das tarefas foi realizado e os resultados da distribuição e o tempo da tarefa mais longa são apresentados na Figura 12.

Figura 12 - Escalonamento das tarefas do Cenário 1 para um conjunto de 16 recursos paralelos.

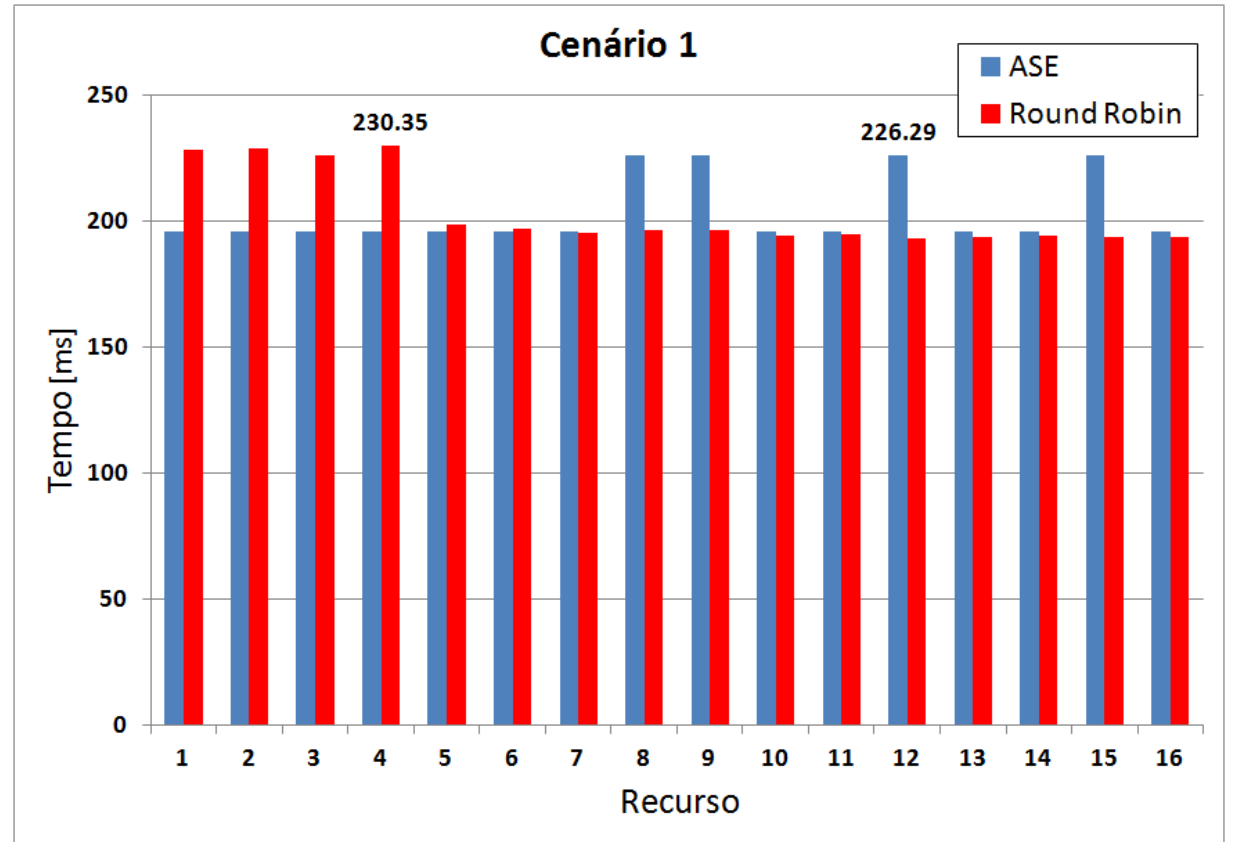

Fonte: Próprio Autor (2015).

Com este resultado obtido, conclui-se que o escalonamento utilizando o algoritmo da metodologia ASE é em torno de $2 \%$ mais rápido que o algoritmo Round Robin.

Além disso, consegue-se observar que a distribuição das tarefas para 16 recursos paralelos não ficou balanceada, pois alguns recursos ficaram mais sobrecarregados em relação com outros.

Isso ocorre devido à baixa heterogeneidade das tarefas que compõem o cenário 1 .

Quando se tem baixa heterogeneidade das tarefas paralelas, apenas quando o número de tarefas tiver um valor múltiplo do número de recursos, a distribuição das tarefas ficará balanceada. 
Na Figura 13 é apresentada uma distribuição balanceada, considerando 20 recursos paralelos. Lembrando que o Cenário 1 possui 100 tarefas, temos que o número de tarefas é múltiplo do número de recursos. Desta forma temse uma distribuição de cargas balanceada.

Figura 13 - Escalonamento das tarefas do Cenário 1 para um conjunto de 20 recursos paralelos.

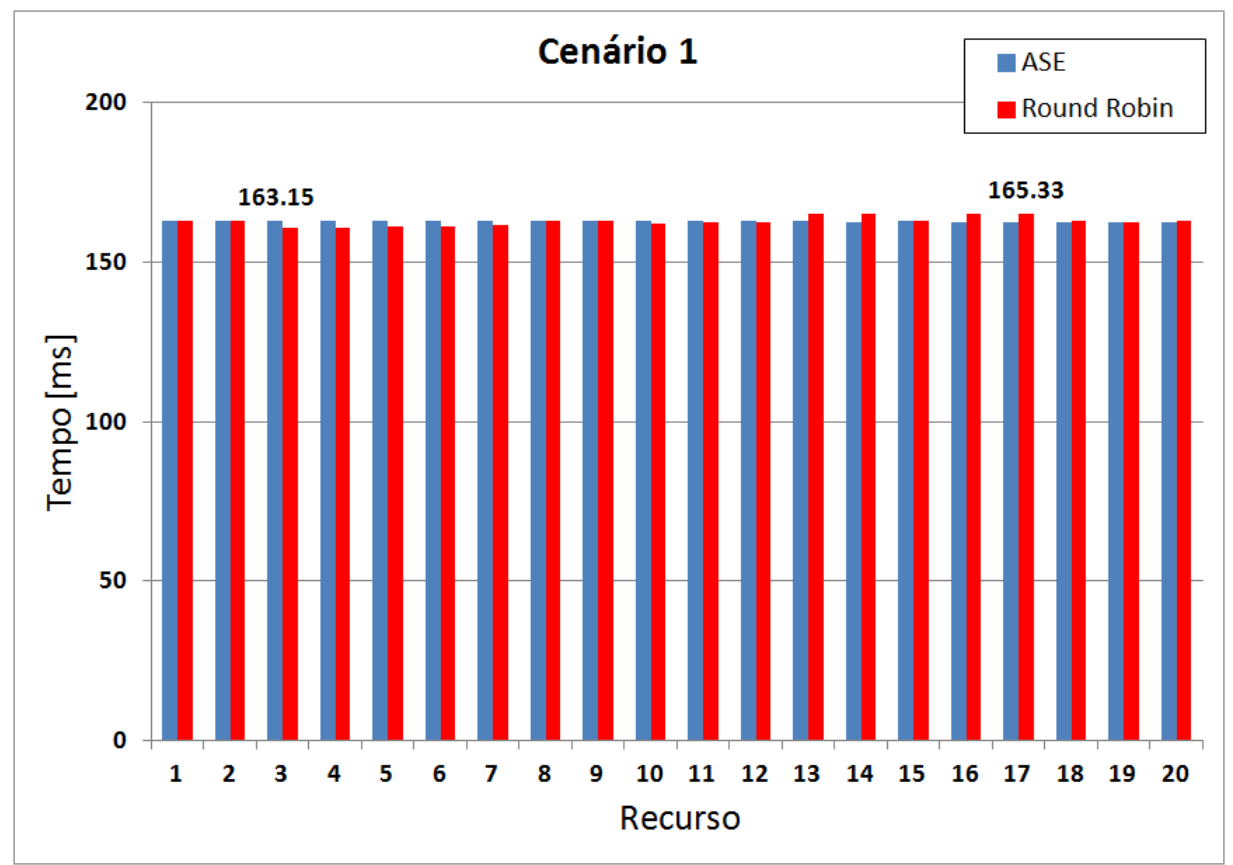

Fonte: Próprio Autor (2015).

Mas mesmo neste caso, o Round Robin não conseguiu obter uma distribuição balanceada das tarefas, ocorrendo sobrecarga em alguns recursos. Fenômeno que não ocorre no balanceamento utilizado na metodologia ASE.

Já no Cenário 2, o balanceamento das tarefas já é obtido com 16 recursos. Isso ocorre devido à heterogeneidade dos tempos das tarefas que constituem este cenário, conforme apresentado na Figura 14.

E neste cenário o escalonamento das tarefas proposto pela metodologia também consegue obter um balanceamento melhor em relação ao Round Robin. 
Figura 14 - Escalonamento das tarefas do Cenário 2 para um conjunto de 16 recursos paralelos.

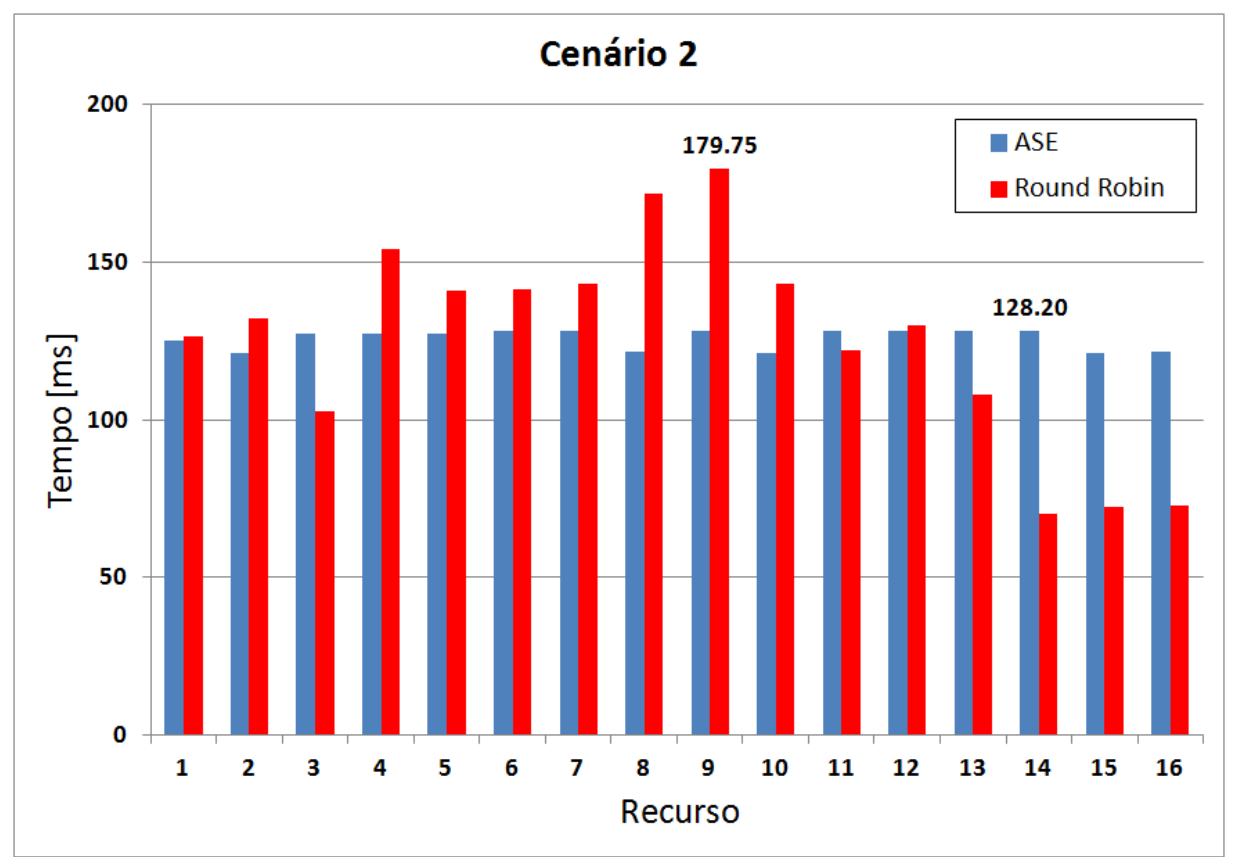

Fonte: Próprio Autor (2015).

Nos Cenários 3 e 4, foram observados comportamentos similares aos dos Cenários 1 e 2 , respectivamente.

As Figuras 15 e 16 apresentam as distribuições para 16 recursos.

Já nos Cenários 5 e 6, o conjunto de tarefas que estes cenários possuem (20 tarefas) é bem próximo da quantidade de recursos disponibilizados, consequentemente o escalonamento não causa um balanceamento das cargas paralelas, devido a pouca quantidade de tarefas para serem distribuídas pelos recursos disponibilizados.

Observa-se este padrão nas Figuras 17 e 18.

Comprova-se que em todos os casos, a execução utilizando a distribuição proposta pela metodologia ASE conseguiu uma distribuição das tarefas paralelas melhor em comparação com o escalonamento utilizando o Round Robin. 
Figura 15 - Escalonamento das tarefas do Cenário 3 para um conjunto de 16 recursos paralelos.

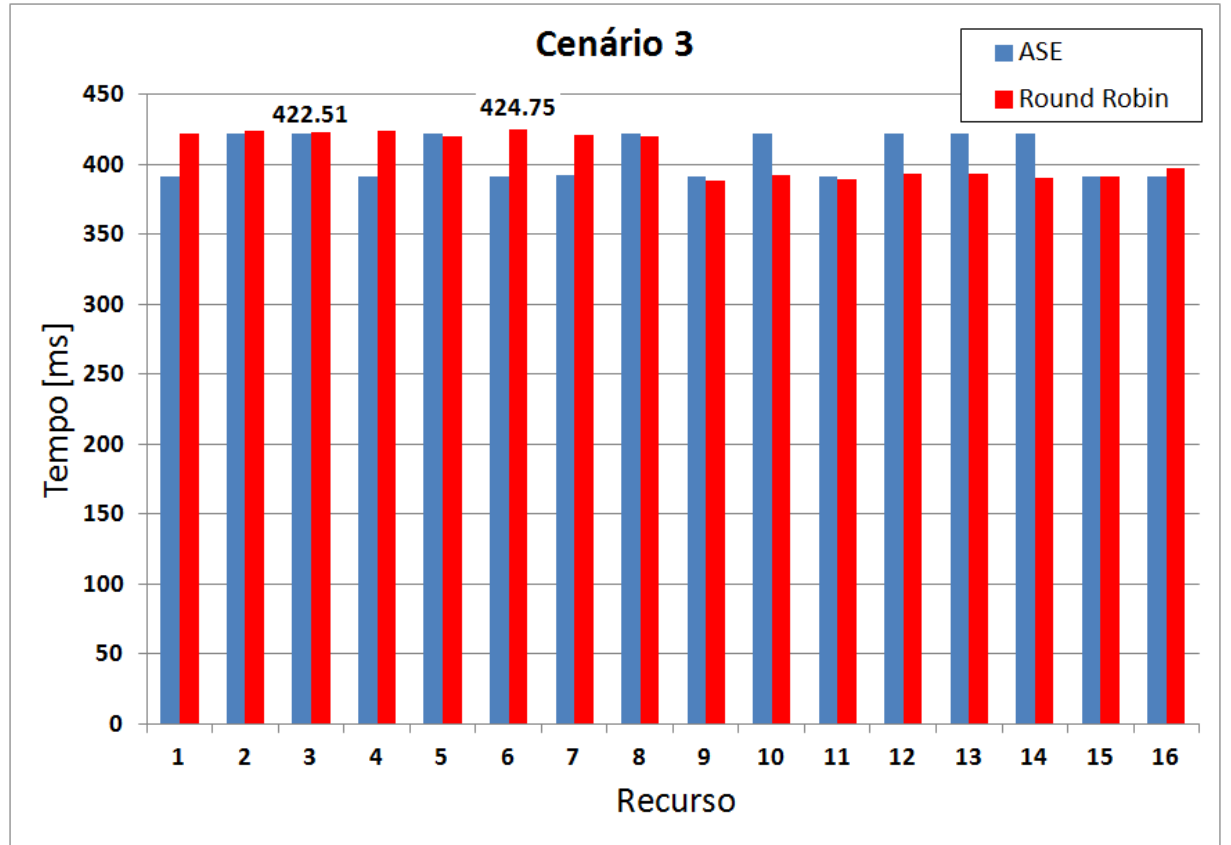

Fonte: Próprio Autor (2015).

Figura 16 - Escalonamento das tarefas do Cenário 4 para um conjunto de 16 recursos paralelos.

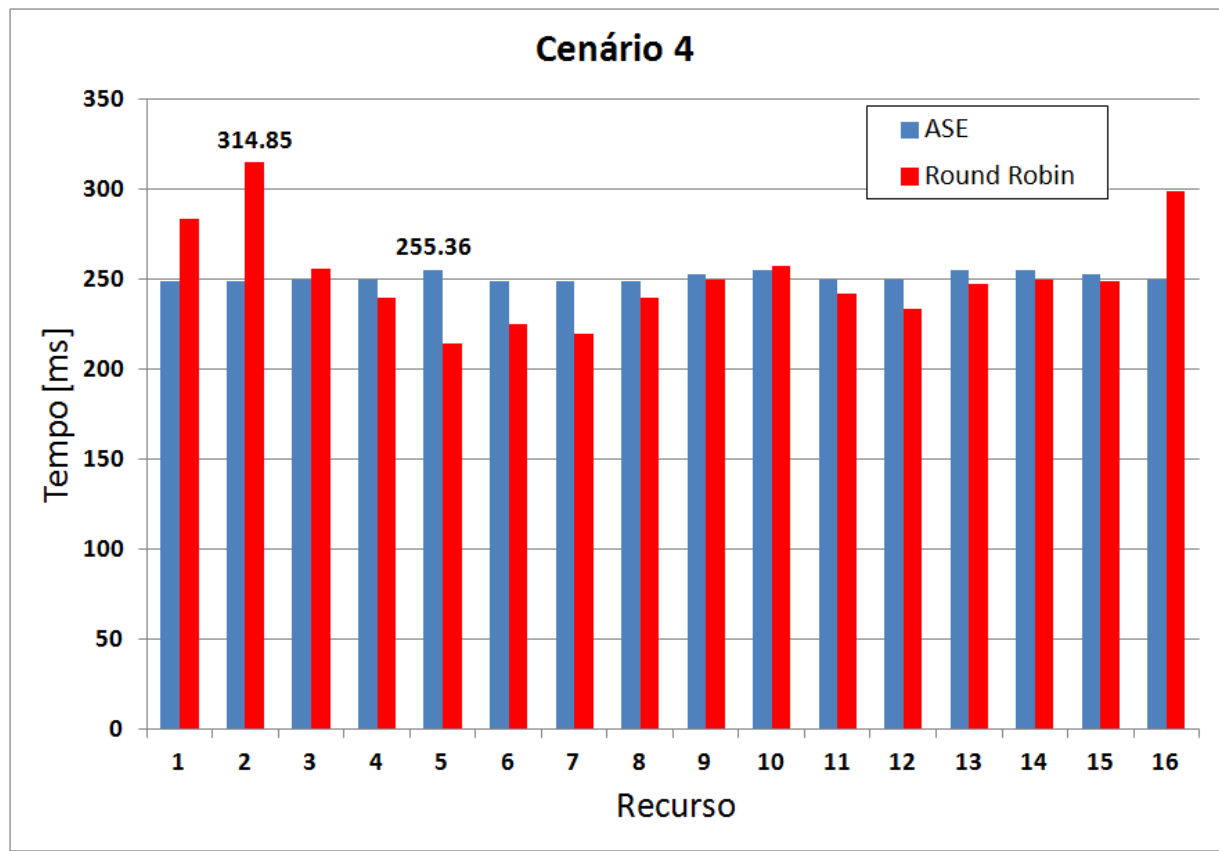

Fonte: Próprio Autor (2015). 
Figura 17 - Escalonamento das tarefas do Cenário 5 para um conjunto de 16 recursos paralelos.

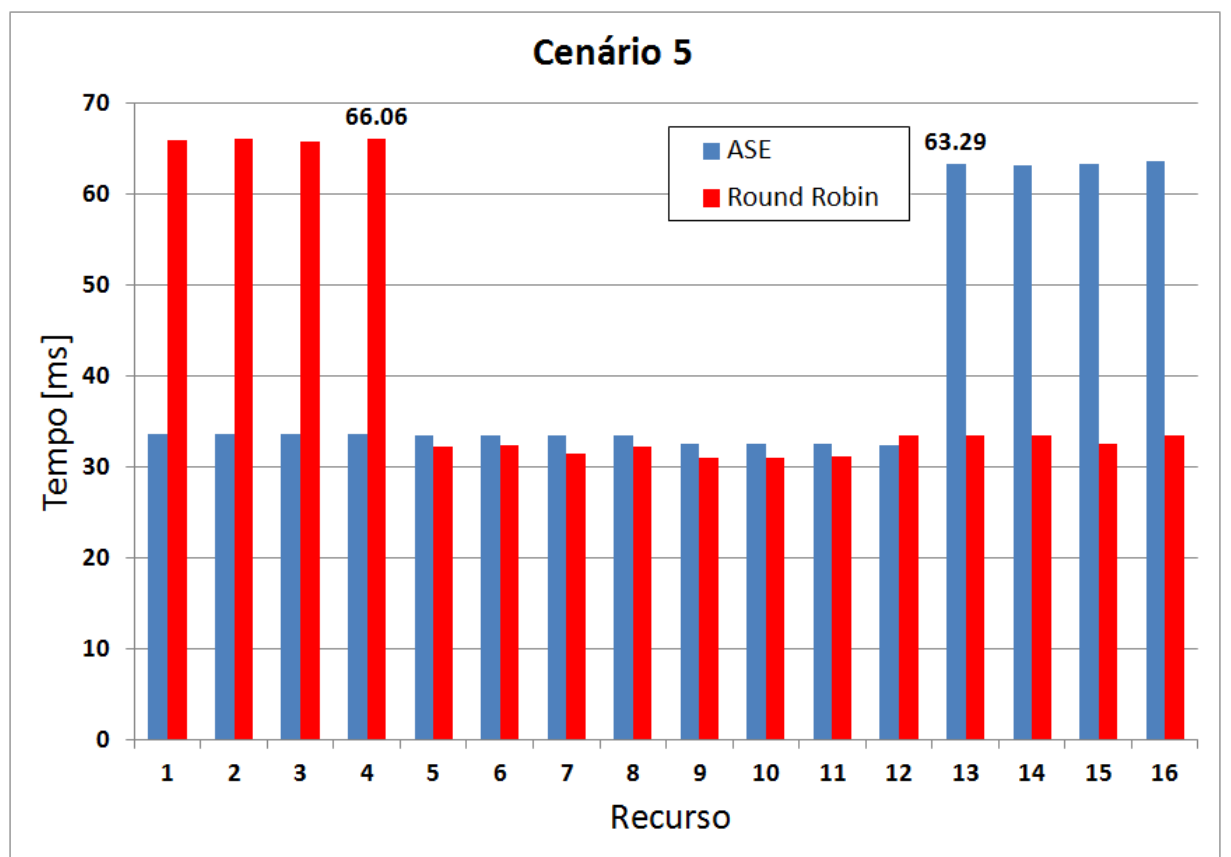

Fonte: Próprio Autor (2015).

Figura 18 - Escalonamento das tarefas do Cenário 6 para um conjunto de 16 recursos paralelos.

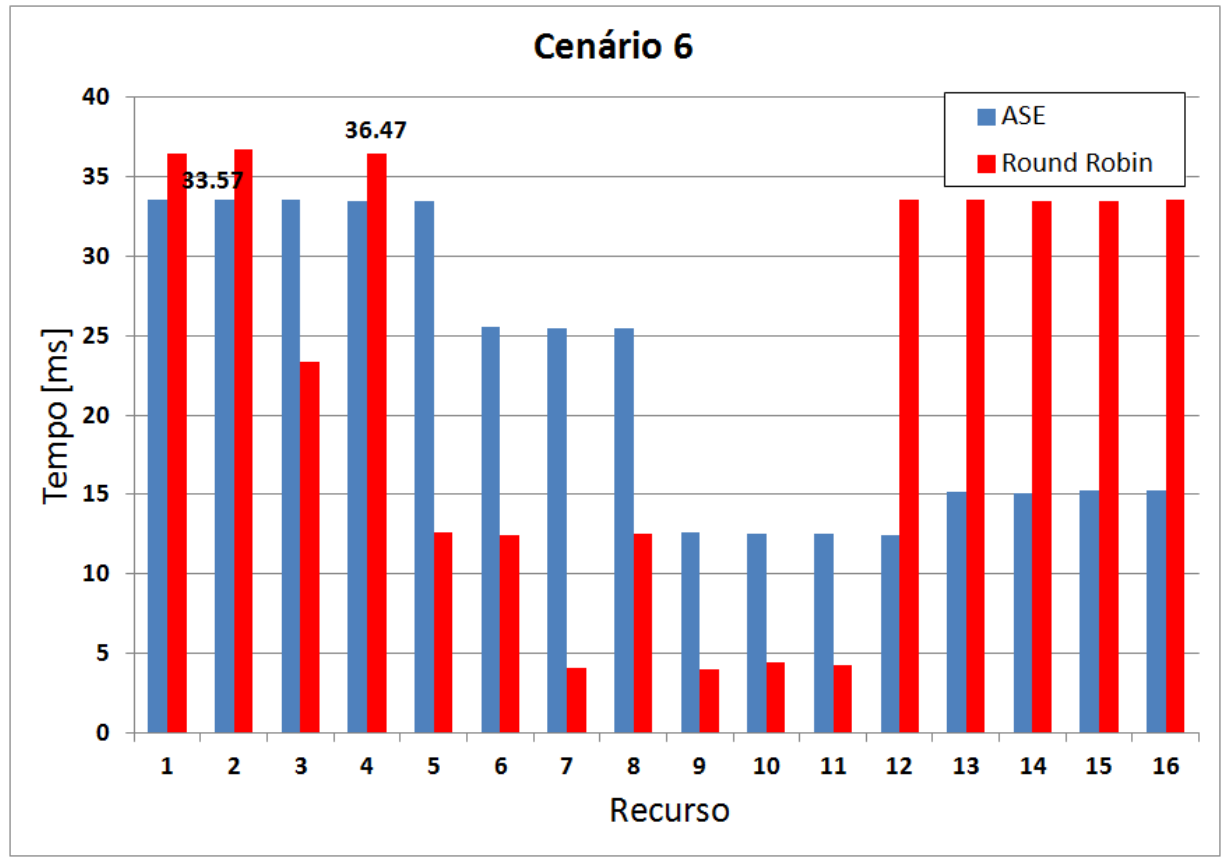

Fonte: Próprio Autor (2015). 
Na seção a seguir foi analisada o ponto de saturação dos recursos paralelos. Isto é, encontrar o valor mínimo de recursos de forma que o Speedup seja o máximo, para um dado conjunto de tarefas.

\subsubsection{Saturação}

Neste teste foi verificado em qual quantidade de recursos que ocorre a saturação. Defini-se saturação o instante em que se adicionam recursos paralelos e não se obtém ganhos no tempo de execução da aplicação. Isto é, a partir de que número de recursos paralelos que Speedup se mantém constante. Esta análise foi realizada em todos os cenários anteriores e são apresentadas a seguir.

\subsubsection{Análise pelo Speedup}

Nesta primeira etapa de análise da saturação foram utilizados os gráficos de Speedup para verificar o comportamento dos cenários.

Vale ressaltar, que o Speedup é definido pela Equação 2.1, com algumas modificações. Consideramos o tempo sequencial como o tempo gasto pela execução de todas as tarefas paralelas em apenas um único recurso.

Ao considerar a execução sequencial desta forma, tenta-se minimizar a influência do custo da comunicação na execução, pois todas as execuções irão possuir um gasto com a comunicação.

Nos cenários que possuem 100 tarefas, a análise do Speedup dos recursos, baseados no gasto com processamento e no custo da comunicação estão apresentados nas Figuras 19 e 20.

No caso do Cenário 1, os tempos das tarefas são próximos uns dos outros e isso acaba prejudicando o processo de escalonamento das tarefas. 
Figura 19 - Speedup dos recursos considerando o cenário 1 utilizando o escalonamento Round Robin e ASE.

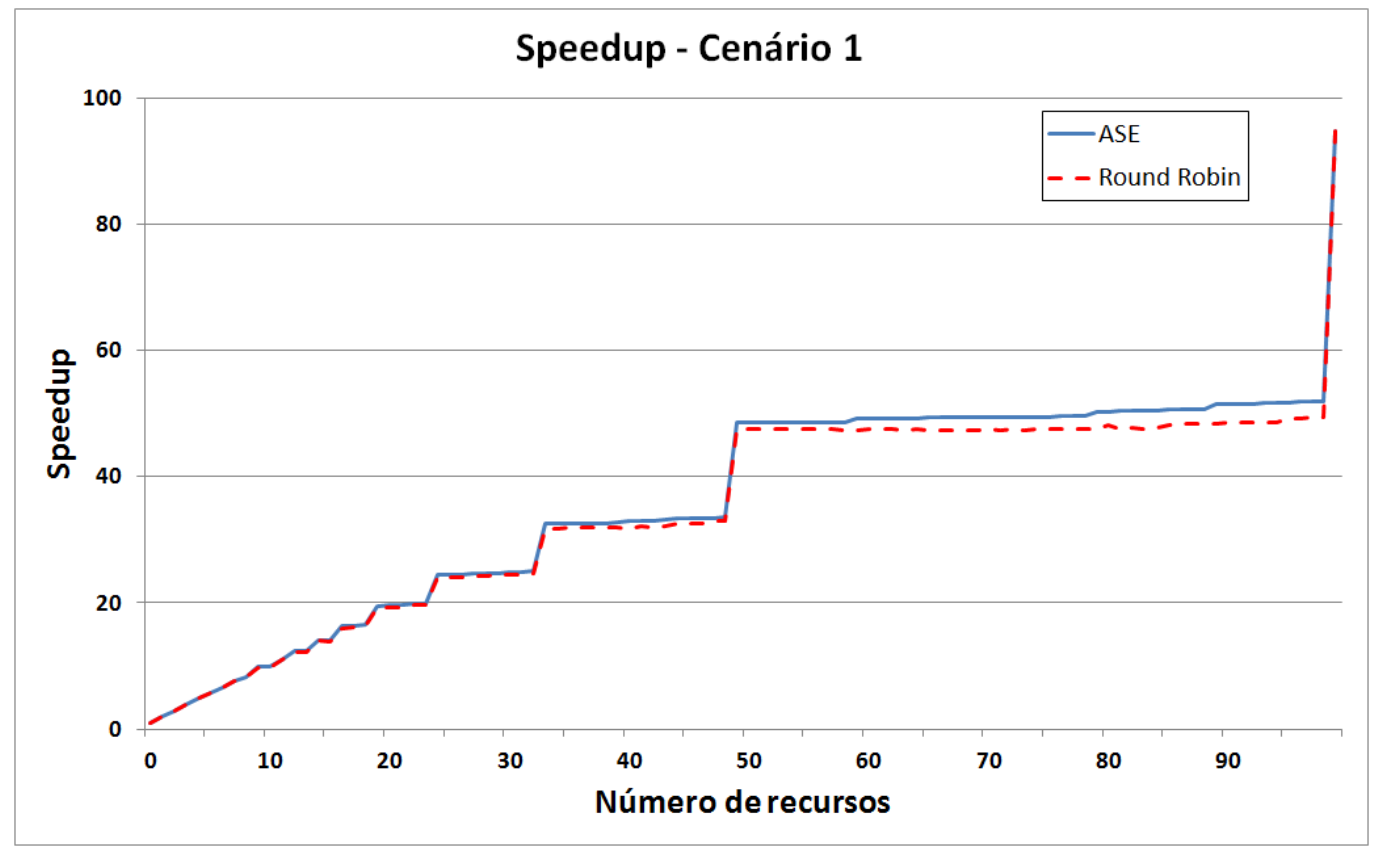

Fonte: Próprio Autor (2015).

Figura 20 - Speedup dos recursos considerando o cenário 2 utilizando o escalonamento Round Robin e ASE.

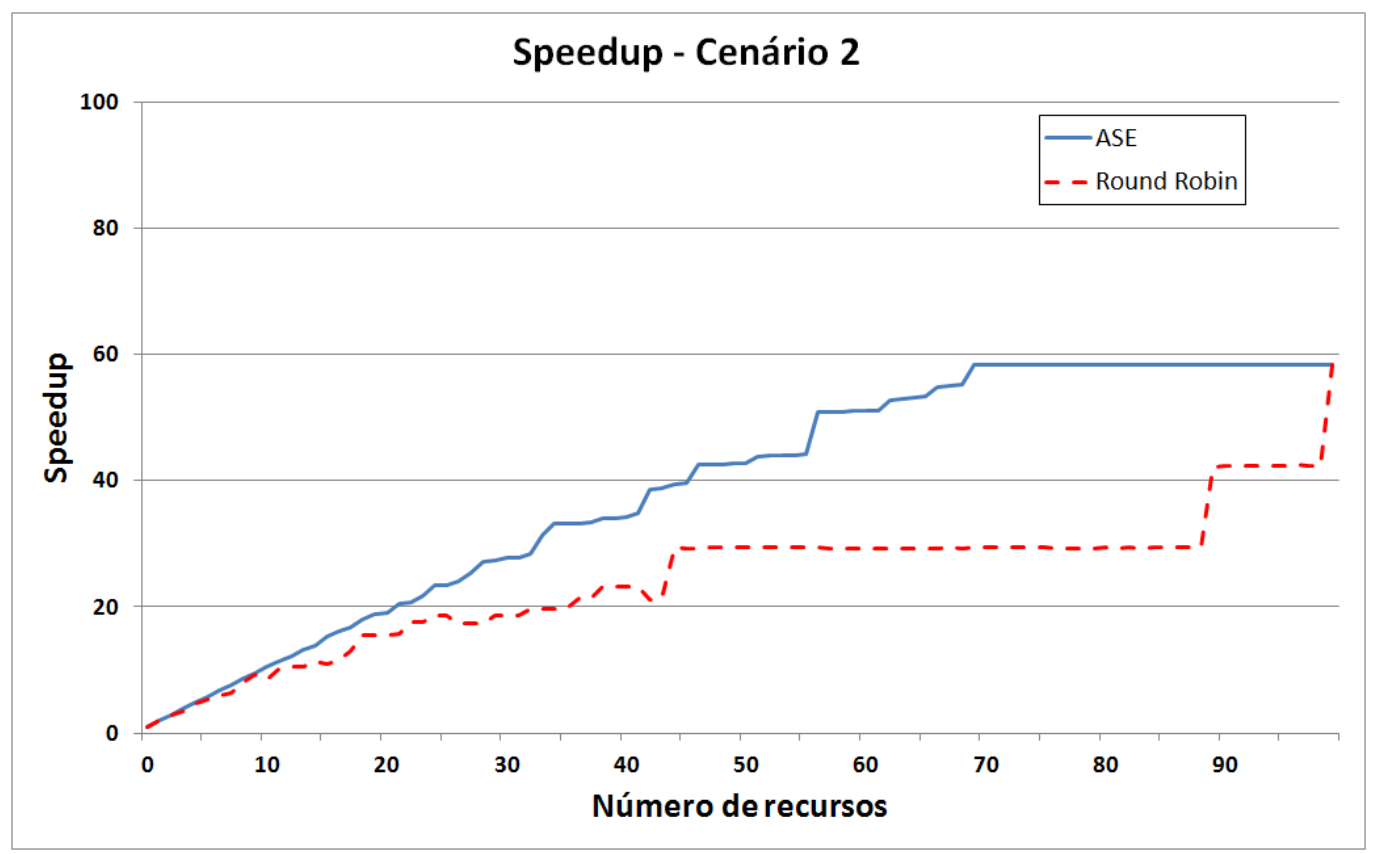

Fonte: Próprio Autor (2015). 
Percebe-se no gráfico que este comportamento é devido à alta homogeneidade dos tempos de processamento das tarefas.

Os aumentos abruptos no valor do Speedup ocorrem quando a quantidade de tarefas se torna múltiplo da quantidade de recursos disponibilizados.

No caso do Cenário 2, as tarefas conseguem ser mais bem escalonadas devido à alta heterogeneidade da sua composição. Isto acaba aumentando as possibilidades de arranjos de tarefas sem prejudicar o Speedup. Nota-se que a partir de cerca de 70 recursos, qualquer acréscimo de recurso não promove mais um ganho de desempenho.

Tem-se que, com a execução de 70 recursos, o Speedup é próximo a 60, aplicando-se o algoritmo de escalonamento apresentado. Este Speedup é obtido com cerca de 100 recursos quando aplicado o escalonamento Round Robin.

Em ambos os cenários, comprova-se que para uma quantidade de recurso $r$, o Speedup maior é obtido no escalonamento ASE em comparação com o escalonamento Round Robin.

Um comportamento análogo é observado nas Figuras 21 e 22, onde os comportamentos são similares aos dos cenários 1 e 2, respectivamente.

A saturação observada nos cenários 5 e 6 mostram os mesmos padrões observados anteriormente, mas com uma curva de gráfico um pouco diferente. As Figuras 23 e 24 apresentam as curvas de Speedup obtidas no escalonamento.

Na próxima seção, a saturação é analisada utilizando os gráficos de eficiência de cada um dos cenários. 
Figura 21 - Speedup dos recursos considerando o cenário 3 utilizando o escalonamento Round Robin e ASE.

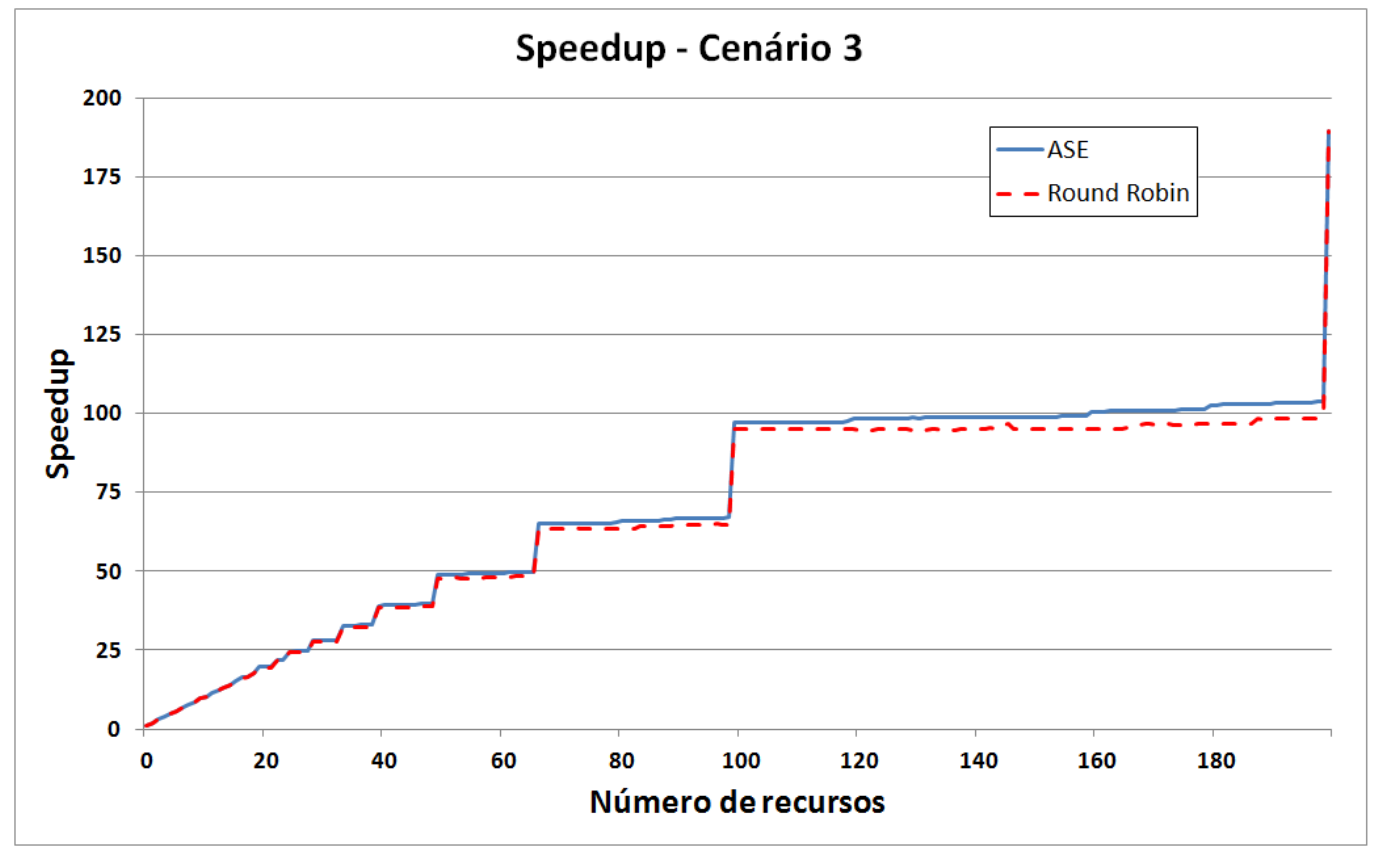

Fonte: Próprio Autor (2015).

Figura 22 - Speedup dos recursos considerando o cenário 4 utilizando o escalonamento Round Robin e ASE.

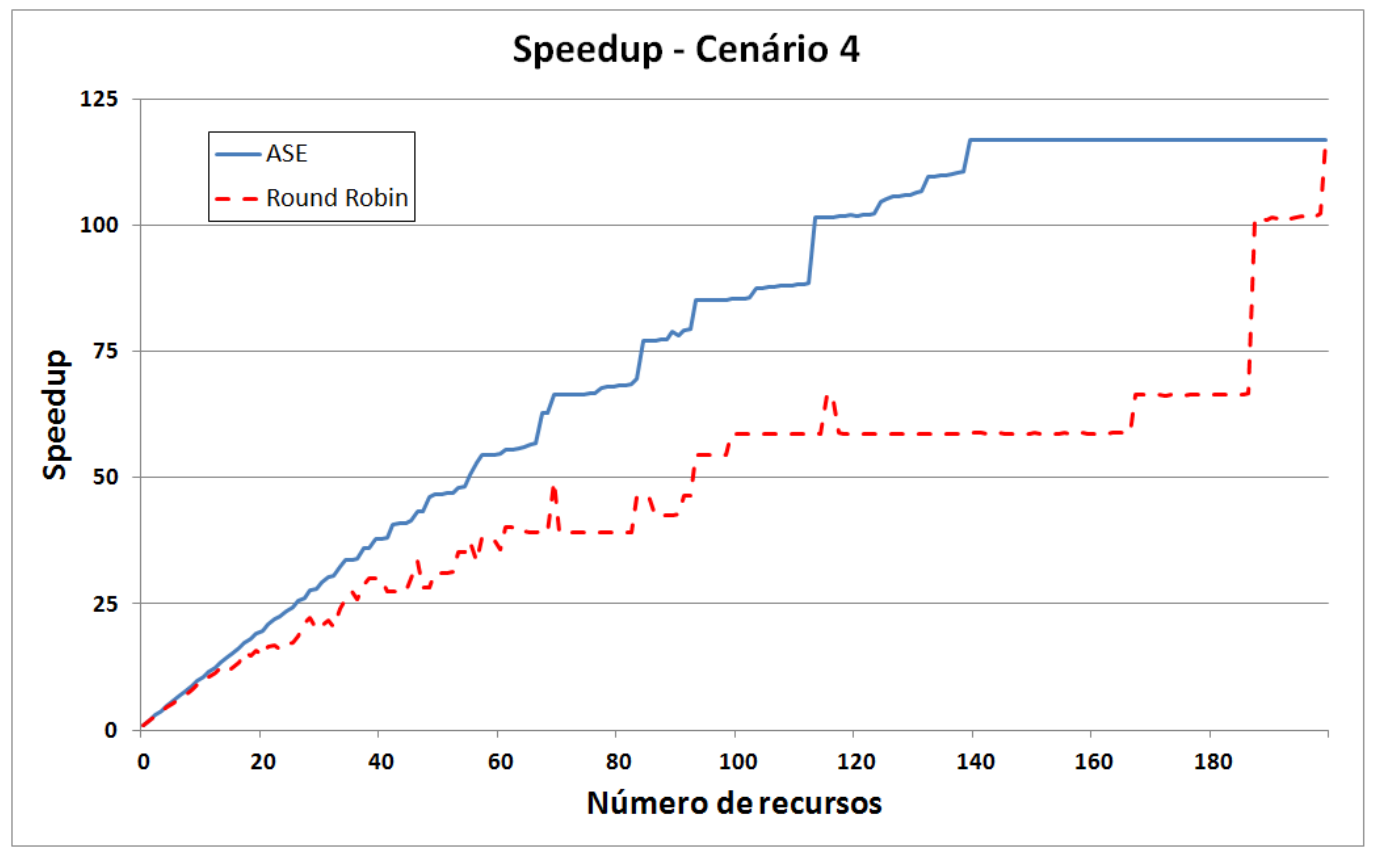

Fonte: Próprio Autor (2015). 
Figura 23 - Speedup dos recursos considerando o cenário 5 utilizando o escalonamento Round Robin e ASE.

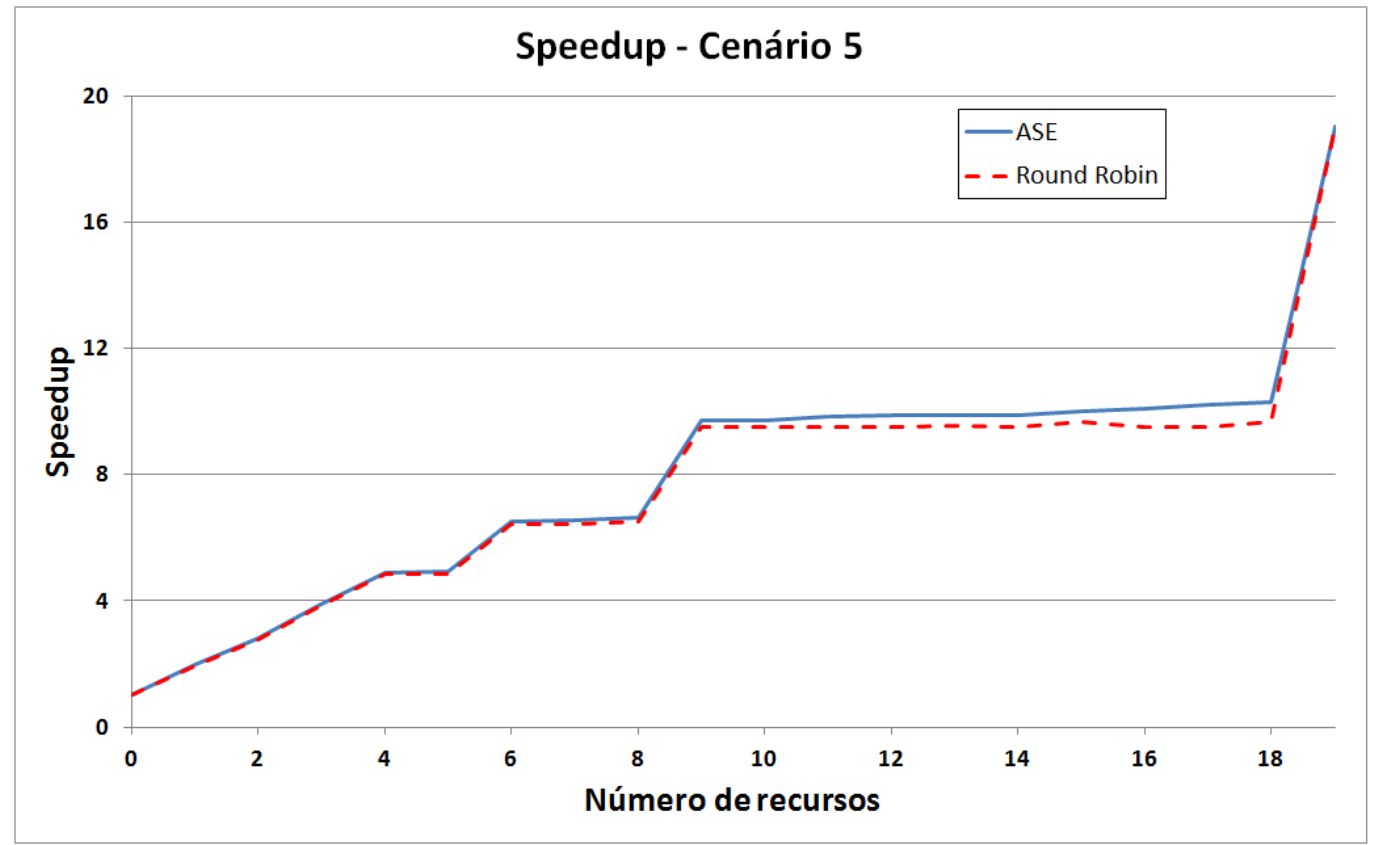

Fonte: Próprio Autor (2015).

Figura 24 - Speedup dos recursos considerando o cenário 6 utilizando o escalonamento Round Robin e ASE.

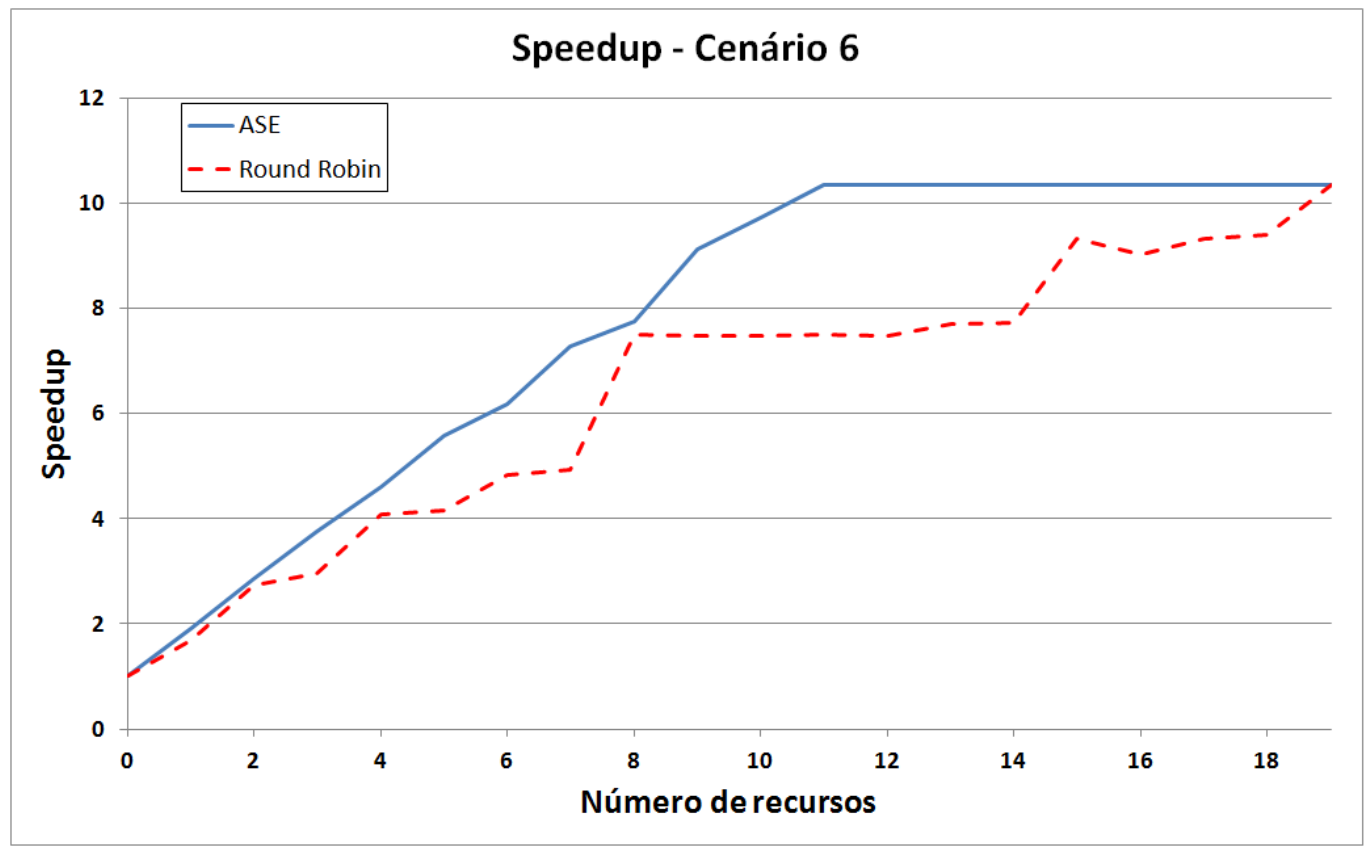

Fonte: Próprio Autor (2015). 


\subsubsection{Análise pela Eficiência}

Outra forma de verificar a saturação durante a execução é utilizando a representação gráfica da eficiência, que indica o aproveitamento dos recursos alocados durante a execução. A equação da eficiência foi apresentada na Seção 2.1.2.

Figura 25 - Eficiência dos recursos considerando o cenário 1 utilizando o escalonamento Round Robin e ASE.

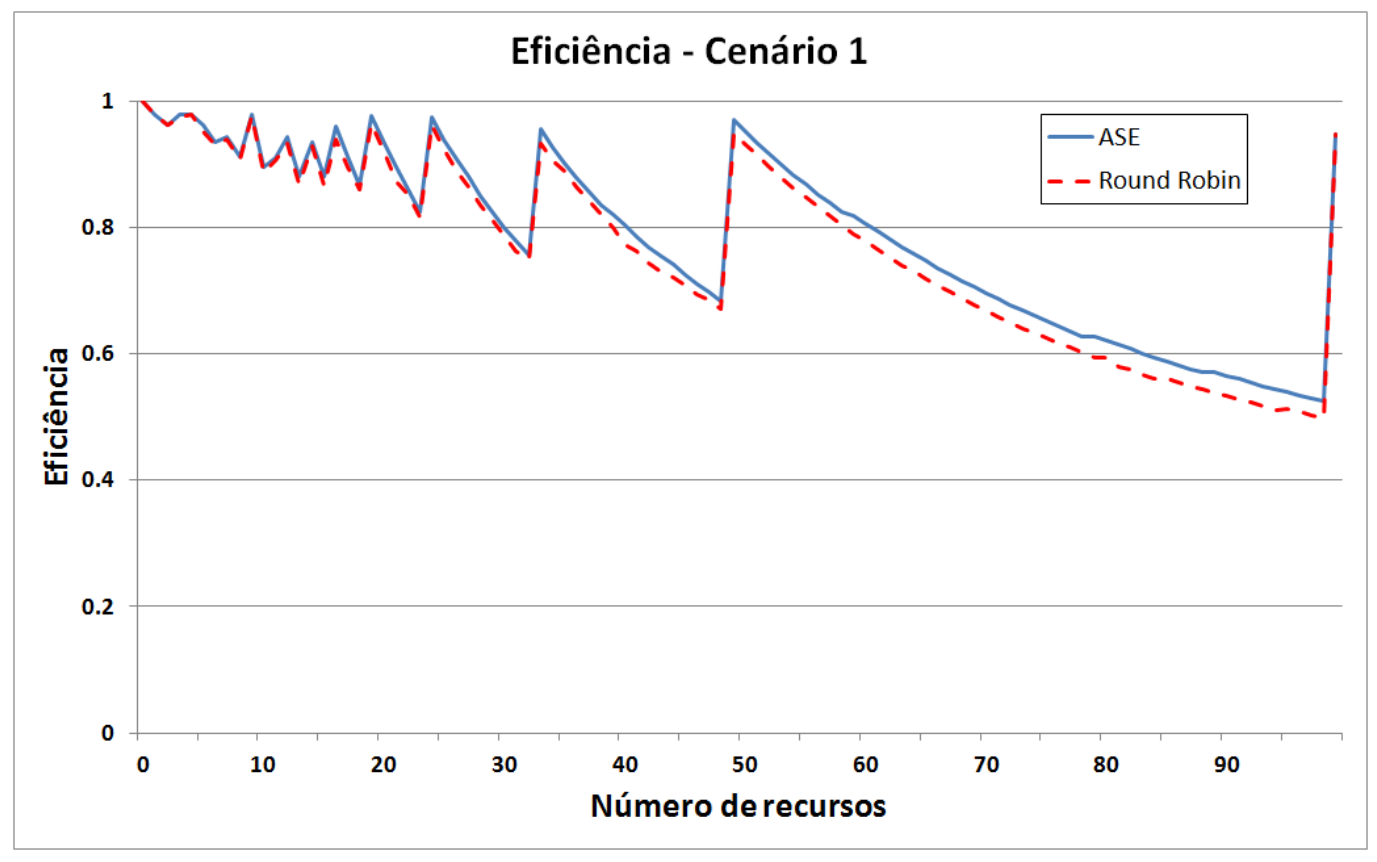

Fonte: Próprio Autor (2015).

As Figuras 25, 26 e 27 apresentam comportamentos parecidos para a eficiência. Todos os gráficos apresentam o padrão "dente de serra".

Nestes gráficos pode-se observar que a curva da eficiência obtida pela metodologia desta tese tem apenas uma ligeira vantagem em relação à curva da eficiência baseada no escalonamento Round Robin.

A explicação para este comportamento é que apesar de as tarefas possuírem baixa heterogeneidade, elas possuem pequenas diferenças nos tempos de processamento, que acaba favorecendo a distribuição das tarefas baseada 
Figura 26 - Eficiência dos recursos considerando o cenário 3 utilizando o escalonamento Round Robin e ASE.

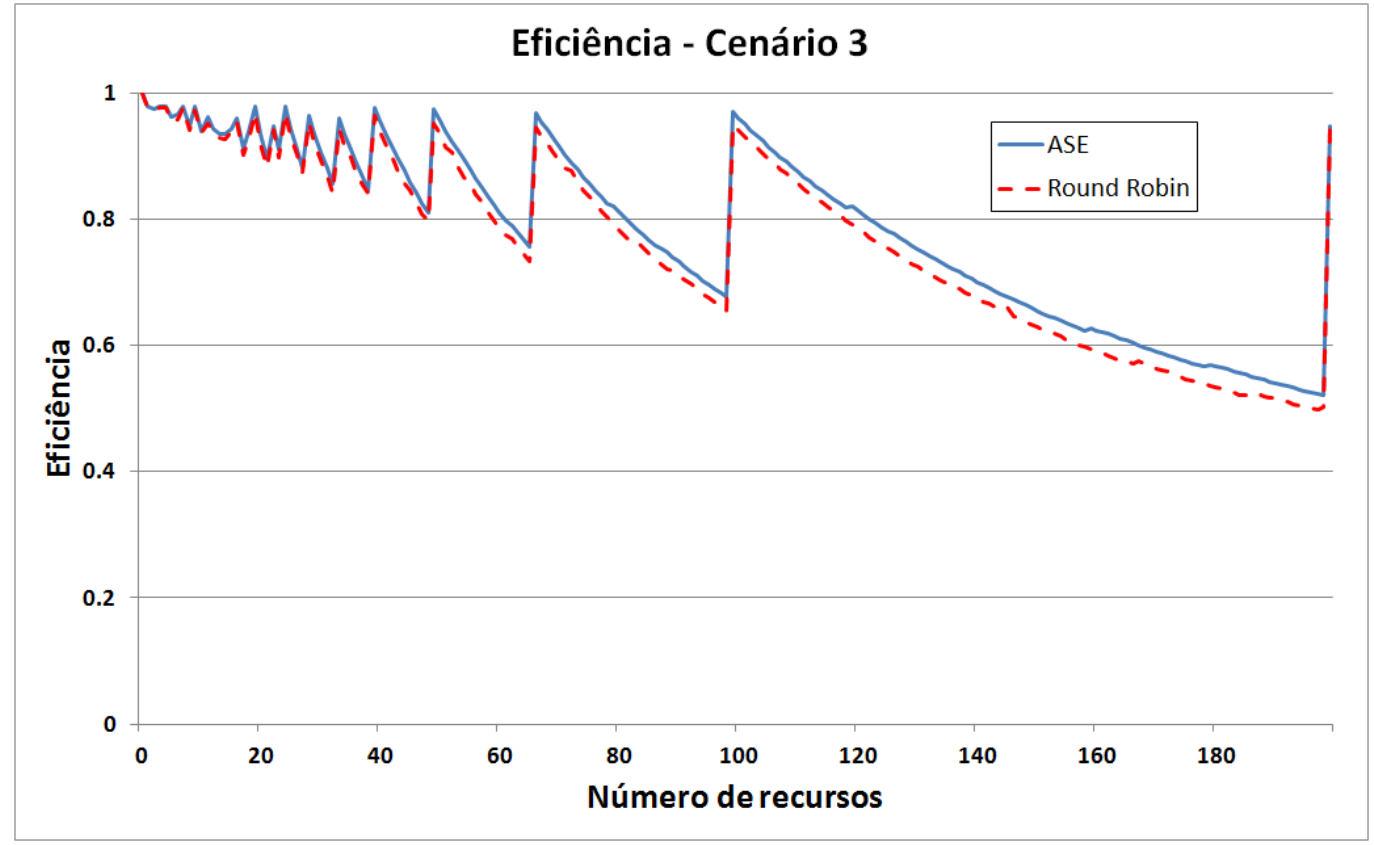

Fonte: Próprio Autor (2015).

Figura 27 - Eficiência dos recursos considerando o cenário 5 utilizando o escalonamento Round Robin e ASE.

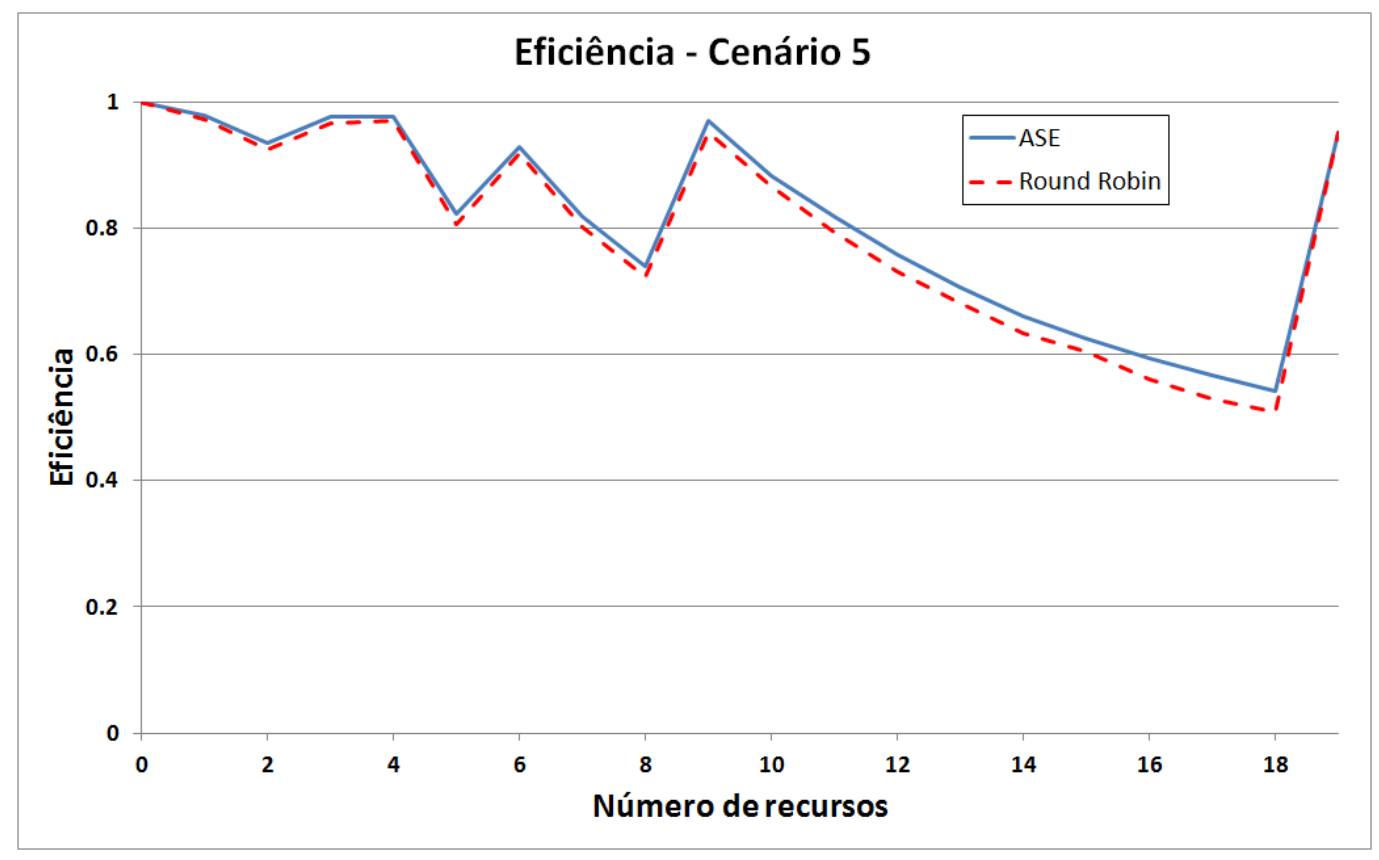

Fonte: Próprio Autor (2015). 
na metodologia ASE.

Ou seja, enquanto a o escalonamento Round Robin faz a distribuição apenas considerando o número da tarefa, a metodologia ASE permite realizar a distribuição considerando o tempo de cada tarefa.

Além disso, pode-se observar que os saltos de Speedup observados nas Figuras 19, 21 e 23 possuem relação com os picos observados nestes gráficos. E justamente nestes pontos, que se tem um aumento abrupto de Speedup, é que se tem um pico no gráfico que representa a eficiência.

Figura 28 - Eficiência dos recursos considerando o cenário 2 utilizando o escalonamento Round Robin e ASE.

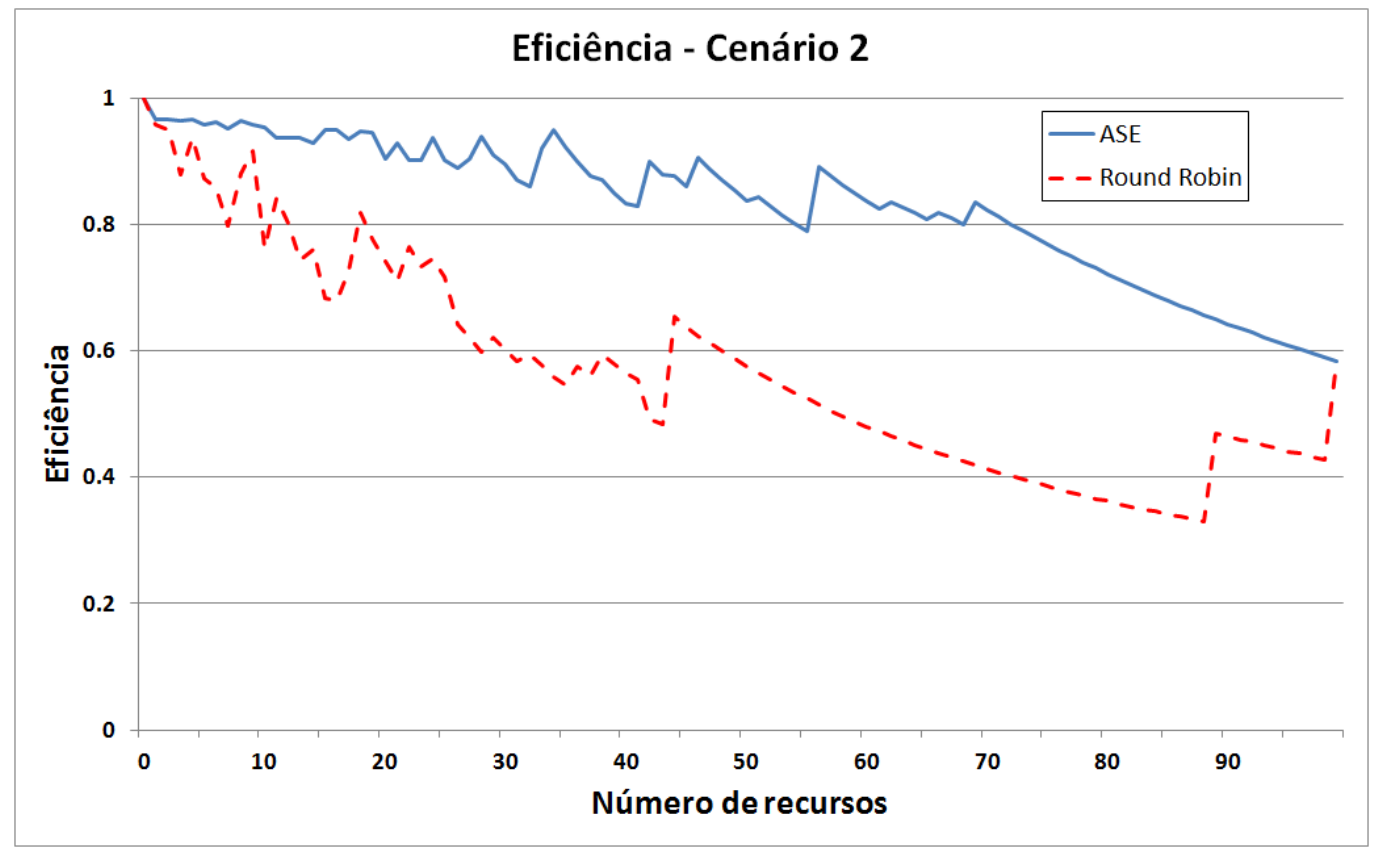

Fonte: Próprio Autor (2015).

Já nas Figuras 28, 29 e 30, os padrões das curvas entre a metodologia ASE e o escalonamento Round Robin são bem distintos, onde também se observa que as curvas se encontram no final. Isso era esperado, pois no último ponto de cada gráfico, cada recurso possui apenas uma tarefa atribuída a ele, isto é, tem-se uma distribuição 1-1 entre recurso e tarefa.

Além disso, percebe-se que o ganho da eficiência utilizando a metodologia 
Figura 29 - Eficiência dos recursos considerando o cenário 4 utilizando o escalonamento Round Robin e ASE.

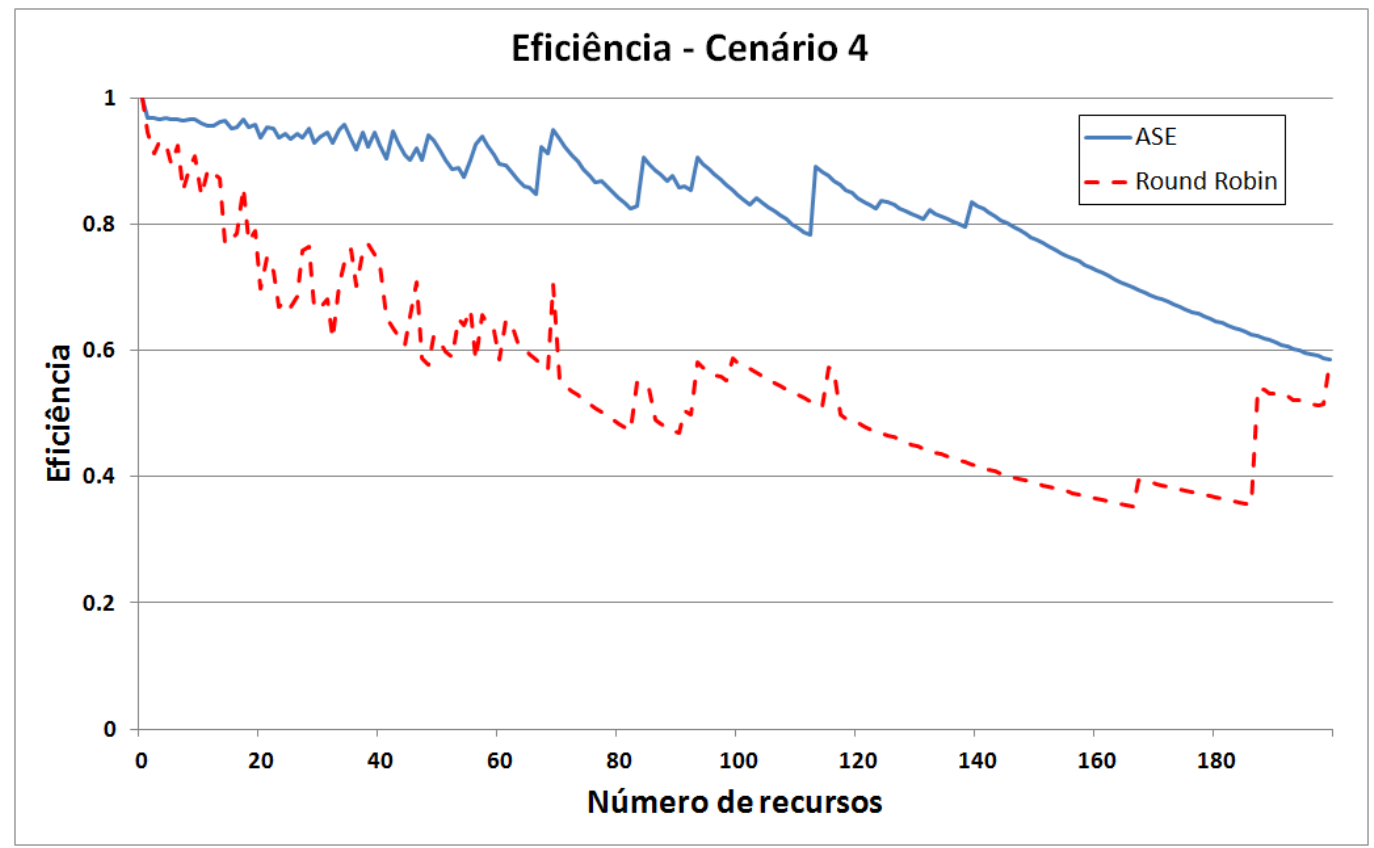

Fonte: Próprio Autor (2015).

Figura 30 - Eficiência dos recursos considerando o cenário 6 utilizando o escalonamento Round Robin e ASE.

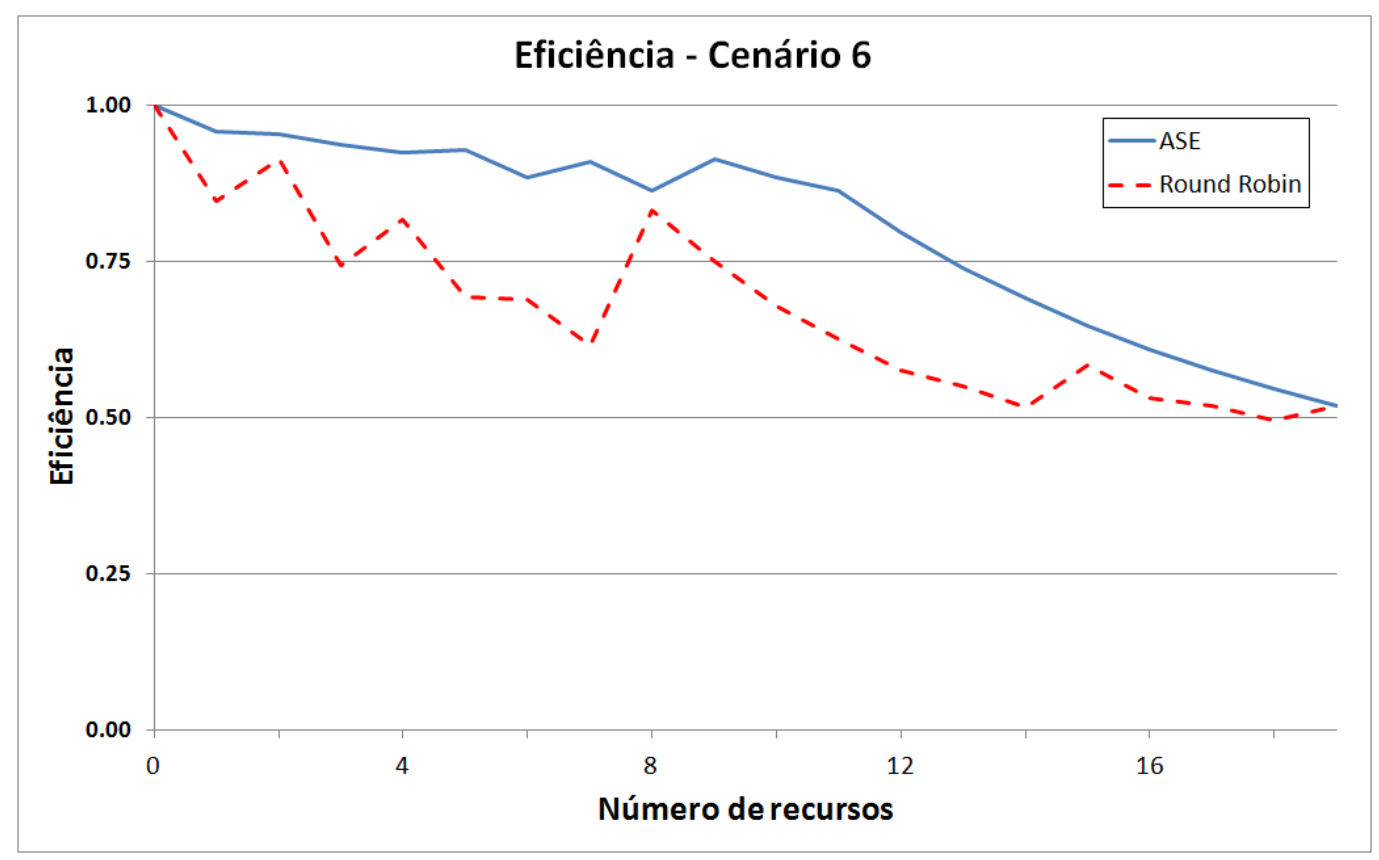

Fonte: Próprio Autor (2015). 
desta tese, em relação ao escalonamento Round Robin, é mais significativo que os observados nos cenários 1,3 e 5. Isto é explicado devido à alta heterogeneidade das tarefas, permitindo que as mesmas possam ser escalonadas de uma forma melhor para uma dada quantidade de recursos.

Novamente uma comparação pode ser realizada com as Figuras 20, 22 e 24, que apresentam os Speedup dos cenários 2, 4 e 6 respectivamente. Quando se tem um aumento abrupto do valor de Speedup, se tem um acréscimo no valor da eficiência.

Observa-se que os recursos paralelos são melhores utilizados ao executar o escalonamento desenvolvido neste trabalho.

\subsection{Teste: Limitação dos recursos}

O objetivo neste teste é verificar qual é o menor número de recursos em que se obtém o maior valor de Speedup.

O teste realizado aqui foi aplicado no cenário 4 e consistiu em verificar qual a quantidade de recursos máxima que promoveria um ganho de desempenho.

O número máximo de recursos que pode ser utilizado pelo sistema é 140, que forneceu um Speedup de 117, ou seja, a partir deste valor, o Speedup permanece constante.

Na metodologia, é permitido selecionar a quantidade de recursos que se deseja utilizar na aplicação. Caso seja selecionado um número de recursos maior que o valor definido como máximo, a execução acaba utilizando o máximo definido pela metodologia.

Outro aspecto interessante da metodologia é que se for selecionado uma quantidade de recursos menor que o máximo definido pela metodologia, ainda 
assim, é possível obter um ganho de Speedup em relação ao escalonamento Round Robin.

Apresentaremos a seguir o uso da implementação ASE em uma aplicação real e verificar de que forma ela conseguiu aprimorar a execução da aplicação paralela.

\subsection{Teste: Aplicação Real - TPN}

Para realizar uma avaliação da metodologia apresentada com uma aplicação real, escolheu-se o solver numérico TPN, que se enquadra no modelo BSP adaptado neste trabalho.

O TPN é um simulador que agrupa diversos métodos (NISHIMOTO; FUCATU; MASETTI, 2001; NISHIMOTO et al., 2003) e algoritmos em uma única ferramenta que permite a analise hidrodinâmica de diversas configurações de sistemas offshore. O simulador foi desenvolvido em uma colaboração entre diversas instituições de ensino e a Petrobras.

O principal objetivo desta aplicação é simular o comportamento de um sistema offshore composto de diversas forças e condições ambientais, atuando em corpos flutuantes, tais como plataformas e navios.

Em alguns casos, para a sua execução é necessário utilizar um cluster de computadores, devido ao alto custo computacional envolvido. A execução da aplicação neste ambiente é dividida em tarefas que são distribuídas permitindo o processamento de forma paralela. 


\subsubsection{Estrutura}

A fórmula de processamento do TPN pode ser descrita pela discretização do tempo, e o ciclo em cada passo temporal pode ser descrito pelas seguintes etapas:

i O processo corpo flutuante, que representa uma embarcação realiza o cálculo da força resultante, após receber as forças de todos os elementos que atuam no comportamento da sua dinâmica;

ii Com a aplicação desta força resultante, ele atualiza a sua posição;

iii Esta nova posição é repassada a todos os elementos que tem forças atuantes na embarcação. Sendo necessário um novo cálculo para atualizar o valor da força aplicada;

iv Os cálculos de força são realizados para cada elemento;

v Cada elemento envia as forças para a embarcação;

vi Volta para o etapa i.

A Figura 31 representa o ciclo descrito acima. Na Figura 32 são apresentadas as correlações deste ciclo com o modelo BSP adaptado.

As tarefas possuem características diferentes, implicando desta forma, em tempos distintos de execução. Portanto, a correta distribuição das tarefas é um ponto chave para a execução otimizada da simulação. Na próxima subseção é apresentada a forma de balanceamento atual utilizada pelo TPN.

\subsubsection{Balanceamento Atual}

Atualmente no TPN, a distribuição destas tarefas é realizada utilizando uma estimativa do custo de cada tarefa para realizar o balanceamento das 
Figura 31 - Fluxo de execução do processo de execução do TPN, mostrando a relação entre forças e posicionamento.

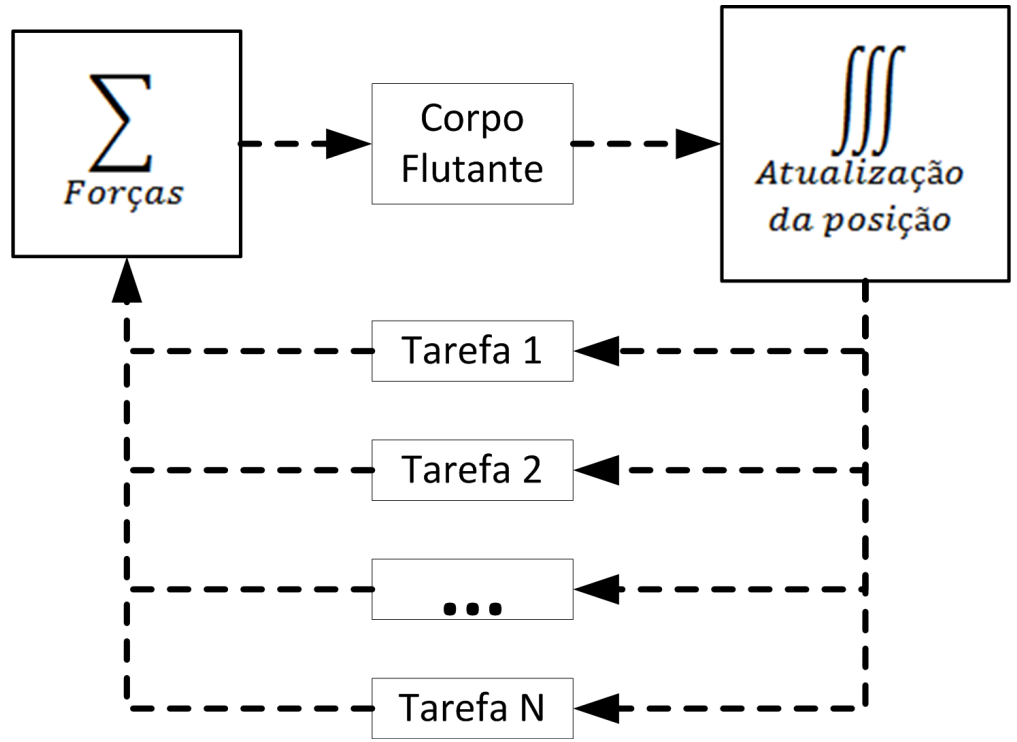

Fonte: Próprio Autor (2015)

Figura 32 - Fluxo de execução do processo de execução do TPN, utilizando a representação do BSP adaptado.

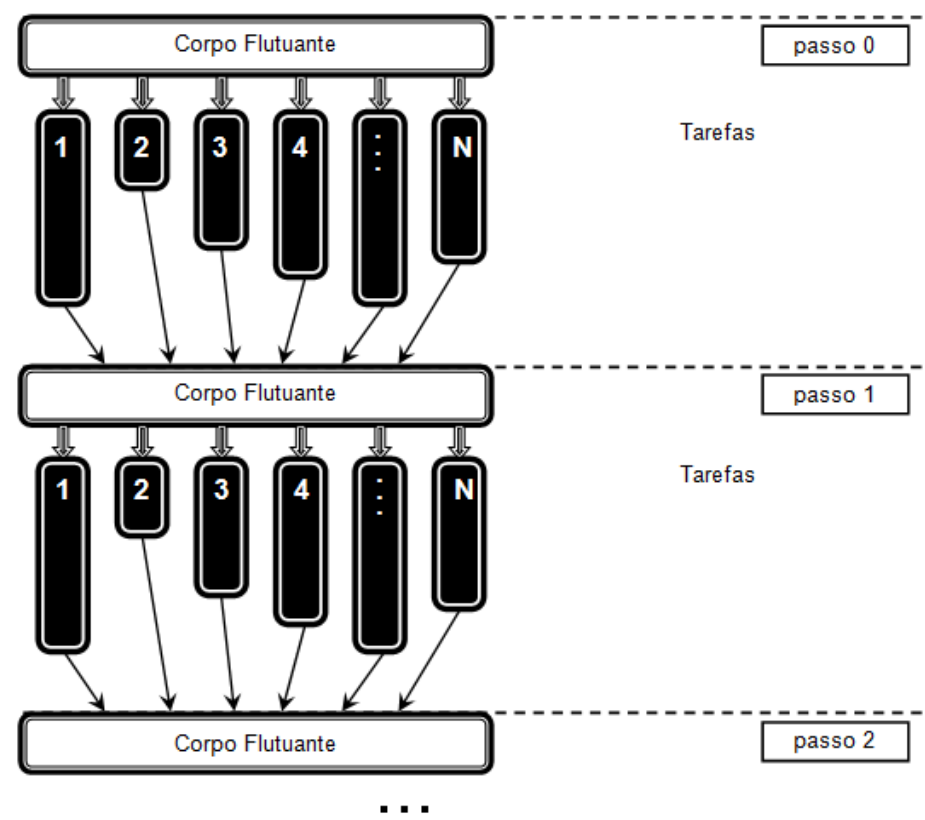

Fonte: Próprio Autor (2015) 
cargas. Este custo é calculado utilizando os seguintes parâmetros:

Método Define a complexidade de executar a sua computação, sendo que para cada método, um peso computacional é associado. A seguir são apresentados alguns dos métodos existentes:

Curva Característica Pode ser considerada a representação mais simplificada do comportamento de uma dinâmica de linha, pois pode ser considerada como se fosse um valor obtido de uma tabela. No nosso exemplo é o caso em que o custo para a sua execução é o mais simples.

Catenária A formulação utilizada para representar a linha utiliza a equação de uma curva catenária, sendo também de custo bastante leve.

DooLines Esse método usado para representar a dinâmica de linhas possui um nível de complexidade maior, pois utiliza o método de elementos finitos. Desta forma, já se tem um custo de processamento elevado devido a sua complexidade.

Sub Time Step Em alguns métodos, para descrever o comportamento da linha, se faz necessária uma discretização maior do tempo, para evitar a não convergência da dinâmica. A quantidade de passos intermediários é dada pela variável Sub Time Step. Isto é, um valor alto de Sub Time Step indica uma computação maior para descrever a dinâmica da linha. Esta variável geralmente é associada a métodos de linhas que utilizam elementos finitos.

Número de Segmentos Define a discretização do elemento que será simulado, isto é, representa a quantidade de segmentos que a linha vai ser dividida. Um número maior de segmentos indica uma linha com um custo maior para ser processada. 
Desta forma, o custo $C_{i}$ de uma linha $i$ é calculado da seguinte forma:

$$
C_{i}=P_{i} * N \_S E G_{i} * S T S_{i}
$$

Onde:

- $P_{i}$ é o custo computacional associado ao método escolhido para representar a dinâmica da linha $i$, este valor foi obtido de forma empírica;

- $N \_S E G$ representa o número de segmentos que a tarefa possui;

- STS indica a quantidade de sub Time step usado para executar o cálculo da dinâmica do processo $i$.

O custo total para executar a simulação é dado pela soma de todos os custos individuais das linhas, isto é, $\sum_{i=1}^{n} C_{i}$.

Para realizar a distribuição das tarefas são realizados os seguintes procedimentos:

1. Na inicialização da execução é definido o número de recursos paralelos que serão disponibilizados para a aplicação.

Essa definição dos número de recursos é baseada no número de processadores e não no número de máquinas.

Por exemplo, ao disponibilizar 20 recursos em um cluster onde cada nó possui 4 processadores, tem-se 5 nós para executar a aplicação.

2. As tarefas são ordenadas em ordem decrescente;

3. As tarefas são alocadas uma a uma para os recursos disponibilizados. Sempre o recurso com menor carga no instante da alocação recebe a próxima tarefa; 
4. Em cada nó são colocados em execução, via ssh, um programa para processar cada uma das tarefas a ele alocado. Por exemplo: Se para um determinado nó foram alocadas cinco tarefas, serão colocados em execução cinco programas.

Cada linha será processada por uma tarefa.

Esta forma de escalonamento, contuto, geram os seguintes problemas:

- A heterogeneidade entre os custos de processamento de cada linha e considerando que cada tarefa executa um conjunto de interaçÕes, com uma sincronização entre as tarefas a cada iteração, poderá gerar uma significativa ociosidade dos recursos.

- A distribuição de tarefas em sequência poderá acarretar em cargas distintas entre os nós, impactando no desempenho.

- A quantidade de recursos para a execução da aplicação é definida pelo usuário, e isto pode causar desperdício ou sobrecarga de recursos durante a execução da simulação.

- A forma de cálculo utilizada para definir o custo da tarefa foi obtida empiricamente, baseada em formulações iniciais dos métodos. Isto pode não representar mais o valor correto do custo $C_{i}$ das tarefas.

O processamento de uma i

Por fim, a distribuição de tarefas não consegue fazer a associação das tarefas diretamente aos processadores. Ao se alocar tarefas para o recurso 1 as recurso 4 , considerando uma máquina composta por 4 processadores, todas as alocações serão realizadas para o mesma máquina, e o sistema operacional será responsável em fazer a distribuição das tarefas nas máquinas. 
Os objetivos ao se utilizar a metodologia ASE nesta execução é permitir que o número ótimo de nós fosse encontrado, isto é, a quantidade máxima de processadores a ser utilizada evite o desperdício além de definir de que forma as tarefas deverão ser distribuídas por estes recursos paralelos. Além disso, a etapa de aquisição da ASE permite obter um valor de custo computacional de cada tarefa muito mais confiável para a realização da distribuição das tarefas.

\subsubsection{Implementação da ASE}

Para fazer uso da ASE no TPN, foi necessário alterar a forma de comunicação usada pelo TPN para a troca de informações, de socket para MPI. Isso possibilitou utilizar o MPE que é essencial na fase de aquisição.

Feito este procedimento, bastou apenas realizar a ligação da biblioteca do MPE com o TPN, para conseguir fazer uso da ASE.

\subsubsection{Testes}

Para realizar a análise de desempenho foi escolhido um caso genérico de simulação do TPN, utilizado em um projeto real. Ele é composto por 85 tarefas (84 linhas e uma embarcação) que são executadas com diferentes valores de recursos paralelos, para avaliar o comportamento da execução paralela. A Tabela 2 apresenta 3 tipos de casos que foram elaborados.

\begin{tabular}{cccc}
\hline Caso & $\begin{array}{c}\text { Curva } \\
\text { Característica }\end{array}$ & Catenária & DooLines \\
\hline A & 84 & - & - \\
B & 50 & 34 & - \\
C & 50 & - & 34 \\
\hline
\end{tabular}

Tabela 2 - Casos elaborados para a simulação do TPN onde será utilizada a distribuição original e a proposta pela ASE.

Todos os casos são compostos por 50 tarefas com a mesma configura- 
ção (Curva Característica, 5 segmentos, 1 STS) e acrescentados de outras 34 tarefas, que são descritas em cada caso.

No Caso A, são adicionadas mais 34 tarefas configuradas com o método de Curva Característica, com 15 segmentos e 1 STS. Já no Caso B, se tem 34 tarefas usando o método de linha Catenária, com 60 segmentos e 1 STS. Por fim, no Caso C são adicionados 34 tarefas utilizando o método DooLines, com 60 segmentos e 1 STS.

Estes testes foram realizados no intuito de fazer uma análise do uso em uma aplicação real da metodologia e da ferramenta implementada, além de comparar com a forma atual de execução. Uma primeira etapa do teste definiu o número ideal de recursos para executar a aplicação, sem ter perda de desempenho e minimizando o desperdício de recursos. Um segundo teste realizado para analisar o desempenho da execução da aplicação, variando-se o número de recursos e comparando o método atual com a metodologia que foi proposta.

No primeiro conjunto de testes, os valores obtidos de execução são apresentados na Tabela 3.

\begin{tabular}{cccc}
\hline Caso & $\begin{array}{c}\text { Núm. de recursos } \\
\text { obtido pela ASE }\end{array}$ & $\begin{array}{c}\text { Tempo } \\
\text { ASE [s] }\end{array}$ & $\begin{array}{c}\text { Tempo TPN } \\
\text { Normal [s] }\end{array}$ \\
\hline A & 59 & $38 \pm 3$ & $83 \pm 5$ \\
B & 45 & $41 \pm 4$ & $120 \pm 10$ \\
C & 36 & $821 \pm 15$ & $1877 \pm 67$ \\
\hline
\end{tabular}

Tabela 3 - Comparação do resultado da forma atual de escalonamento do TPN e da metodologia ASE nos casos especificados da Tabela 2. Foi obtido o número ideal de recursos paralelos e executado utilizando as duas formas de distribuição.

Inicialmente foi utilizado a metodologia ASE, definindo primeiramente qual o número de recursos ideal para realizar a execução dos casos definidos na Tabela 2. Após isto, foi executada a aplicação usando a forma atual com o 
mesmo número de recursos. E em todos os casos, a distribuição utilizando a metodologia ASE promoveu uma execução em tempo menor. Isso permite dizer que o processo de mensuração do custo das tarefas e a sua distribuição com a metodologia ASE ocorrem de forma mais precisa e balanceada do que a forma atual utilizada pelo TPN.

No segundo teste, foi utilizado o Caso C, que possui um conjunto de linhas mais complexas e é analisada a distribuição de tempos de execução variando o número de recursos. Desta forma foi obtido o seguinte gráfico apresentado na Figura 33.

Figura 33 - Variação do número de recursos fornecido para o Caso C, ocorrendo na aplicação TPN.

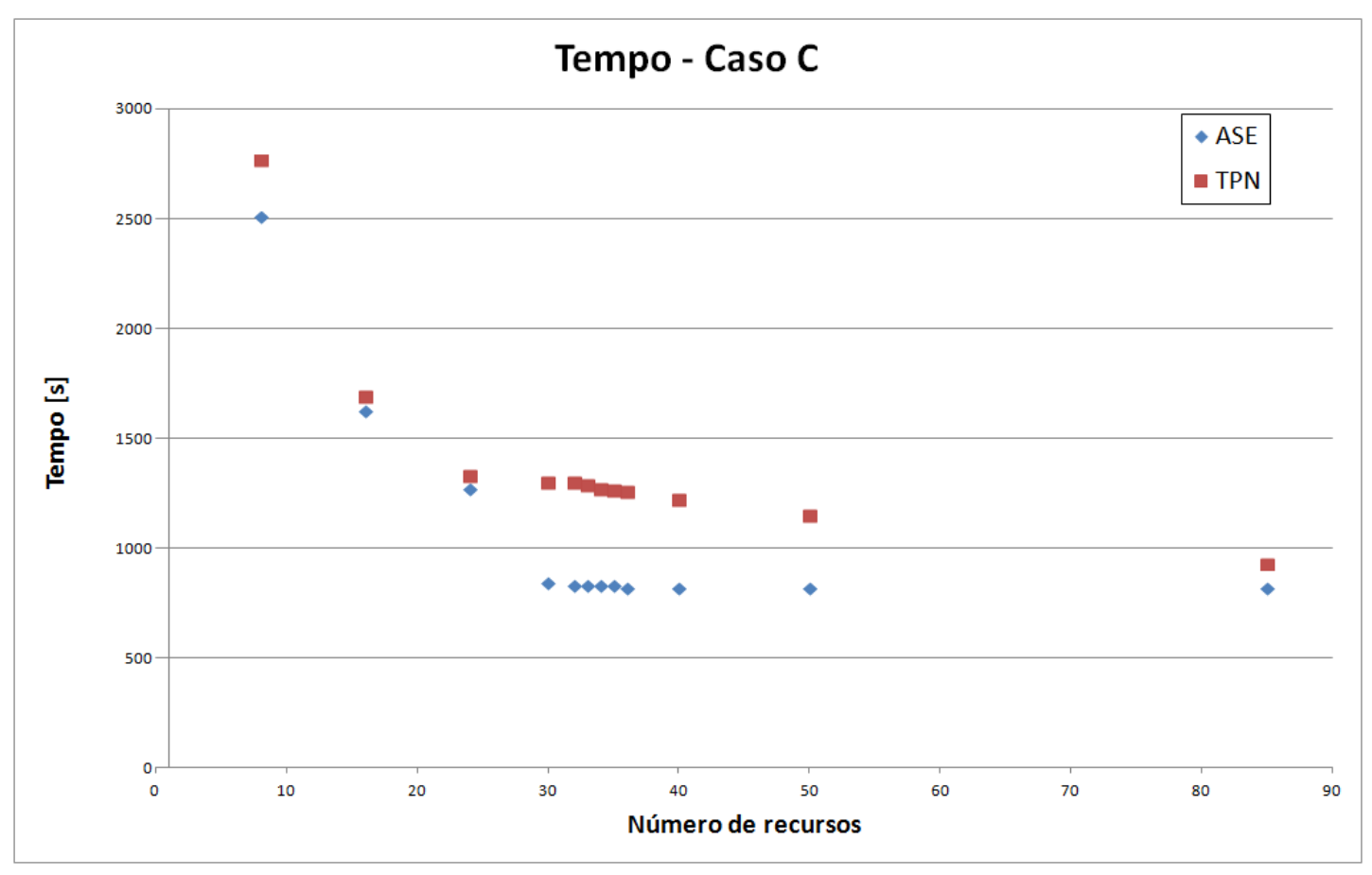

Fonte: Próprio Autor (2015).

Observa-se que os valores de tempo de execução obtido com a distribuição ASE foram menores para qualquer escolha de recurso, concluindo que o uso da metodologia permitiu obter ganhos com o desempenho da aplicação, em qualquer escolha de recursos. E a partir do momento que o número de recursos fornecidos é acima do valor obtido no teste anterior (que no Caso 
C equivale à quantidade de 36 recursos), o tempo de execução permanece constante, implicando que a adição de mais recursos apenas irá acarretar em desperdício de recursos. 


\section{CONCLUSÕES}

A computação paralela está presente em diversas áreas da ciência, permitindo que as aplicações possam fazer uso da capacidade de processamentos maior do que a disponível em máquinas sequenciais, e a busca de forma que maximize o desempenho minimizando o desperdício de recursos é um dos principais estudos na computação de alto desempenho.

As soluções existentes dependem da modificação do código fonte original, e não garantem que a ociosidade não seja significativa durante a execução.

Neste trabalho foi elaborada uma ferramenta para a execução de aplicações que seguem o modelo BSP que permite realizar o escalonamento de tarefas heterogêneas. Esta ferramenta obtém os tempos de computação das tarefas paralelas, a partir dai consegue fazer um balanceamento equilibrado e por fim realizar a execução na configuração que aperfeiçoe o tempo de execução e minimize o uso de recursos paralelos.

Para isso, foi definido um modelo para descrever uma computação paralela, que consiste de um conjunto de $N$ iterações, onde uma existe uma tarefa principal que distribui as computações para tarefas secundárias, que realizam os processamentos e em seguida retransmitem os resultados para a tarefa principal. Cada iteração só ocorre quando todas as tarefas secundárias transmitem os resultados.

Foram realizados testes em um conjunto de cenários que permitiram veri- 
ficar diferentes comportamentos durante a execução da aplicação.

Os testes mostraram que a captura dos tempos de cada uma das tarefas paralelas, a forma de escalonamento das tarefas foram realizados com sucesso. Foi verificado que com a aplicação da metodologia e o uso dos algoritmos desenvolvidos, o tempo de execução diminuiu e a eficiência aumentou dentro de uma execução.

Foi também verificado com sucesso o cálculo do número máximo de recursos, a partir do qual ocorre a saturação do ganho de desempenho. Se o usuário especificar um número maior do que o calculado é assumido o valor calculado, caso contrário, o valor especificado.

A metodologia para ser implementada não demanda nenhuma modificação no código fonte original das aplicações paralelas, o que é um diferencial em relações a outras propostas.

A metodologia foi capaz de obter um aumento no desempenho de aplicações paralelas com tarefas com alta heterogeneidade de custo de computação, permitindo ao mesmo tempo um uso menor no número de recursos paralelos utilizados durante uma execução do que quando aplicado o algoritmo Round Robin e obtendo o mesmo desempenho.

\subsection{Contribuições}

As principais contribuições deste trabalho os seguintes pontos:

- Apresentar uma forma de cálculo máximo de recursos para ser utilizado na execução de aplicações paralelas baseadas no modelo BSP com tarefas heterogêneas, de forma que o Speedup seja o maior possível e não ocorrendo desperdício de recursos computacionais. Isso foi possí- 
vel com a observação da saturação da aplicação paralela.

- Realizar o escalonamento das tarefas baseado nos tempos de execução da própria aplicação. Ao se obter o tempo de computação de cada tarefa paralela, considerando a média dos tempos obtidos pela execução de algumas iterações, tem-se uma distribuição de tarefas mais precisa.

- A execução da implementação da metodologia ocorre de forma automatizada, sendo que o usuário da aplicação não precisa realizar nenhuma alteração no código fonte e no ambiente computacional. As ferramentas utilizadas para prover esta automação são ferramentas abertas e disponíveis na maioria dos ambientes de execução paralelos.

\subsection{Propostas Futuras}

O escalonamento das tarefas dentro deste trabalho só ocorrem em clusters homogêneos. Utilizar estas técnicas em ambientes heterogêneos, tais como clusters de computadores compostos com máquinas distintas ou até mesmo em grids de clusters, onde poderia selecionar em qual cluster a execução teria o melhor desempenho poderá uma área interessante de prosseguimento com a pesquisa.

Além disso, se fosse possível tentar ampliar a aplicação desta técnica em outros modelos de programação além do BSP, poderia permitir uma abrangência maior de utilidade da metodologia.

Neste trabalho foi implementada a metodologia utilizando o MPI em conjunto com o MPE, que comprovou a validade das técnicas propostas. Seria interessante estender a metodologia para aplicações implementadas com outras bibliotecas ou linguagens de programação paralela. 


\section{REFERÊNCIAS}

AMDAHL, G. Validity of the single-processor approach to achieving large scale computing capabilities. In: AFIPS Conference Proceedings. Atlantic City, NJ: ACM Press, 1967. v. 30, p. 483-485.

BALAJI, P. et al. MPICH2 User's Guide. Argonne, IL, 2011. 45 p.

BERZINS, M. Notas de aula do curso CS6230. Salt Lake City, UT, 2010.

BORKAR, S. Thousand core chips - a technology perspective. In: Proceedings of the 44th Annual Design Automation Conference. San Diego, CA: ACM Press, 2007. p. 746-749.

BRAY, T. et al. Extensible Markup Language (XML) 1.0. 2008. Disponível em: <http://www.w3.org/TR/2008/REC-xml-20081126/>. Acesso em: 12 abr. 2015.

BRESCIA, M.; LONGO, G.; PASIAN, F. Mining knowledge in astrophysical massive data sets. Nuclear Instruments and Methods in Physics Research, v. 623, n. 2, p. 845-849, 112010.

CHAN, A. et al. Jumpshot-4 Users Guide. Argonne, IL, 2007.

CHAN, A.; GROPP, W.; LUSK, E. An efficient format for nearly constant-time access to arbitrary time intervals in large trace files. Scientific Programming, IOS Press, v. 16, n. 2, p. 155-165, 2008.

CHIEN, A. A.; KARAMCHETI, V. Moore's law: The first ending and a new beginning. Computer, v. 46, n. 12, p. 48-53, 122013.

DONGARRA, J. et al. Sourcebook of Parallel Computing. San Francisco, CA: Morgan Kaufmann Publishers, 2003.

Ecma International. Introducing JSON. 2015. Disponível em: <http: //www.json.org/>. Acesso em: 12 abr. 2015.

FAZENDA, A. L. et al. Dynamic load balancing in gpu-based systems for a mpi program. In: High Performance Computing \& Simulation (HPCS). Bologna: IEEE, 2014. p. 154-161.

FLYNN, M. J. Some computer organizations and their effectiveness. c, n. 9, p. 948-960, 1972.

FOSTER, I. Designing and Building Parallel Programs. Argonne, IL: Addison-Wesley, 1995. 
Free Software Foundation, Inc. GNU bash. 2015. Disponível em: <https://www.gnu.org/software/bash/>. Acesso em: 12 abr. 2015.

FUCATU, C. H. Desenvolvimento de um simulador dinâmico para análise de navios amarrados. Dissertação (Mestrado) - Universidade de São Paulo, 1998.

GEIST, A. B. A. et al. PVM: Parallel virtual machine: A users' guide and tutorial for networked parallel computing. 1. ed. Cambridge, MA: MIT Press, 1995. $176 \mathrm{p}$.

GRAMA, A. et al. Introduction to Parallel Computing. Boston, MA: Addison Wesley, 2003. 636 p.

HEATH, M.; ETHERIDGE, J. Visualizing the performance of parallel programs. IEEE Software, v. 8, n. 5, 1991.

HILL, J.; SKILLICORN, D. Lessons learned from implementing bsp. Future generation computer systems, 1998.

INPE/CPTEC. BRAMS. 2006. Disponível em: <http://brams.cptec.inpe.br/>. Acesso em: 14 abr. 2015.

KALE, L. Comparing the performance of two dynamic load distribution methods. In: Proceedings of the 1988 International Conference on Parallel Processing. St. Charles, IL: [s.n.], 1988. v. 1, p. 8-12.

KAUFMANN, W. J.; SMARR, L. L. Supercomputing and the Transformation of Science. New York, NY: W. H. Freeman \& Co., 1992.

KRUSKAL, C.; WEISS, a. Allocating independent subtasks on parallel processors. IEEE Transactions on Software Engineering, SE-11, n. 10, p. 1001-1016, 101985.

LANDAU, D. P.; BINDER, K. A Guide to Monte Carlo Simulations in Statistical Physics. New York, NY: Cambridge University Press, 2005. 4-7 p.

Lawrence Livermore National Laboratory. Simple Linux Utility for Resource Management. 2011. Disponível em: <https://computing.Ilnl.gov/linux/slurm/>. Acesso em: $18 \mathrm{dez} .2012$.

LIN, F.; KELLER, R. The gradient model load balancing method. IEEE Transactions on Software Engineering, n. 1, p. 32-38, 1987.

LUZ, F. H. Implementação do software MILC no estudo da QCD completa. Dissertação (Mestrado) — Universidade de São Paulo, 2010.

LUZ, F. H. P.; GASPAR, H. M.; NISHIMOTO, K. System architecture of a numerical model basin simulator. In: 8 Conference on Computer Applications and Information Technology in the Maritime Industries. Budapest: Tutech Technologie Gmbh, 2009. p. 474-485. 
MARKATOS, E.; LEBLANC, T. Using processor affinity in loop scheduling on shared-memory multiprocessors. IEEE Transactions on Parallel and Distributed Systems, v. 5, n. 4, p. 379-400, 41994.

Message Passage Interface Forum. MPI: A Message-Passing Interface Standard. Knoxville, TN, 2009. v. 8, 647 p.

MOORE, G. Cramming more components onto integrated circuits. Proceedings of the IEEE, v. 38, n. 8, 1998.

NISHIMOTO, K. et al. Numerical offshore tank: Development of numerical offshore tank for ultra deep water oil production systems. Volume 1: Offshore Technology; Ocean Space Utilization, Asme, p. 575-584, 2003.

NISHIMOTO, K.; FUCATU, C.; MASETTI, I. Q. Dynasim - a time domain simulator of anchored fpso. In: 20th Int. Conf. Offshore Mechanics and Artic Engineering - OMAE. Rio de Janeiro, RJ: American Society of Mechanical Engineers, 2001.

OLIVEIRA, H. M.; LAINE, J. M.; MIDORIKAWA, E. T. Algumas contribuições para modelagem de programas paralelos mpi. In: Anais do I/ Workshop de Desempenho de Sistemas Computacionais e de Comunicação (WPerformance). Campinas: SBC - Sociedade Brasileira de Computação, 2003.

POLYCHRONOPOULOS, C. D.; KUCK, D. J. Guided self-scheduling: A practical scheduling scheme for parallel supercomputers. IEEE Trans. Comput., IEEE Computer Society, Washington, DC, v. 36, n. 12, p. 1425-1439, 1987.

Python Software Foundation. Python Language. 2015. Disponível em: <https://www.python.org>. Acesso em: 12 abr. 2015.

ROCHA, R. Programação Paralela e Distribuída Métricas de Desempenho. Porto, Portugal, 2007. 1-22 p.

SKILLICORN, D.; HILL, J.; MCCOLL, W. Questions and answers about BSP. Oxford, OX, 1996.

STEVENS, W. R.; FENNER, B.; RUDOFF, A. M. UNIX Network Programming, Volume 1: The Sockets Networking. New York, NY: Pearson Education, 2003. $1024 \mathrm{p}$.

SUJITHAN, K.; HILL, J. Collection types for database programming in the bsp model. PDP, p. 1-10, 1997.

TANG, P.; YEW, P. Processor self-scheduling for multiple-nested parallel loops. In: 1986 International Conference on Parallel Processing. [S.I.]: leee Computer Society, 1986. p. 528-535.

The Green500. The Green 500. 2012. Disponível em: <http://www.green500. org>. Acesso em: 13 mar. 2015. 
The PHP Group, Inc. PHP Language. 2015. Disponível em: <http://php.net/>. Acesso em: 12 abr. 2015.

TIBSHIRANI, R. et al. Clustering methods for the analysis of DNA microarray data. Stanford, CA, 1999.

TOPOL, B.; STASKO, J. T.; SUNDERAM, V. Pvanim: A tool for visualization in network computing environments. Concurrency: Practice \& Experience, v. 10, n. 14, p. 1197-1222, 1998.

VAJDA, A. Multi-core and many-core processor architectures. In: Programming Many-Core Chips. Boston, MA: Springer, 2011. p. 9-43.

VALIANT, L. A bridging model for parallel computation. Communications of the ACM, n. 8, p. 10, 1990.

VASCONCELLOS, J. F. A. et al. Efficient parallel implementations of multiple sequence alignment using bsp/cgm model. In: 2014 International Workshop on Programming Models and Applications for Multicores and Manycores.

Orlando, FL: ACM Press, 2014. p. 103-110.

VENU, B. Multi-core processors-an overview. Computing Research Repository, 2011.

VETTER, J. Performance analysis of distributed applications using automatic classification of communication inefficiencies. In: 14th International Conference on Supercomputing. Santa Fe, NM: ACM Press, 2000. p. 245-254.

W3C. A Little History of the World Wide Web. 2011. Disponível em: <http://www.w3.org/History.html>. Acesso em: 15 out. 2014.

WILLMORE, F. Introduction to Parallel Computing. Austin, TX, 2012. 44 p.

ZAKI, O. et al. Toward scalable performance visualization with jumpshot. International Journal of High Performance Computing Applications, v. 13, p. 277-288, 1999. 


\section{APÊNDICE A - IMPLEMENTAÇÃO EM PYTHON DA METODOLOGIA ASE}

Código A.1 - Código responsável em executar a metodologia ASE.

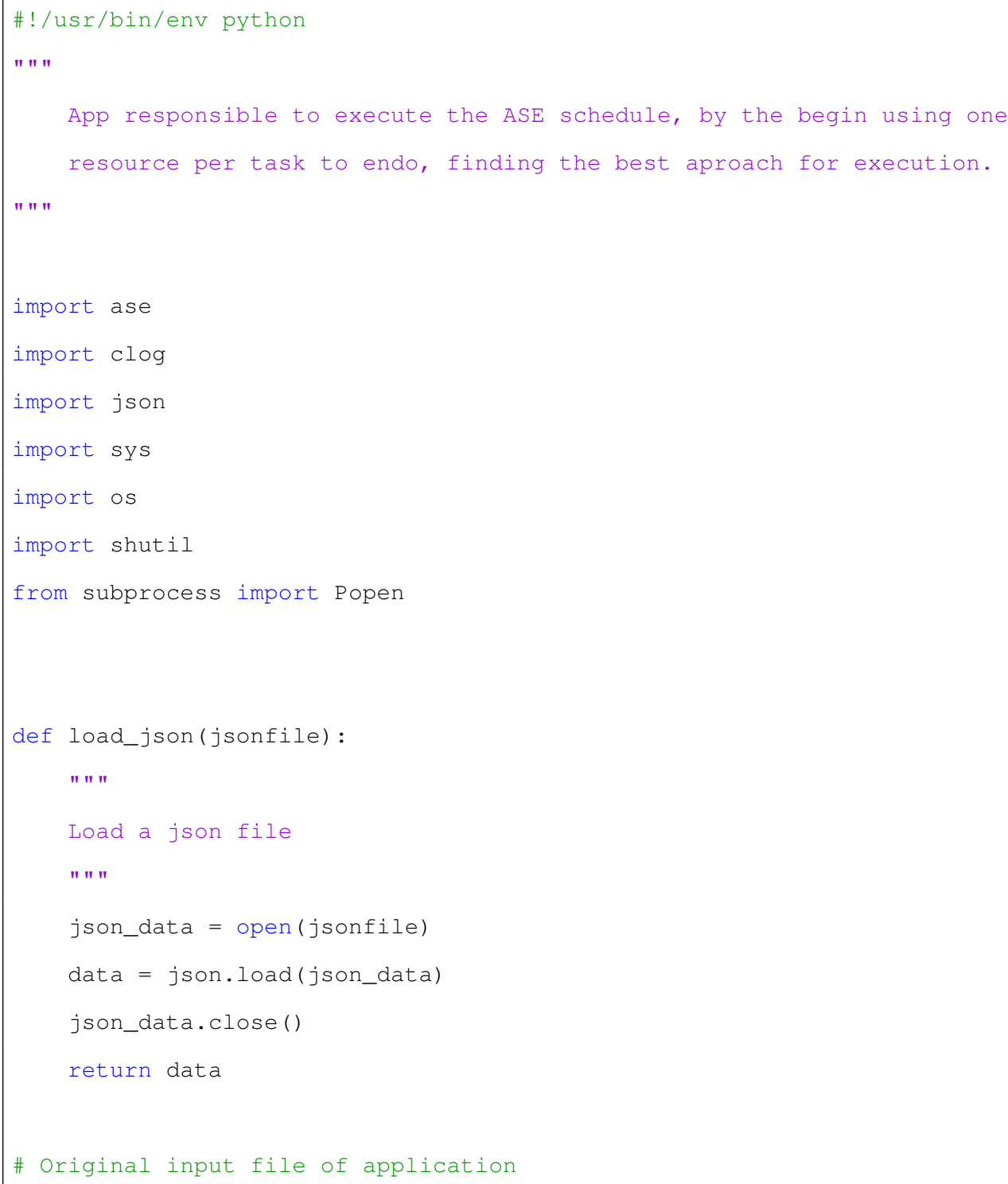




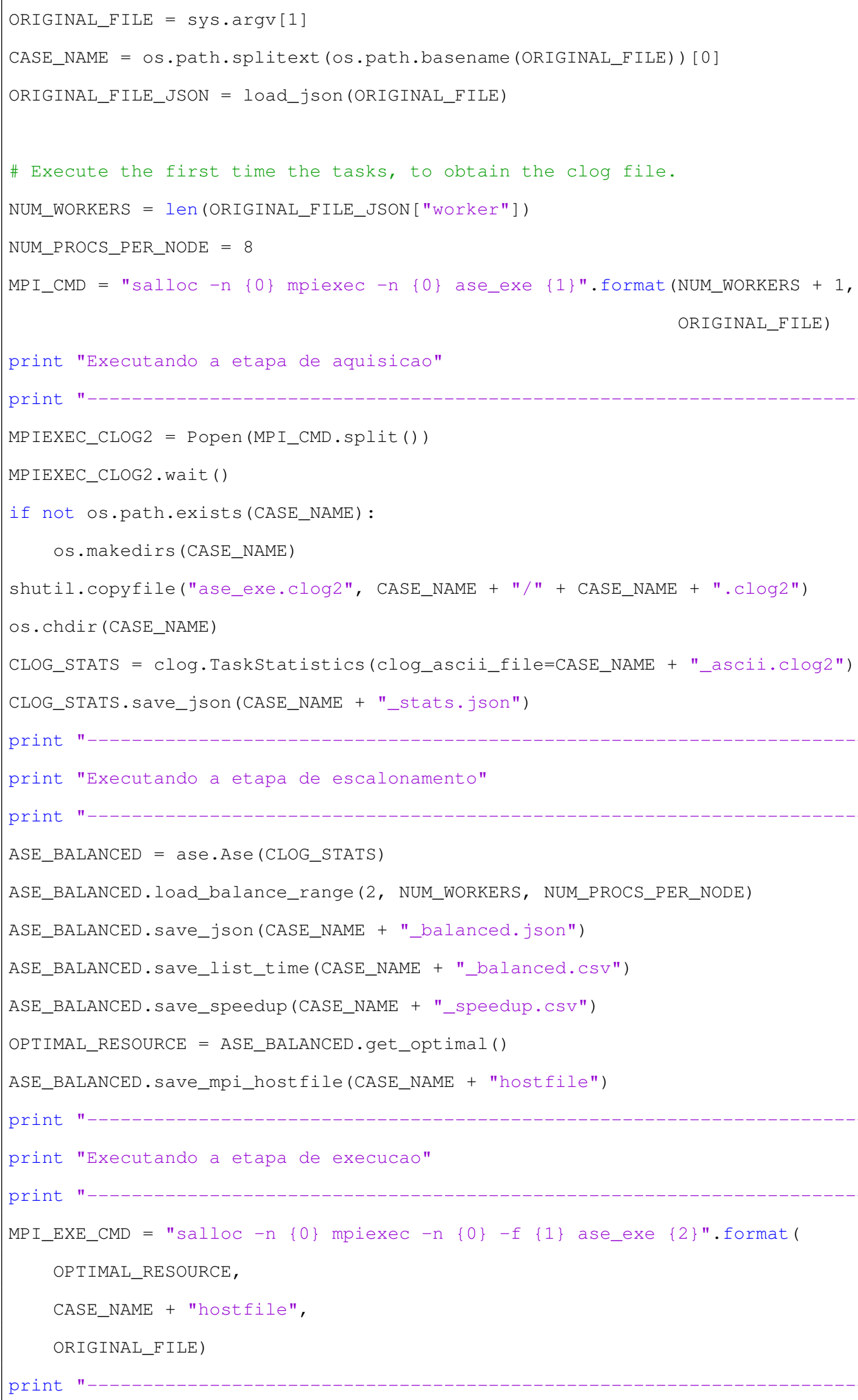


Código A.2 - Classe que define a leitura do arquivo Clog2 para obter as estatísticas para executar a metodologia.

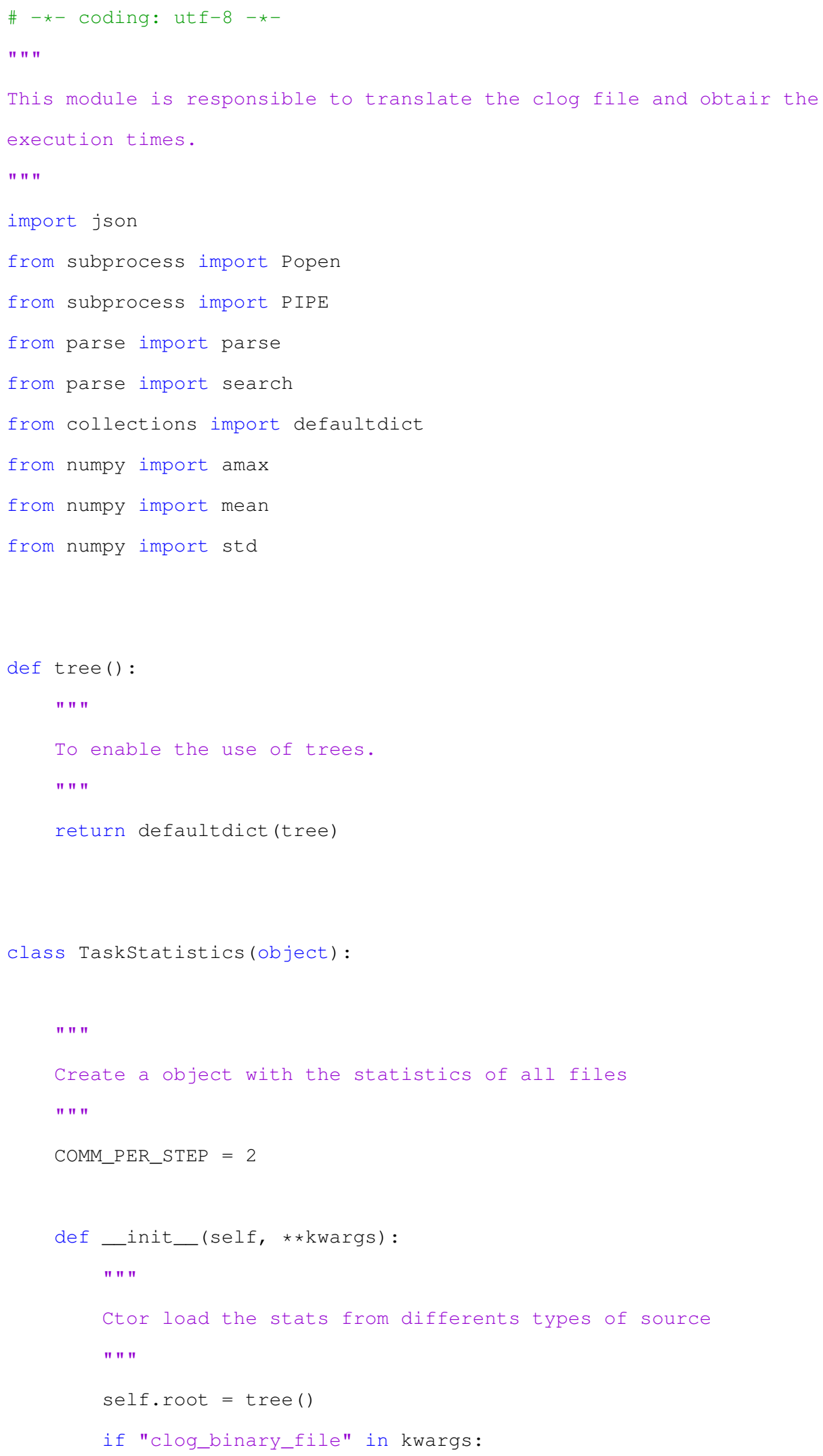


print "With clog binary file"

self.load_clog_binary(kwargs ["clog_binary_file"])

elif "clog_ascii_file" in kwargs:

print "With clog ascii file"

with open(kwargs["clog_ascii_file"], "r") as infile:

clog_data $=$ infile.read ()

self.load_clog_ascii(clog_data)

elif "json_file" in kwargs:

print "With json_file"

self.load_json (kwargs ["json_file"])

else:

print "Without parameter"

def load_clog_binary(self, clog_binary_file) :

" " "

Load the stats from clog binary file. The environment needs to be access to clog2_print program.

" " "

\# Create the command used to obtain the clog data

clog_command = "clog2_print $\{0\} "$.format (clog_binary_file)

clog_exe = Popen(clog_command.split(), stdout=PIPE, stderr=PIPE)

\# Get the output by stdout and stderr

output_clog = clog_exe.communicate()[0]

self.load_clog_ascii(output_clog)

def load_clog_ascii(self, clog_ascii_file):

" " "

Load the file from clog ascii file (results of clog2_print)

" " "

\# Place to store the parsed data

bare_data = defaultdict(lambda: defaultdict(list))

msg_data = defaultdict(lambda: defaultdict(lambda: defaultdict(list))

shft_data = defaultdict(list)

\# For each line in the output, parse the file to obtain the data

for line in clog_ascii_file.splitlines():

searched_type $=$ search $(" t y p e=\{t p: S\} "$, line $)$

if searched_type is not None: 
\# Run respective parser and insert the data

if searched_type ["tp"] == "bare":

r_bare = parse_bare_line(line)

if r_bare is not None:

bare_data[r_bare[0] ] [r_bare[1] ] .append (

r_bare [2])

elif searched_type ["tp"] == "msg":

r_msg = parse_msg_line(line)

msg_data[r_msg[0] ] [r_msg[1] ] [r_msg[2] ].append (

r_msg[3])

elif searched_type ["tp"] == "shft":

r_shft $=$ parse_shft_line(line)

shft_data[r_shft[0]] = r_shft [1]

self.manager_stats (msg_data)

self.workers_stats(msg_data, bare_data)

def save_json(self, jsonfile):

" " "

Save the statistics of execution

" " "

print "Save json file"

with open(jsonfile, "w") as outfile:

json.dump (self.root, outfile)

outfile.close()

def load_json(self, jsonfile):

" " "

Load the statitics from a json file

" " "

print "Loading json"

json_data $=$ open (jsonfile)

self.root $=$ json.load (json_data)

json_data.close()

def manager_stats (self, msg_d):

" " "

Generate the manager stats (comm, calc and wait)

" " "

print "Generate manager stats" 


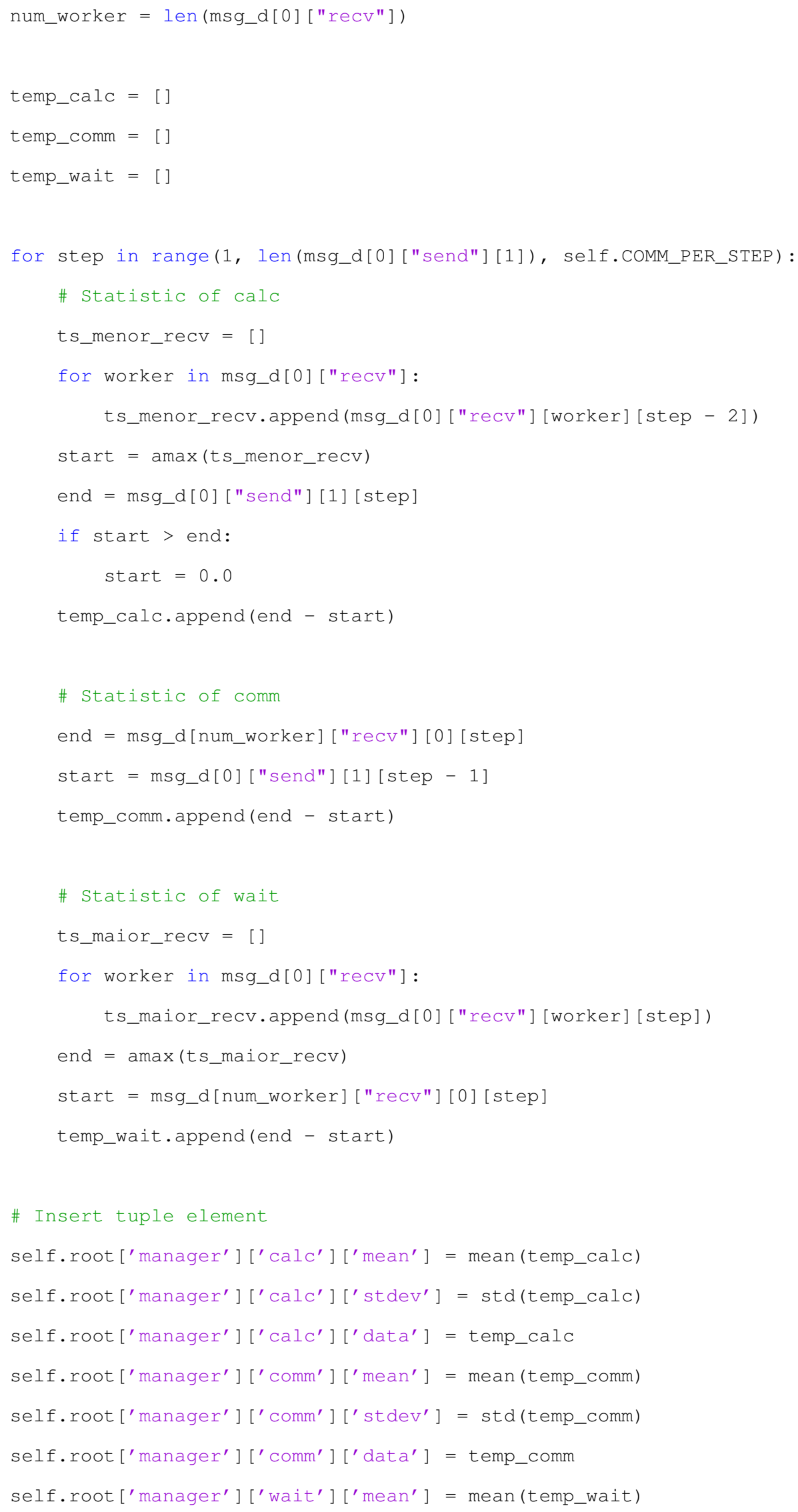


self.root ['manager'] ['wait'] ['stdev'] = std(temp_wait)

self.root ['manager'] ['wait'] ['data'] = temp_wait

def workers_stats(self, msg_d, bare_d):

" " "

Generate the workers stats

" " "

print "Generate workers stats"

for worker in msg_d[0]["recv"]:

temp_calc $=[]$

temp_comm $=[]$

temp_wait $=[]$

for step in range(1, len(msg_d[0]["send"][1]), self.COMM_PER_STEP):

\# Statistic of calc

temp_calc.append(msg_d[worker] ["send"] [0][step] -

msg_d[worker] ["recv"] [0][step])

\# Statistic of comm

temp_comm.append (msg_d[0]["recv"][worker][step] -

msg_d[worker] ["send"] [0] [step])

\# Statistic of wait

temp_wait.append (bare_d[worker] ["erecv"] [step - 1] -

bare_d[worker] ["srecv"] [step - 1])

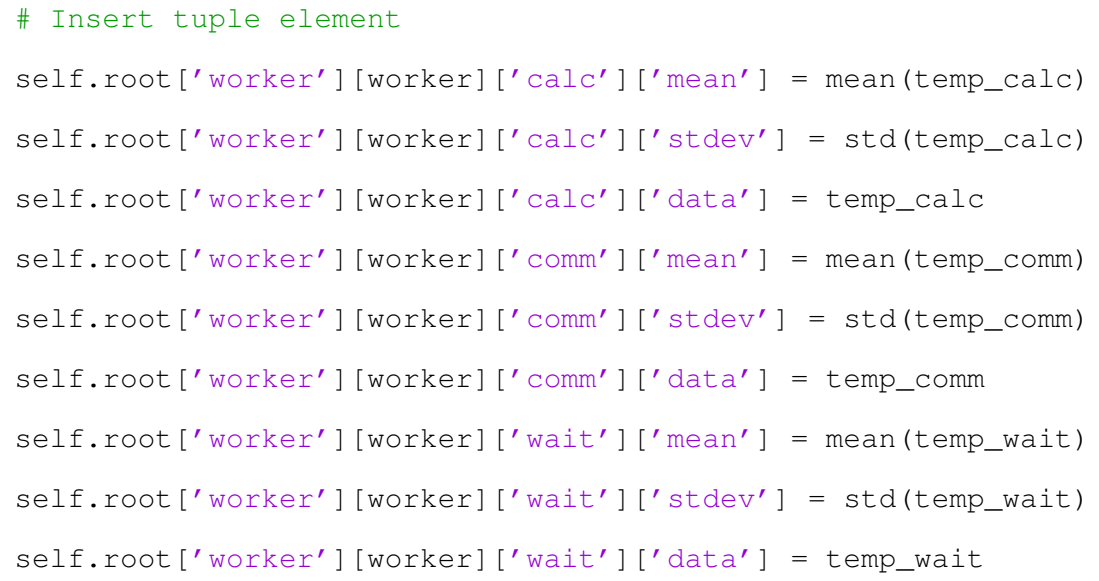




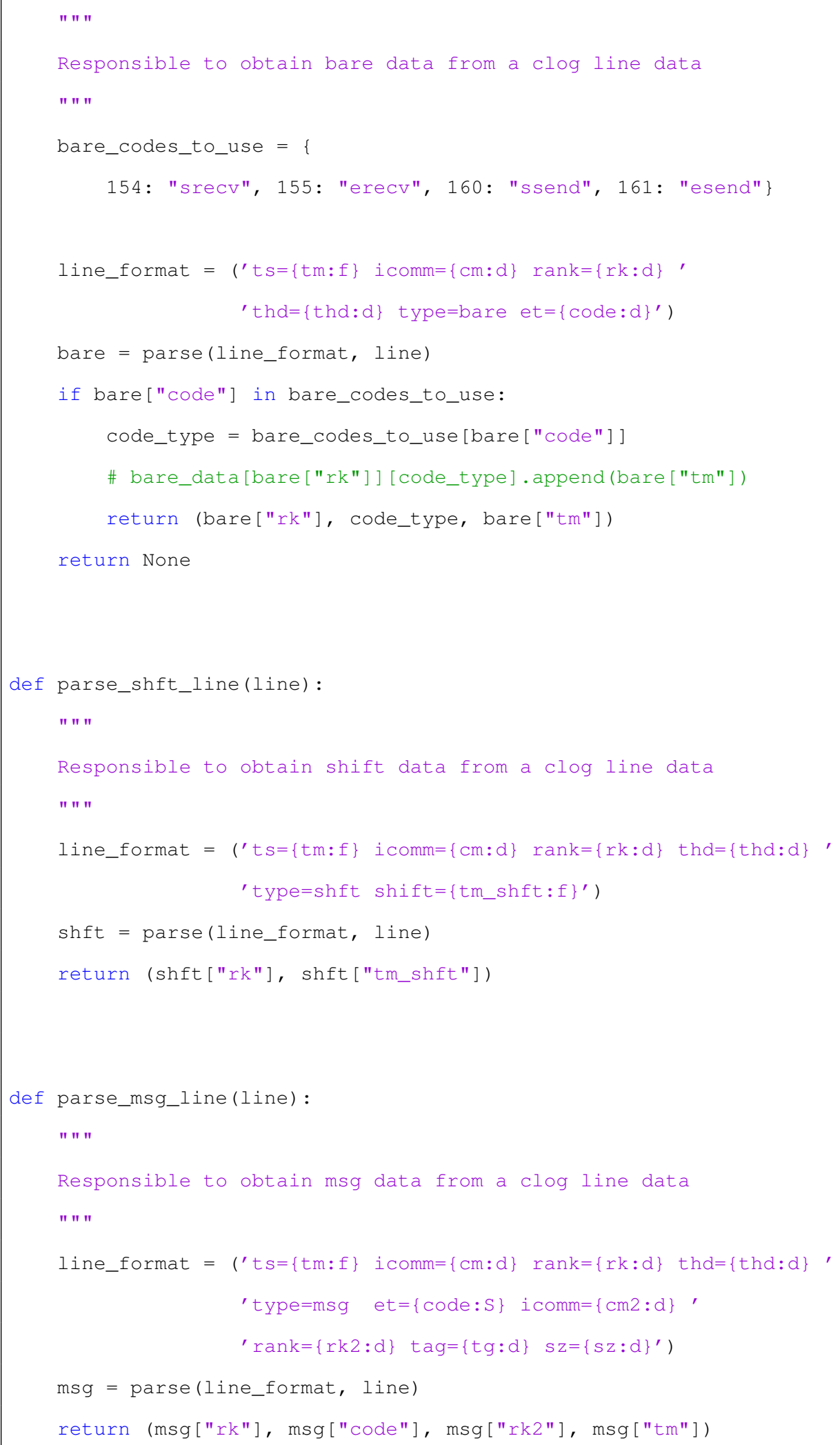


Código A.3 - Implementação da classe ASE utilizada para realizar o tratamento das informações obtidas do arquivo Clog e gerar o escalonamento das tarefas.

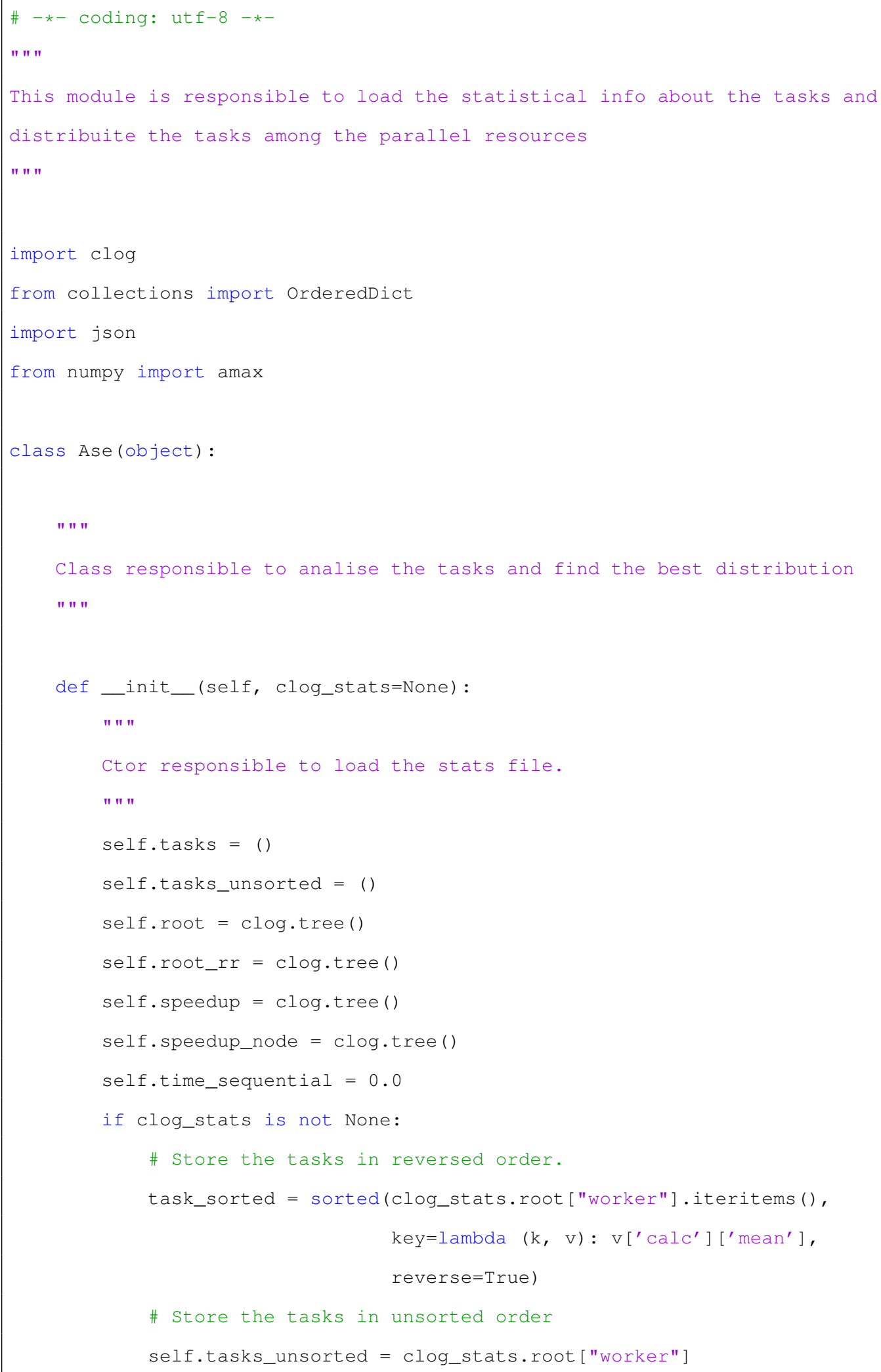




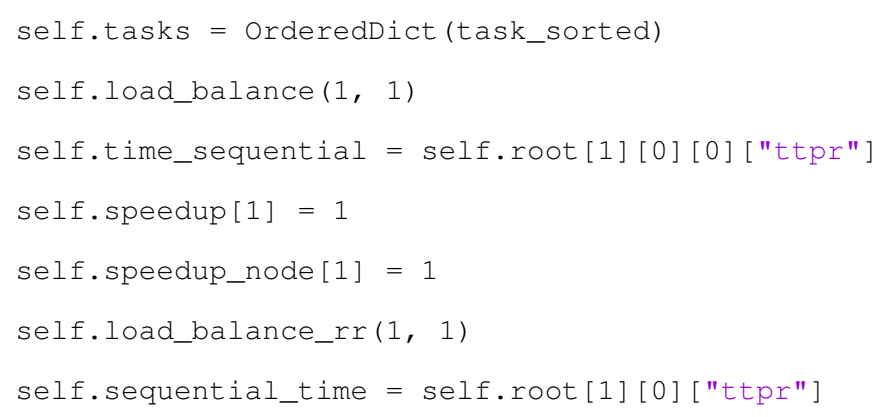


for $j$ in range(resource_per_node[i]) :

tsk_idx $=i *$ num_resource_per_node $+j$

task = self.tasks[task_list[tsk_idx] ]

\# info about node

if $j==0$ :

self.root[num_resource][i]["tei"] = task["comm"]["mean"]

self.root[num_resource][i]["tef"] = (task["comm"]["mean"] +

task ["calc"] ["mean"])

self.root[num_resource] [i] ["ttpn"] = task["calc"] ["mean"]

self.root[num_resource][i]["ttcn"] = task["comm"] ["mean"]

\# info about resource

self.root[num_resource][i][j]["ttpr"] = task["calc"]["mean"]

self.root[num_resource][i][j] ["ttcr"] = task["comm"] ["mean"]

self.root[num_resource][i][j] ["tasks"] [

task_list[tsk_idx]]["calc"] = task["calc"]["mean"]

self.root[num_resource][i][j] ["tasks"] [

task_list[tsk_idx]]["comm"] = task["comm"]["mean"]

self.root[num_resource][i][j] ["tasks"] [

task_list[tsk_idx]]["wait"] = task["wait"]["mean"]

for $j$ in range(num_resource, len(task_list)):

task $=$ self.tasks[task_list $[j]]$

\# Getting the node to use and the resource to use

node_idx $=0$

resource_idx $=0$

menor_ttpr $=$ self.root [num_resource] [0][0]["ttpr"]

for $i$ in range(len(resource_per_node)):

for $k$ in range(resource_per_node[i]):

if menor_ttpr > self.root[num_resource][i][k]["ttpr"]:

node_idx $=i$

resource_idx $=k$

menor_ttpr $=$ self.root[num_resource][i][k]["ttpr"]

\# Update the resource values

self.root[num_resource] [node_idx] [resource_idx] [

"ttpr"] += task["calc"] ["mean"]

self.root [num_resource][node_idx] [resource_idx] [ 
"ttcr"] += task["comm"] ["mean"]

\# Update the node values

if self.root[num_resource][node_idx]["tei"] > task["comm"] ["mean"]:

self.root [num_resource] [node_idx] ["tei"] = task["comm"] ["mean"]

if (self.root[num_resource][node_idx][resource_idx]["ttpr"] >

self.root [num_resource] [node_idx] ["ttpn"]) :

self.root [num_resource] [node_idx] ["ttpn"] = self.root [

num_resource] [node_idx] [resource_idx] ["ttpr"]

\# print " $\{0\}\{1\}\{2\} "$.format (node_idx, resource_idx, self.root [

\# num_resource][node_idx] [resource_idx] ["ttpr"])

tef $=($ self.root [num_resource] [node_idx] [

"tei"] + self.root[num_resource][node_idx]["ttpn"])

self.root[num_resource][node_idx]["tef"] = tef

\# self.root[num_resource][node_idx]["tasks"].append(self.tasks.items

( ) $[j])$

self.root [num_resource] [node_idx] [resource_idx] ["tasks"] [

j] ["calc"] = task["calc"] ["mean"]

self.root [num_resource] [node_idx] [resource_idx] ["tasks"] [

j] ["comm"] = task["comm"] ["mean"]

self.root [num_resource] [node_idx] [resource_idx] ["tasks"] [

j] ["wait"] = task["wait"] ["mean"]

def load_balance_rr(self, num_resource, num_resource_per_node):

" " "

Load balance for a specific resource number.

" " "

resource_per_node $=$ [ ]

\# Define number of tasks per node

for i in range (num_resource / num_resource_per_node):

resource_per_node.append (num_resource_per_node)

if num_resource 을 num_resource_per_node $!=0$ :

resource_per_node.append (num_resource num_resource_per_node)

\# Initial load with the most expensives tasks

\# List of keys in tasks

task_list $=$ list (self.tasks_unsorted.keys()) 
for $i$ in range(len(resource_per_node)):

for $j$ in range(resource_per_node[i]) :

tsk_idx $=i \star$ num_resource_per_node $+j$

task = self.tasks_unsorted[task_list[tsk_idx]]

\# info about node

if $j==0$ :

self.root_rr[num_resource][i]["tei"] = task["comm"]["mean"]

self.root_rr[num_resource][i]["tef"] = (task["comm"]["mean"]

task ["calc"] ["mean"

])

self.root_rr[num_resource] [i] ["ttpn"] = task["calc"] ["mean"]

self.root_rr[num_resource][i]["ttcn"] = task["comm"] ["mean"]

\# info about resource

self.root_rr[num_resource][i][j]["ttpr"] = task["calc"] ["mean"]

self.root_rr[num_resource][i][j]["ttcr"] = task["comm"] ["mean"]

self.root_rr[num_resource][i][j] ["tasks"][

task_list[tsk_idx]]["calc"] = task["calc"]["mean"]

self.root_rr[num_resource][i][j] ["tasks"] [

task_list[tsk_idx]]["comm"] = task["comm"] ["mean"]

self.root_rr[num_resource][i][j]["tasks"][

task_list[tsk_idx]] ["wait"] = task["wait"]["mean"]

for $j$ in range (num_resource, len(task_list)):

task = self.tasks_unsorted[task_list[j]]

$i d x=j \circ$ num_resource

node_idx $=i d x$ / num_resource_per_node

resource_idx $=i d x \div$ num_resource_per_node

\# Update the resource values

self.root_rr[num_resource][node_idx][resource_idx] [

"ttpr"] += task["calc"] ["mean"]

self.root_rr[num_resource][node_idx] [

resource_idx]["ttcr"] += task["comm"] ["mean"]

\# Update the node values

if (self.root_rr[num_resource][node_idx]["tei"] > 


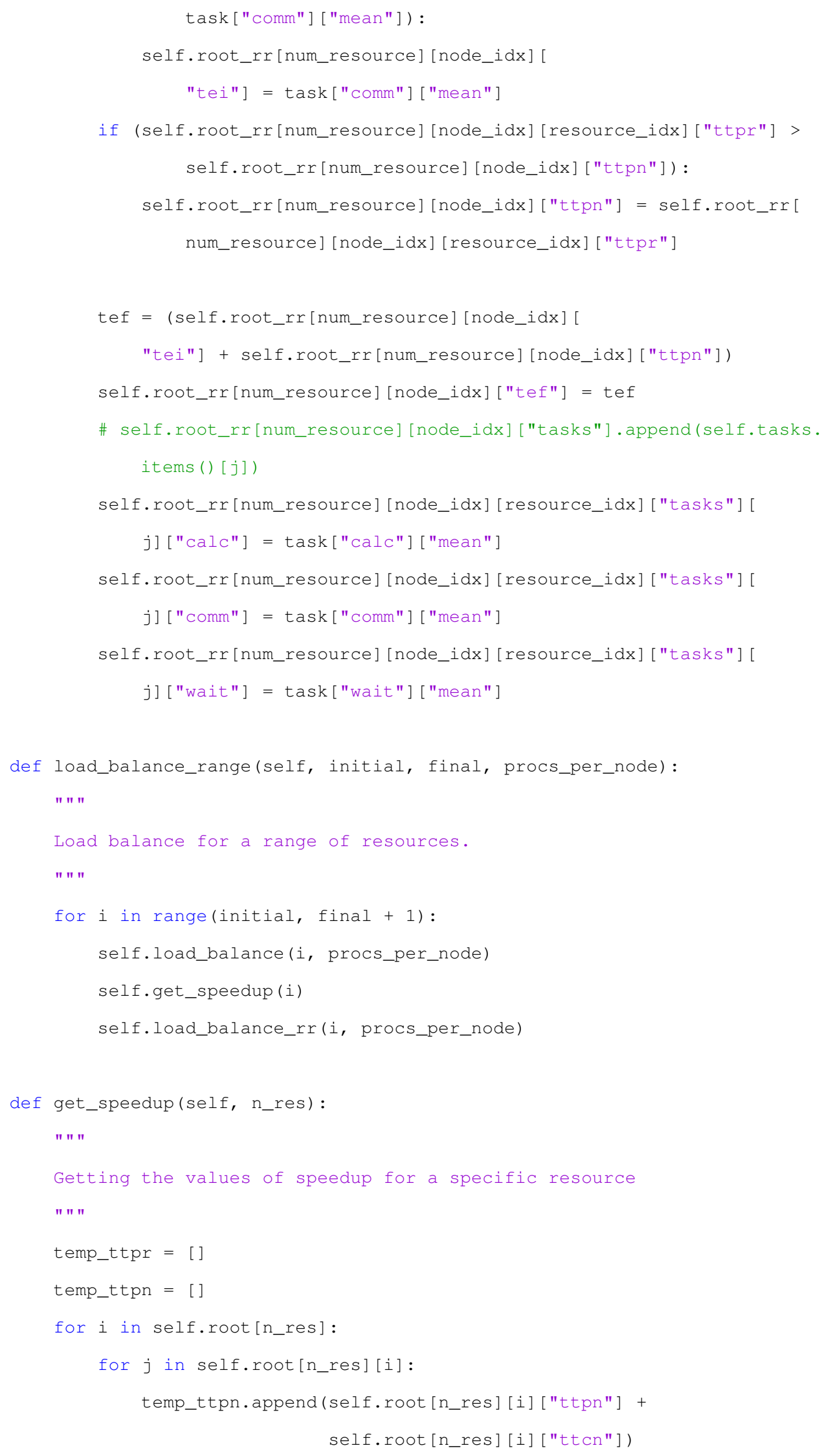




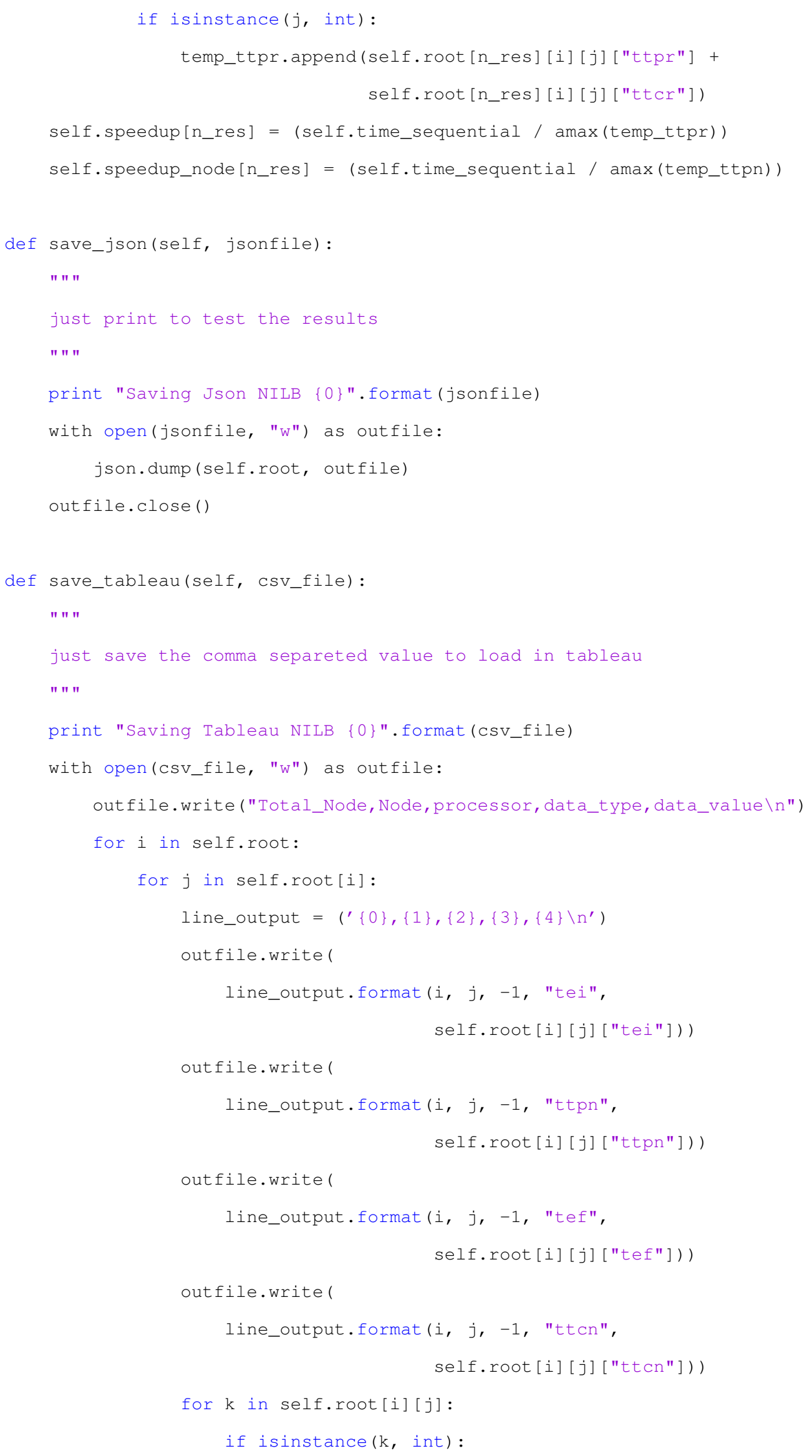


outfile.writel

line_output.format(i, j, k, "ttpr", self.root[i][j][k]["ttpr"]))

outfile.write(

line_output.format(i, j, k, "ttcr_rr", self.root[i][j][k]["ttcr"]))

outfile.close()

def save_excel(self, csv_file):

" " "

just save the comma separeted value to load in tableau

" " "

print "Saving excel NILB $\{0\}$ ".format (csv_file)

with open(csv_file, "w") as outfile:

outfile.write("Total_Node, Node,processor,data_type, data_value $\backslash n$ ")

for $i$ in self.root:

for $j$ in self.root[i]:

line_output $=\left(^{\prime}\{0\},\{1\},\{2\},\{3\},\{4\} \backslash n^{\prime}\right)$

for $k$ in self.root[i][j]:

if isinstance(k, int):

outfile.write(

line_output.format(i, j, k, "ttpr",

self.root[i][j][k]["ttpr"]))

outfile.write(

line_output.format(i, j, k, "ttpr_rr",

self.root_rr[i][j][k][

"ttpr"]))

outfile.close()

def save_list_time(self, txt_file):

" " "

just save the comma separeted value to load in excel

" " "

print "Saving list_time NILB $\{0\}$ ".format(txt_file)

with open(txt_file, "w") as outfile:

outfile.write ("recurso, tempo \n")

for $i$ in self.tasks_unsorted:

task = self.tasks_unsorted[i]

outfile.write("\{0\},\{1\}\n".format (i, task["calc"] ["mean"])) 
def save_speedup (self, csv_file):

" " "

Get all values in speedup vector and print in a cvs file

" " "

print "Saving speedup NILB $\{0\}$ ".format(CSV_file)

with open(csv_file, "w") as outfile:

outfile.write ("Recurso, speedup \n")

for $i$ in self. speedup:

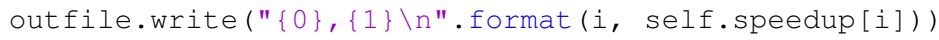

with open(csv_file + "_node", "w") as outfile:

outfile.write ("Recurso, speedup \n")

for $i$ in self.speedup_node:

outfile.write("\{0\},\{1\}\n".format(i, self.speedup_node[i])) 